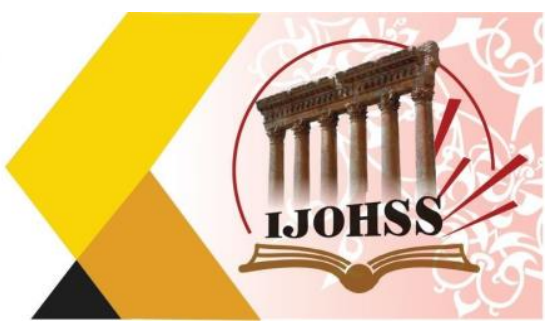

\title{
جيومورفولوجية المنخفضات في بادية النجف والمثنى المئي والأثكال الأرضية الناتجة عنها والعوامل المولية المؤثرة فيها
}

\author{
م.م. حمزية ميري كاظم الخزعلي الخي

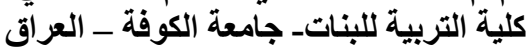 \\ haamziy.am.alghazeily@uokufa.edu.iq \\ أ.د. حسين موسى حسين الشمري \\ كلية العلوم - جامعة الكوفة ـ العراق الئين \\ أ.د. فلاح حسن شنون الكعبي \\ كلية الآداب ـ جامعة الكوفة ـ العراق القي
}

الملخص

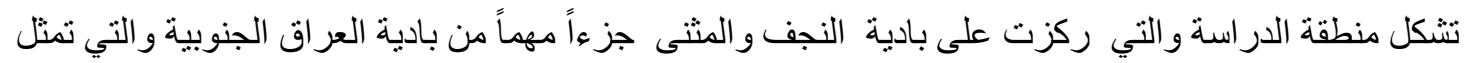

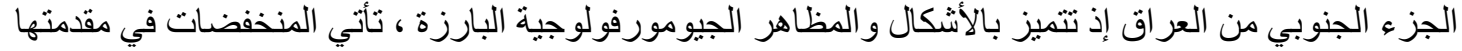

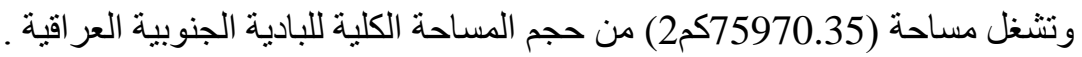

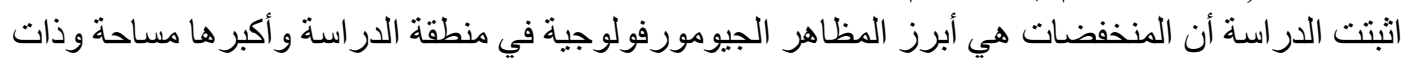

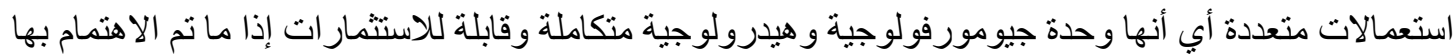

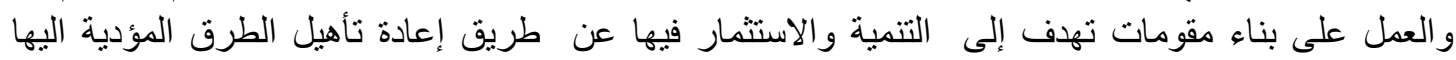

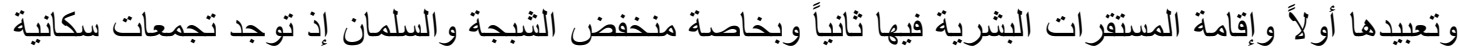
تر اوحت بين (70-750) وحدة سكنية.

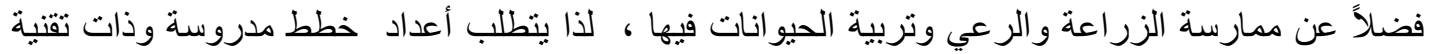

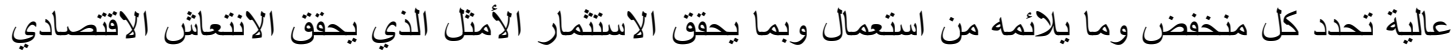

الكلمات المفتاحية: جيومورفولوجية المنخفضات، بادية النجف، بادية المثنى، الأشكال الأرضية. 


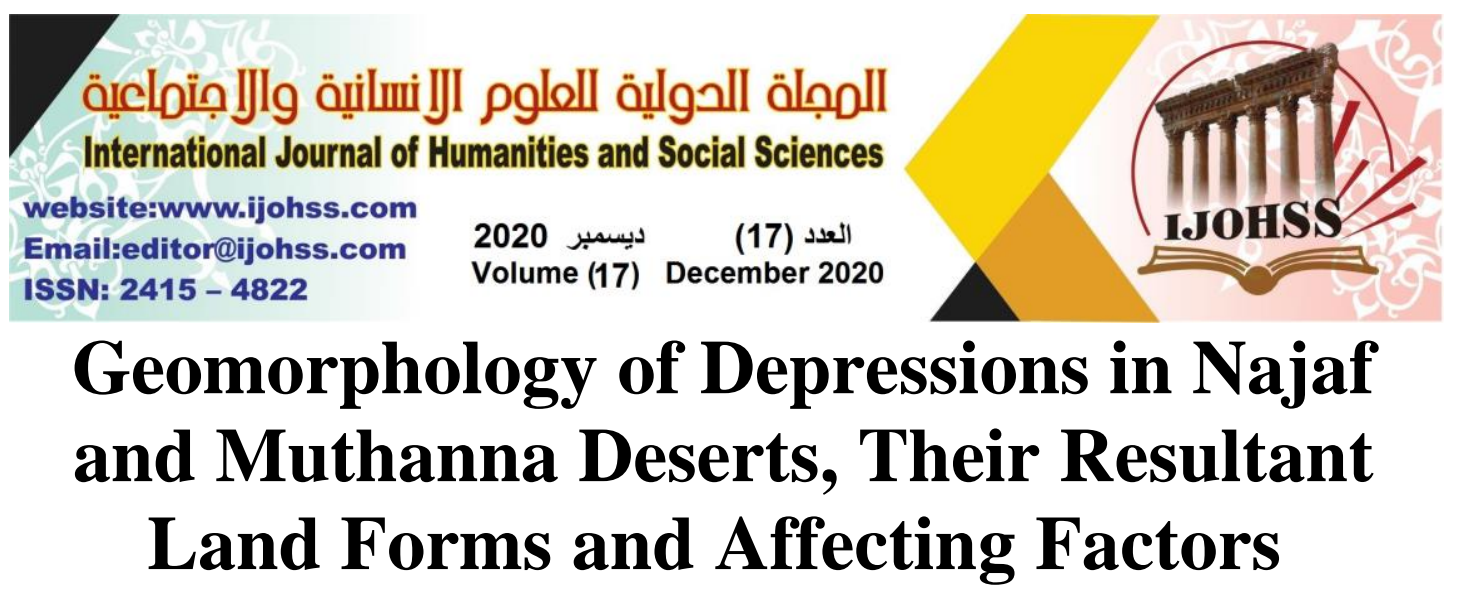

\author{
Asst. Lect. Hamzyah Miri Kadhim Al-Khazaali \\ University of Kufa/ Faculty of Education for Girls
}

Prof. Dr. Hussein Musa Al-Shimmeri

Prof. Dr. Falah Hassan Al-Kaabi

University of Kufa/Faculty of Science

University of Kufa/Faculty of Arts

\begin{abstract}
The study area of Najaf and Muthanna Deserts represent a significant part of the Southern Desert of Iraq, which constitute the southern part of Iraq. It is characterized by prominent geomorphological forms and features, of which depressions come in the forefront occupying an area of (75970.35) $\mathrm{km}^{2}$ of the total area of the Southern Desert of Iraq.

The study indicate that depressions are the most prominent geomorphological features in the study area, the largest of them, and with the most multiple uses. This means that they are an integrated geomorphological and hydrological unit and are investible if given care and building constituents are developed, aiming at development and investment in these deserts by rehabilitating the roads leading to them, paving them, and establishing human settlements. Especially, Shabecha and Salman depressions, there are population of (70-450) housing units.

In addition, agriculture, grazing and animal husbandry is practiced there. It requires a set of studied and high-tech plans that determine each depression and its appropriate usage in a way that attains the optimal investment that could refresh the economy of the country.
\end{abstract}

Keywords: the geomorphology of the depressions, Deserts of Najaf, Deserts of Muthanna, the landforms. 


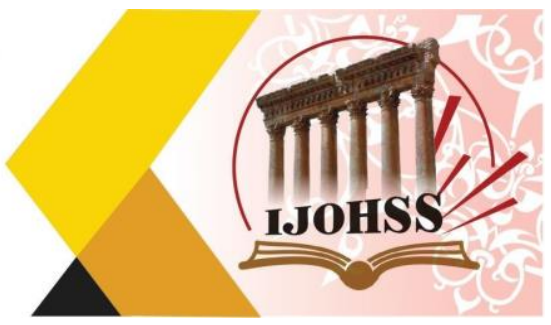

المقدمة Introduction

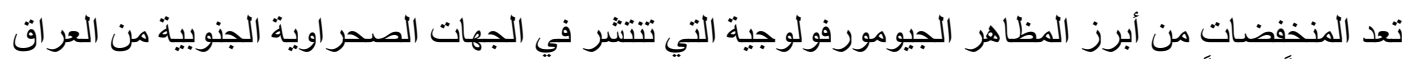

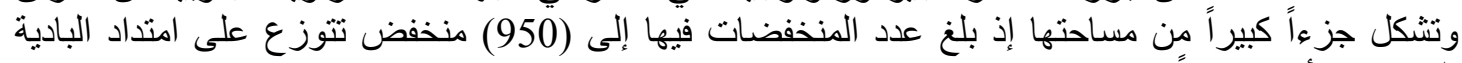

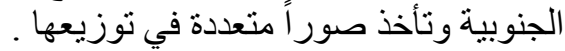

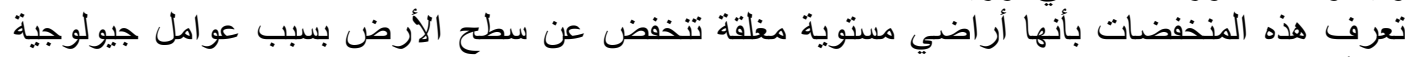

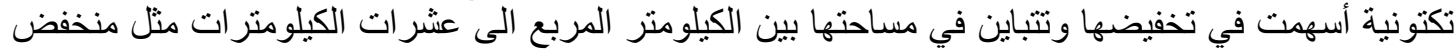

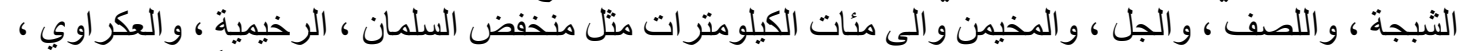

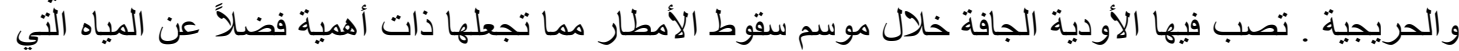

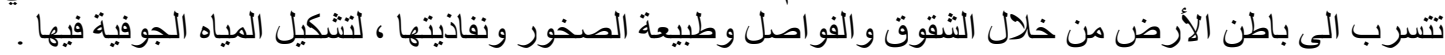

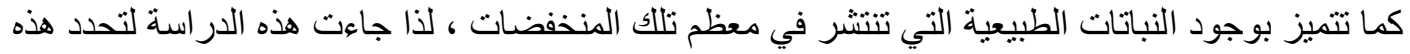

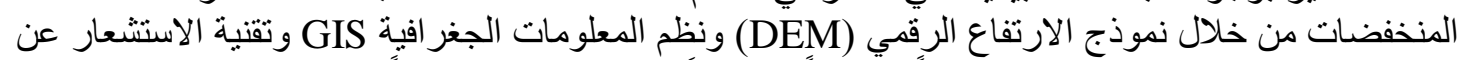

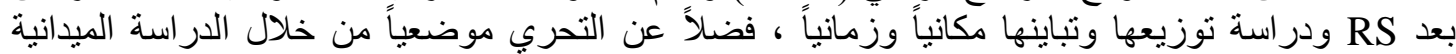

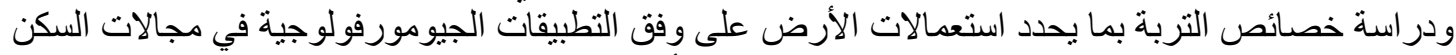

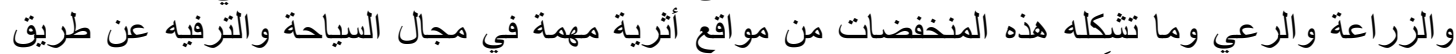

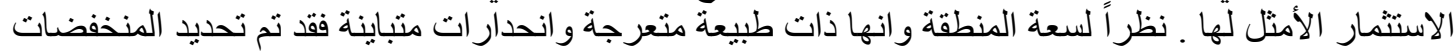

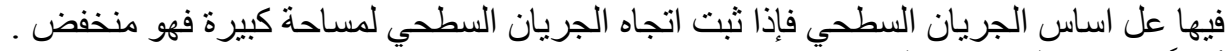
أولاً : مشكلة الاراسة (Study problem):

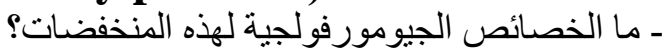

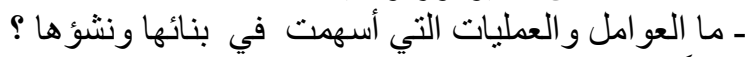

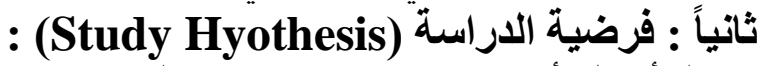

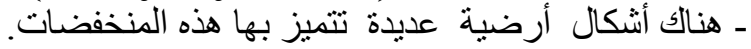

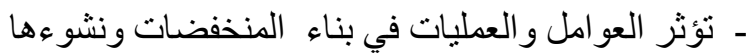
ثُالثاً : هاف الاراسة (Study Aim):

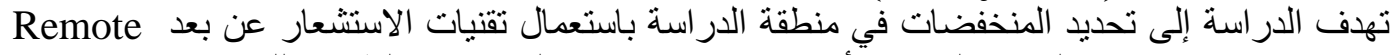

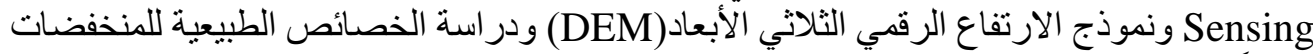
رابعاً : أهمية الدراسة ومبرراتها (Study important end Raisoms) :

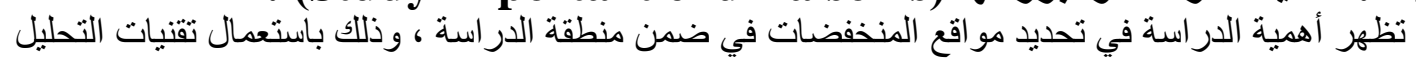

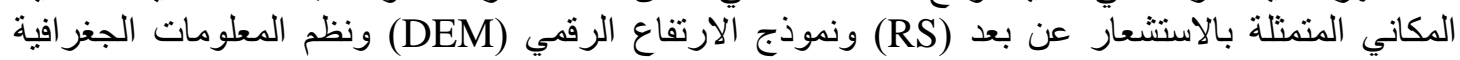

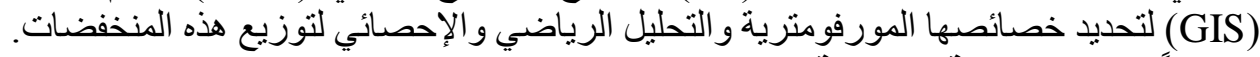
خامساً: حدود منطقة الاراسة (Study Area): تحدد منطقة الدراسة بالبادية الجنوبية للعر اق ، ونظر البراً لسعة مساحتها وصعوبة تغطيتها ميدانياً ، فقد ارتائنا

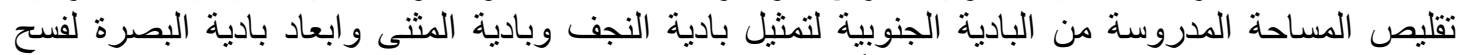

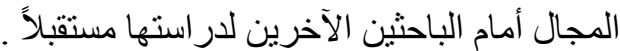

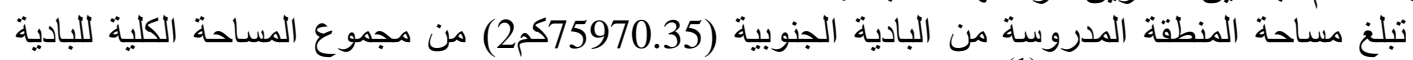

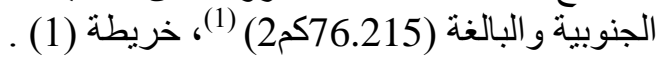

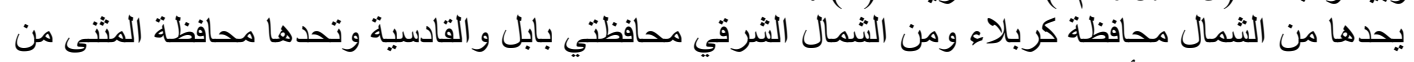

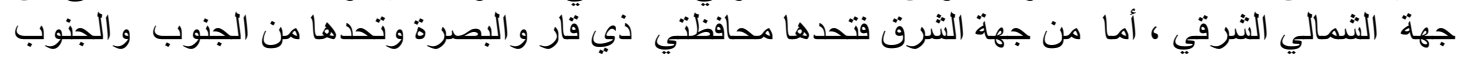
الغربي الحدود السياسية لجمهورية العراق مع المملكة العربية التسعودية ومن الثمال الثرال الغربي تحدها محافظة

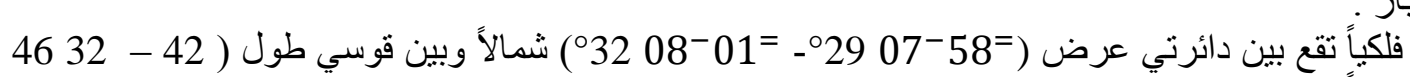
الانبار 5) شرقاً ، خريطة (2) بين دئر 
المجلة المولية اللملوم الآنسانية والامتماعية International Journal of Humanities and Social Sciences website:www.ijohss.com Email:editor@ijohss.com

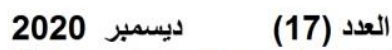
ISSN: 2415 - 4822

Volume (17) December 2020

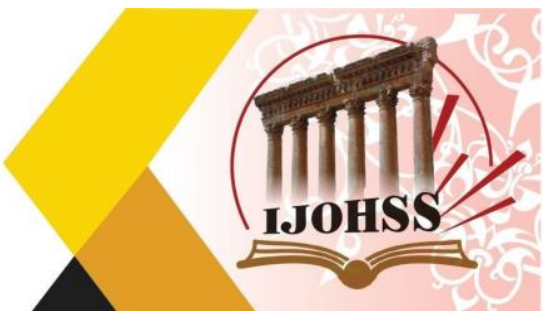

ساداً : منهجية الدراسة (Study methodology):

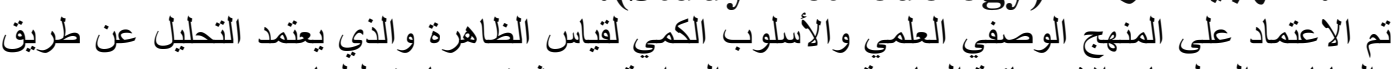

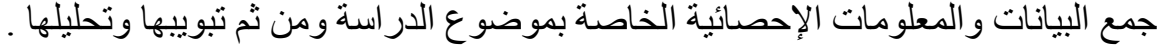

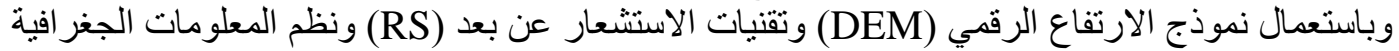
ومو اقع الانترنيت و المرئيات الفضائية .

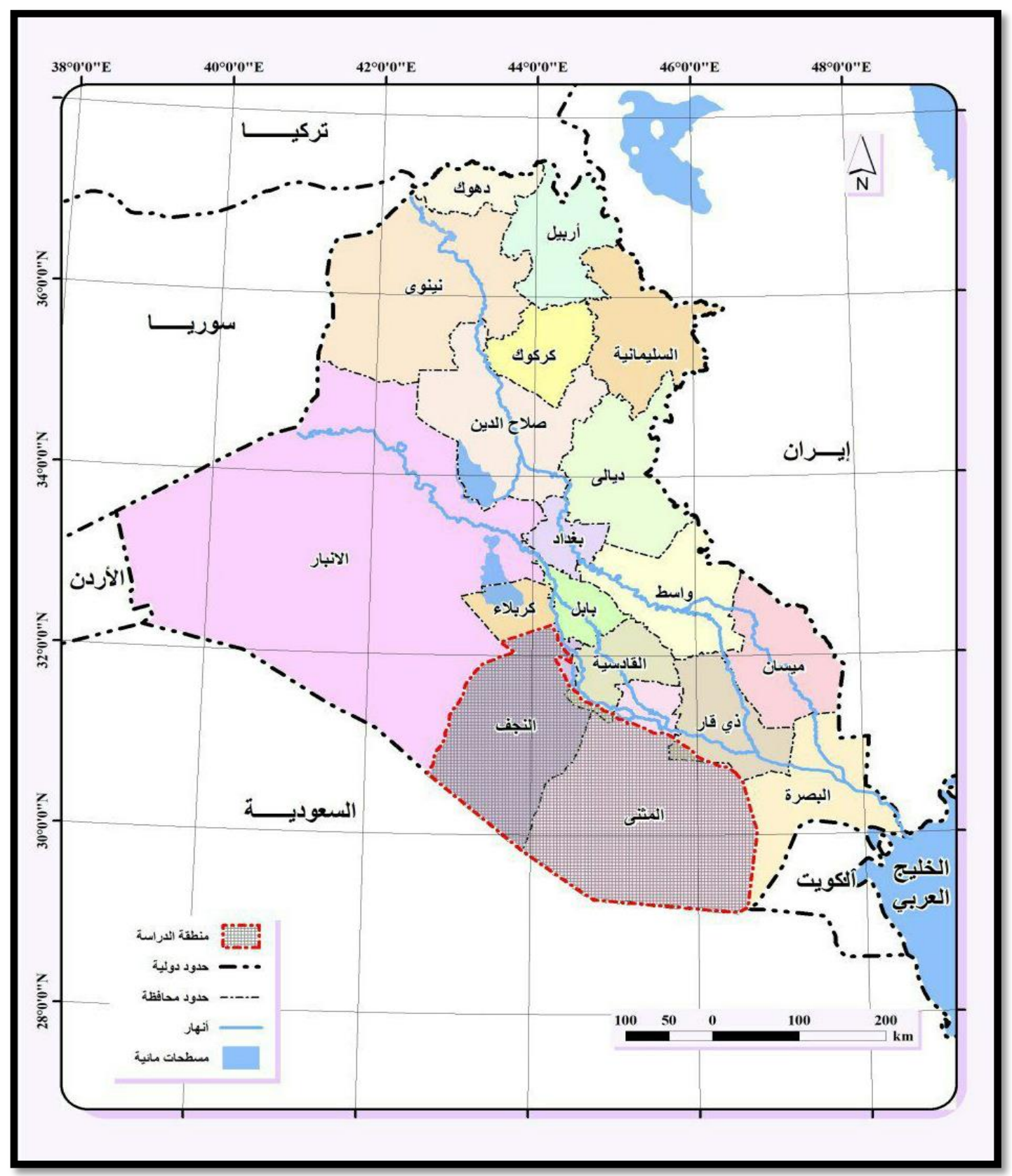

Arc GIS المصدر : بالاعتماد على نموذج الارتفاع الرقمي 10.3 
المجلة اللحولية اللملوم الآنسانية والامتماعية International Journal of Humanities and Social Sciences website:www.ijohss.com Email:editor@ijohss.com العدد (17) ISSN: $2415-4822$

Volume (17) December 2020

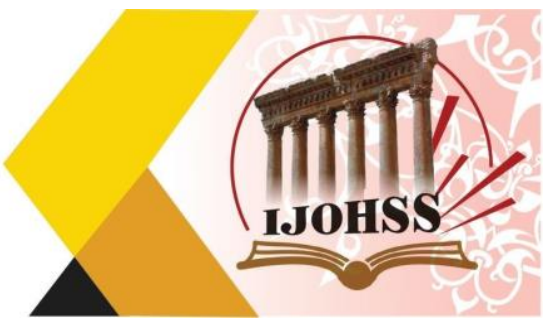

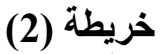

الحدود الإدارية وموقع منطقة الدراسة من المحافظات الجنوبية

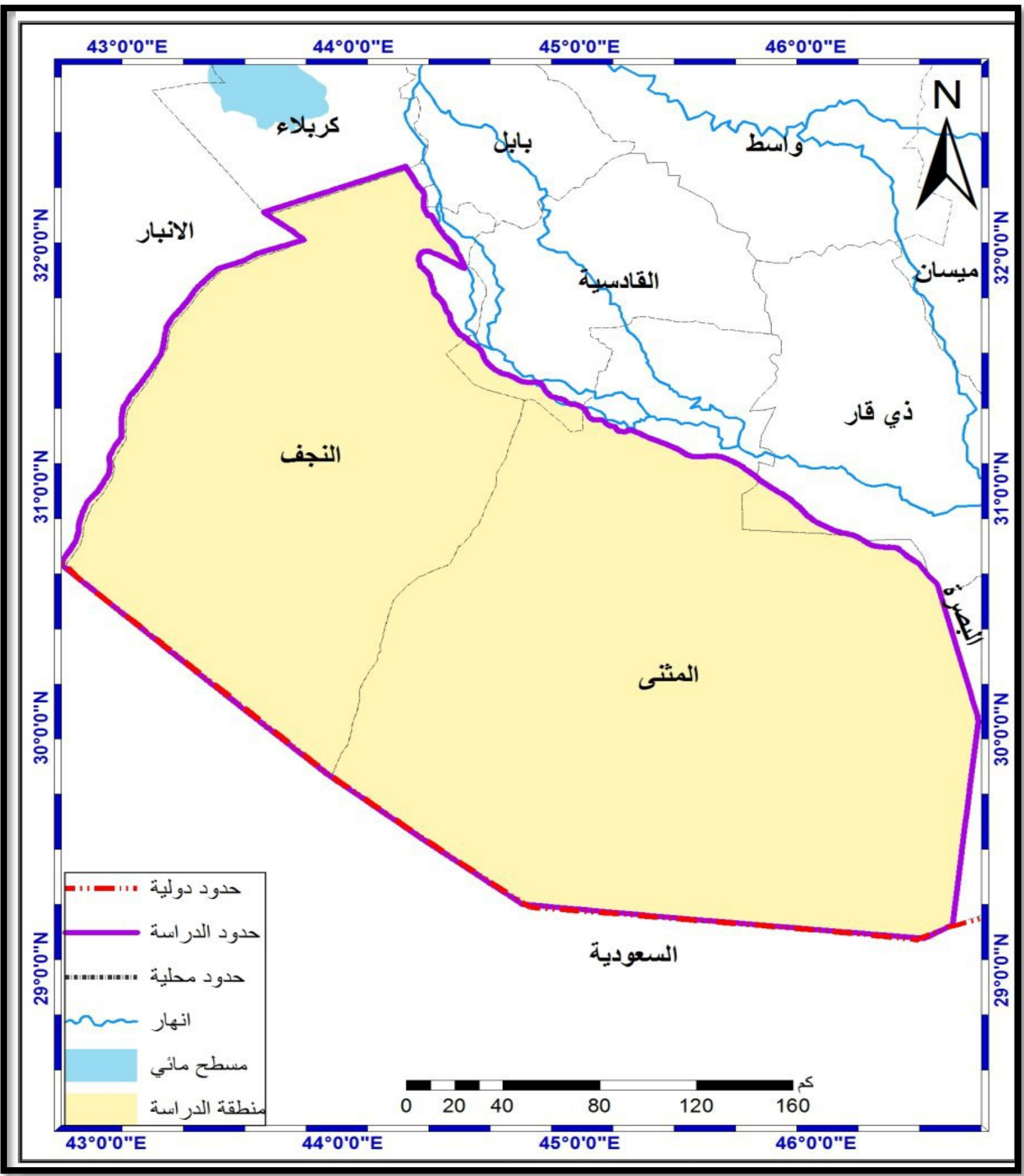

Arc GIS 10.3 المصدر : بالاعتماد على نموذج الارتفاع الرقمي ومخرجات برنامج 


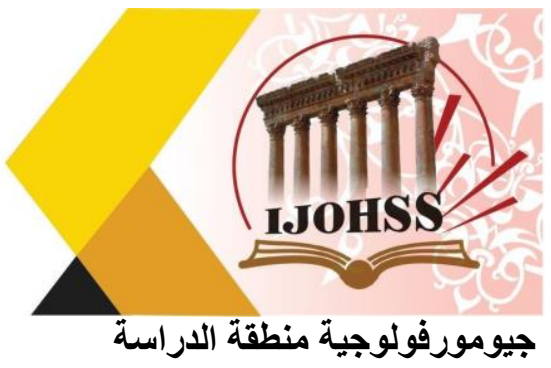

إن العملية الجيومورفولوجية (Geomorphic process)هي وسيلة التأثير في صخور الأرض، وما يتكون

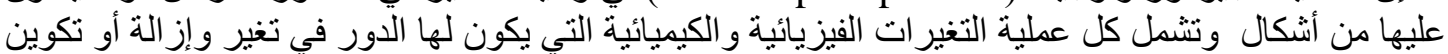

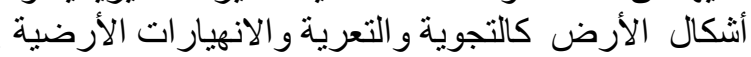

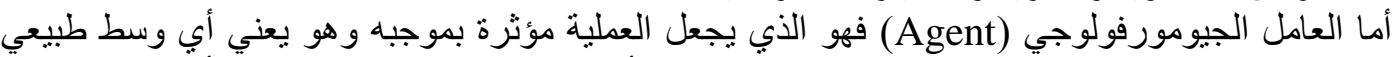

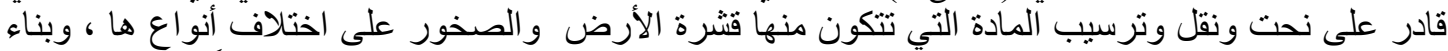

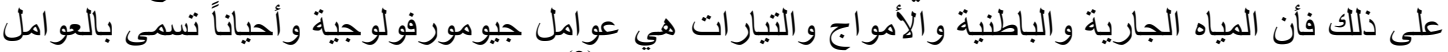

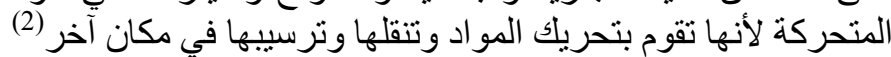

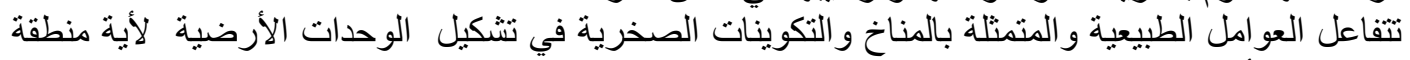

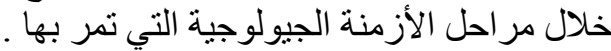
إذ تقع القشرة الأرضية تحت تأثير العديد من العو امل الطبيعية التي تعمل على تشكيلها بمجمو عات متباينة

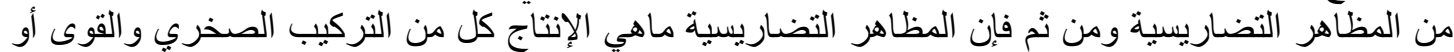

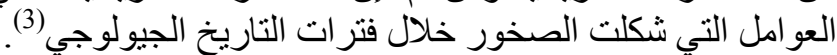
وقد عملت التغيرات المناخية والحركات الأرضية علئ على تشكيل المظاهر التضاريسية في منطقة الدراسة

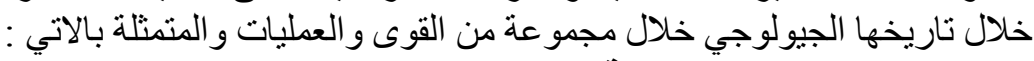

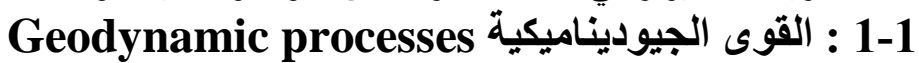
تصنف القوى أو العمليات التي تشكل مظهر سطح الأرض وظو الهو اهره إلى نوعين من القوى هي :

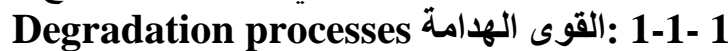

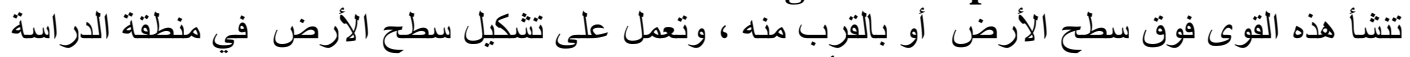

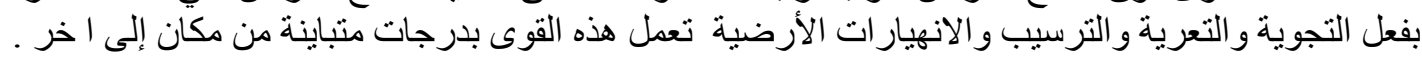
Weathering التجوية

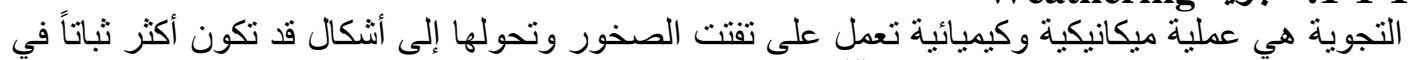

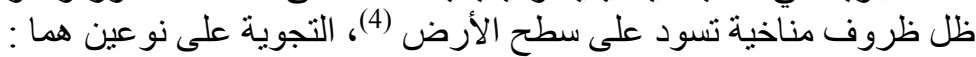
أـ التجوية الميكانيكية

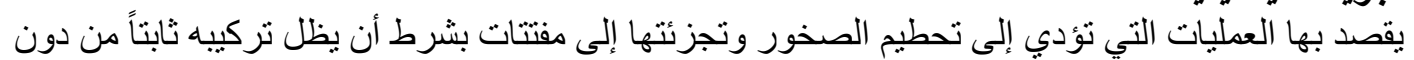

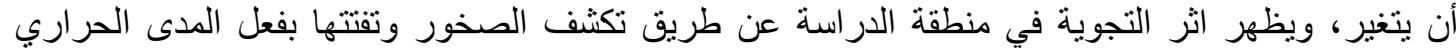

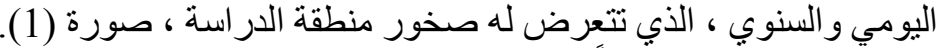

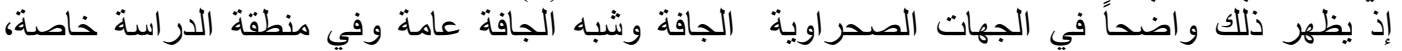

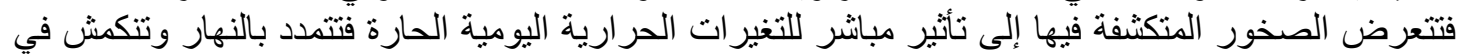

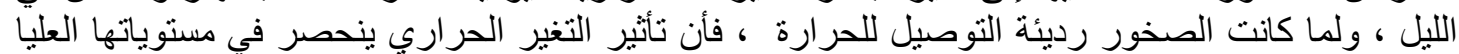

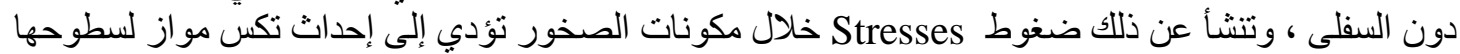

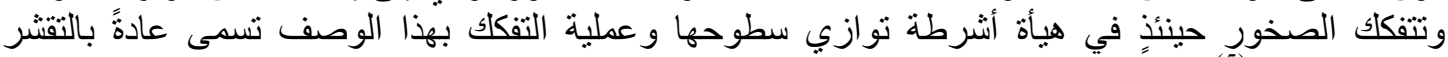

(5) Exfoliation

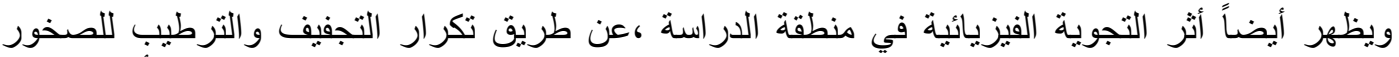

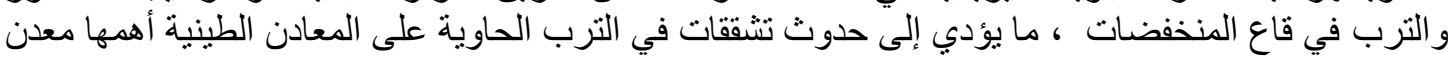

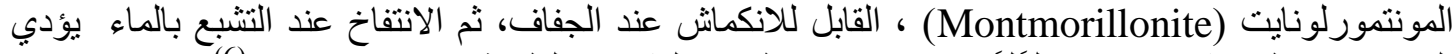

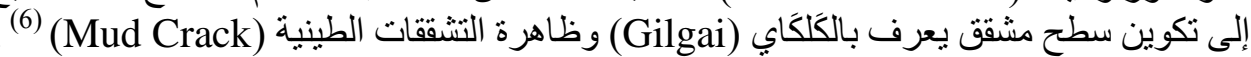

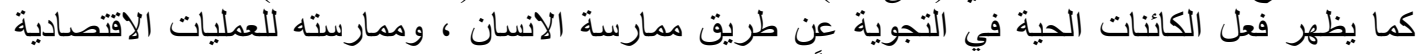

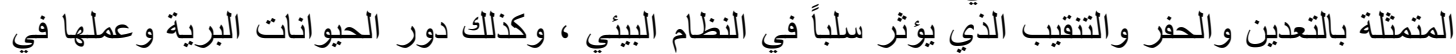

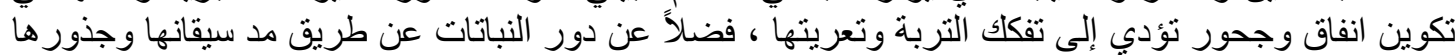

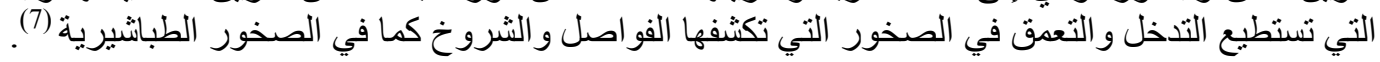



International Journal of Humanities and Social Sciences website:www.ijohss.com Email:editor@ijohss.com ISSN: $2415-4822$

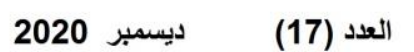
Volume (17) December 2020

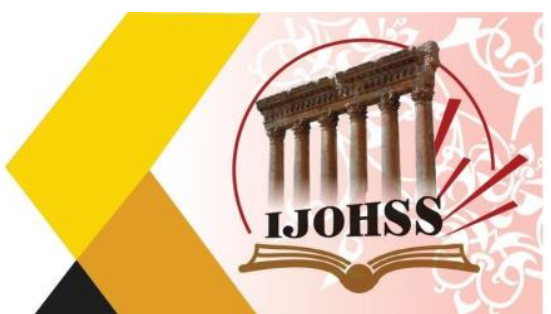

صورة (1)عمليات التمدد و التقلص للصخور في فيضة الحقل قرب منخفض شبجة

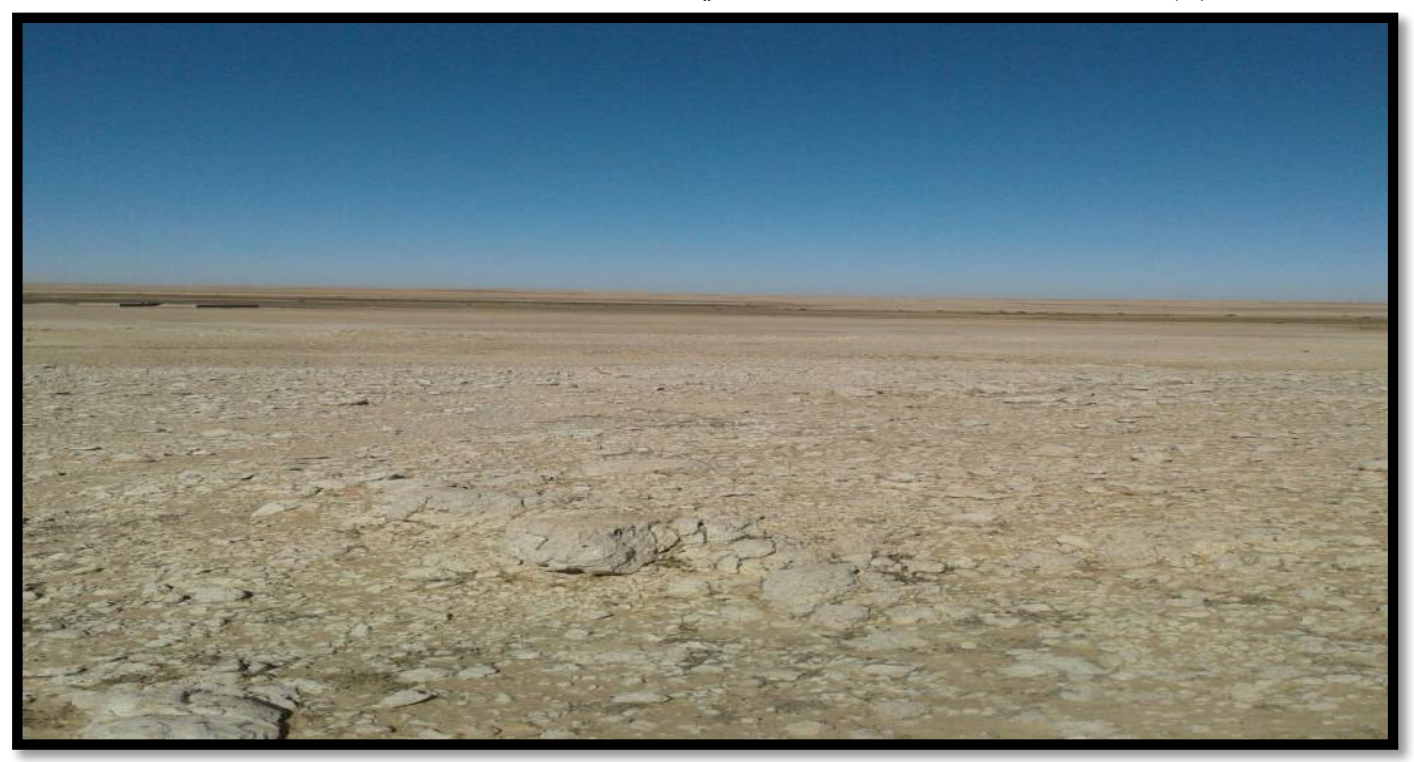

2019/12/26 الدراسة الميدانية/ التقطت بتاريخ

بـ التجوية الميكانيكية بفعل الكائنات الحية (Bio Mechanical Weathering)

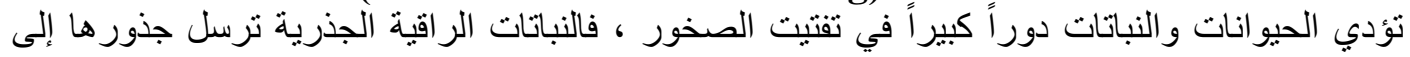

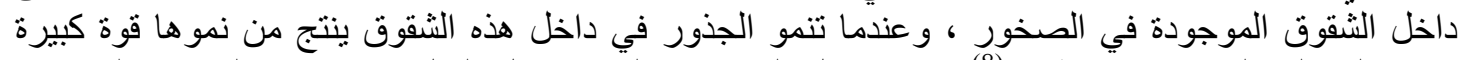

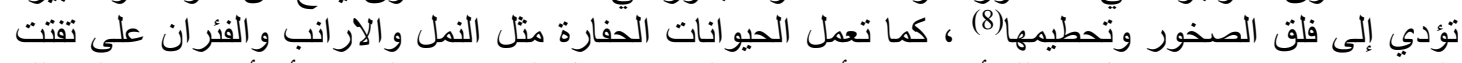

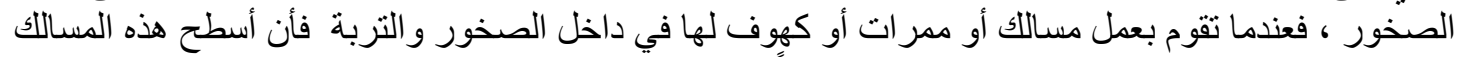

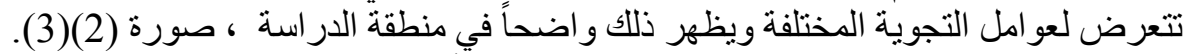

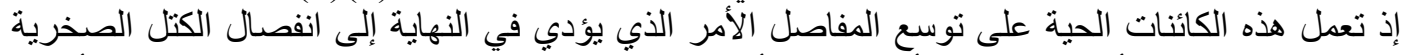

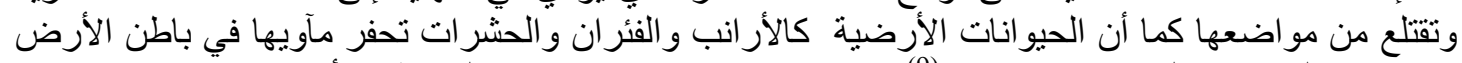

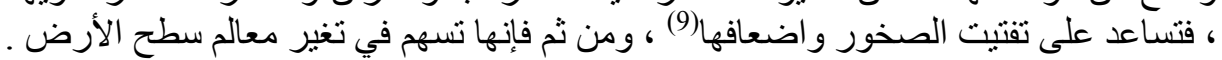

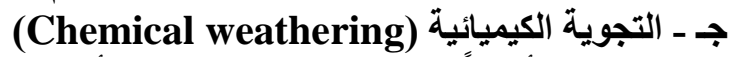

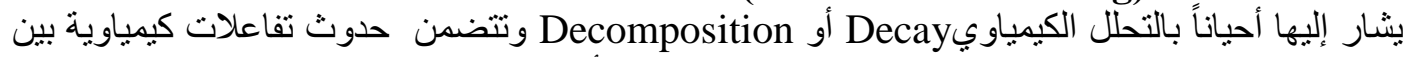

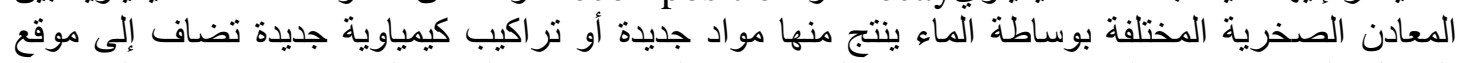

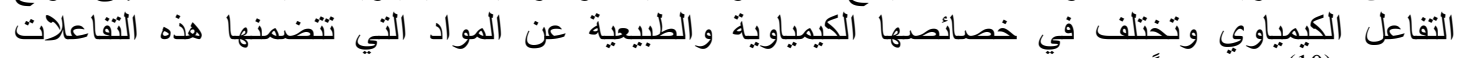

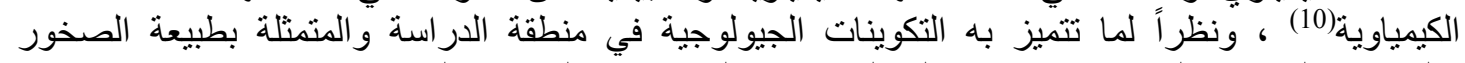

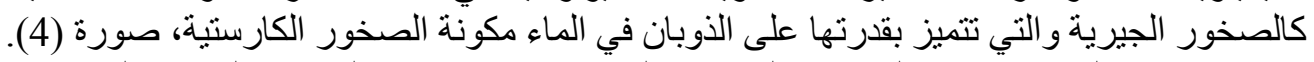

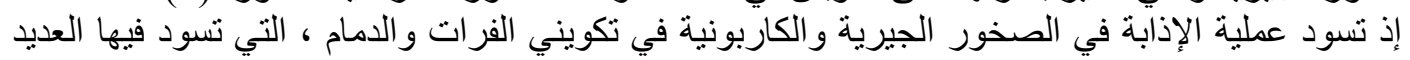

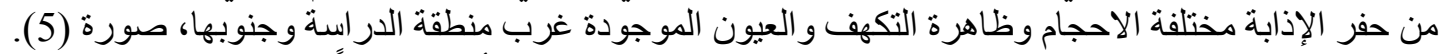

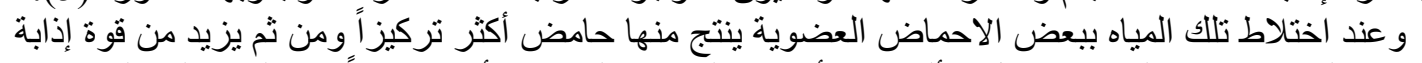

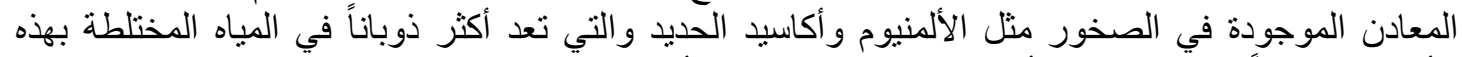

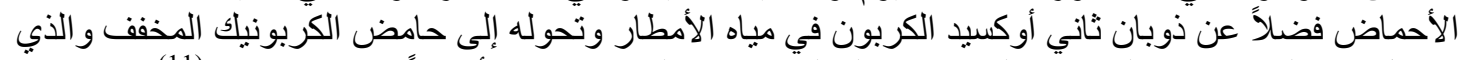

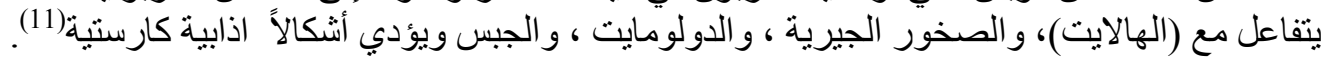


المجلة المولية اللملوم الآنسانية والامتماعية International Journal of Humanities and Social Sciences website:www.ijohss.com Email:editor@ijohss.com ISSN: 2415 - 4822

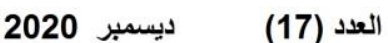

Volume (17) December 2020

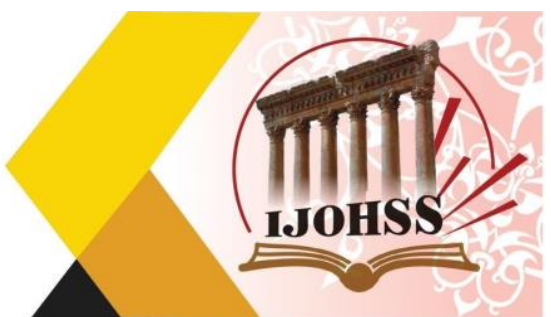

صورة (2) جحور الحيوانات عند الهضبة الغربية من النجف

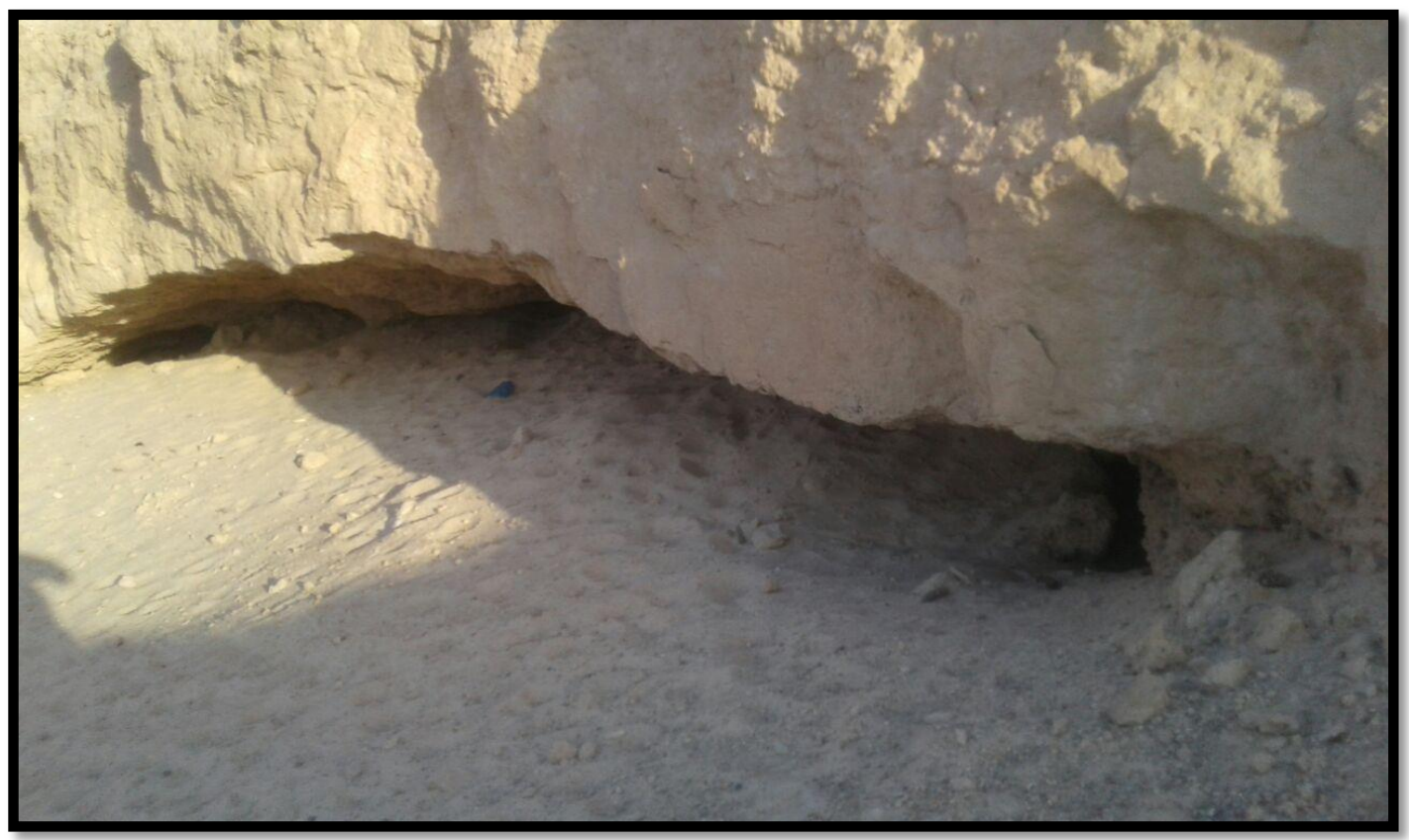

الدراسة الميدانية /التقت بتاريخ 2020/8/7

صورة (3) جحور أحد الحيوانات في منطقة الدراسة

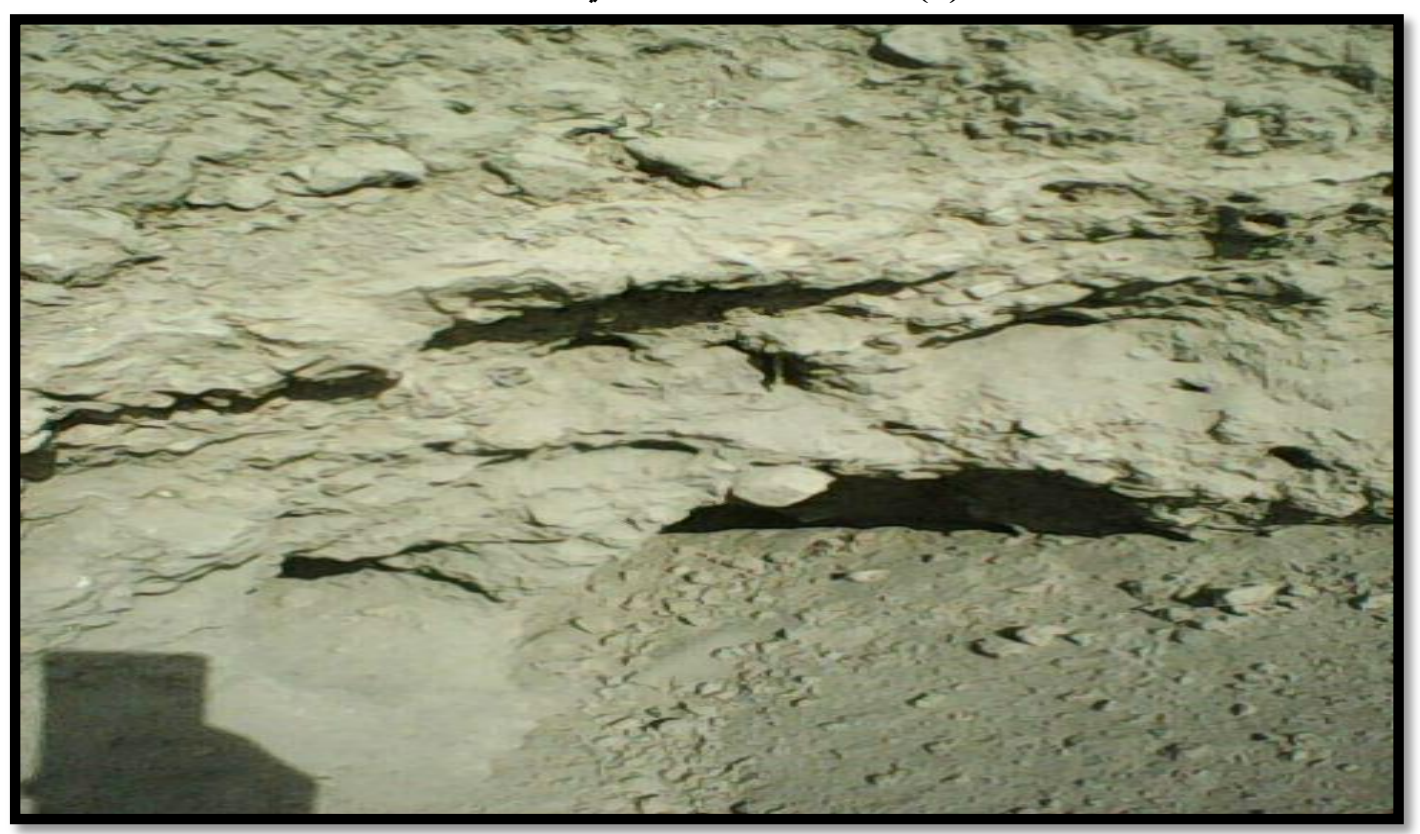

2019/12/28 الدراسة الميدانية / التقطت بتاريخ 
المجلة المولية اللملوم الآنسانية والامتماعية International Journal of Humanities and Social Sciences website:www.ijohss.com Email:editor@ijohss.com ISSN: 2415 - 4822

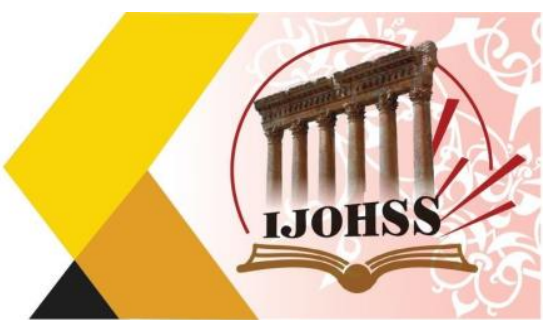
Volume (17) December 2020 صورة (4) عمليات الاذابة في و ادي شويطين

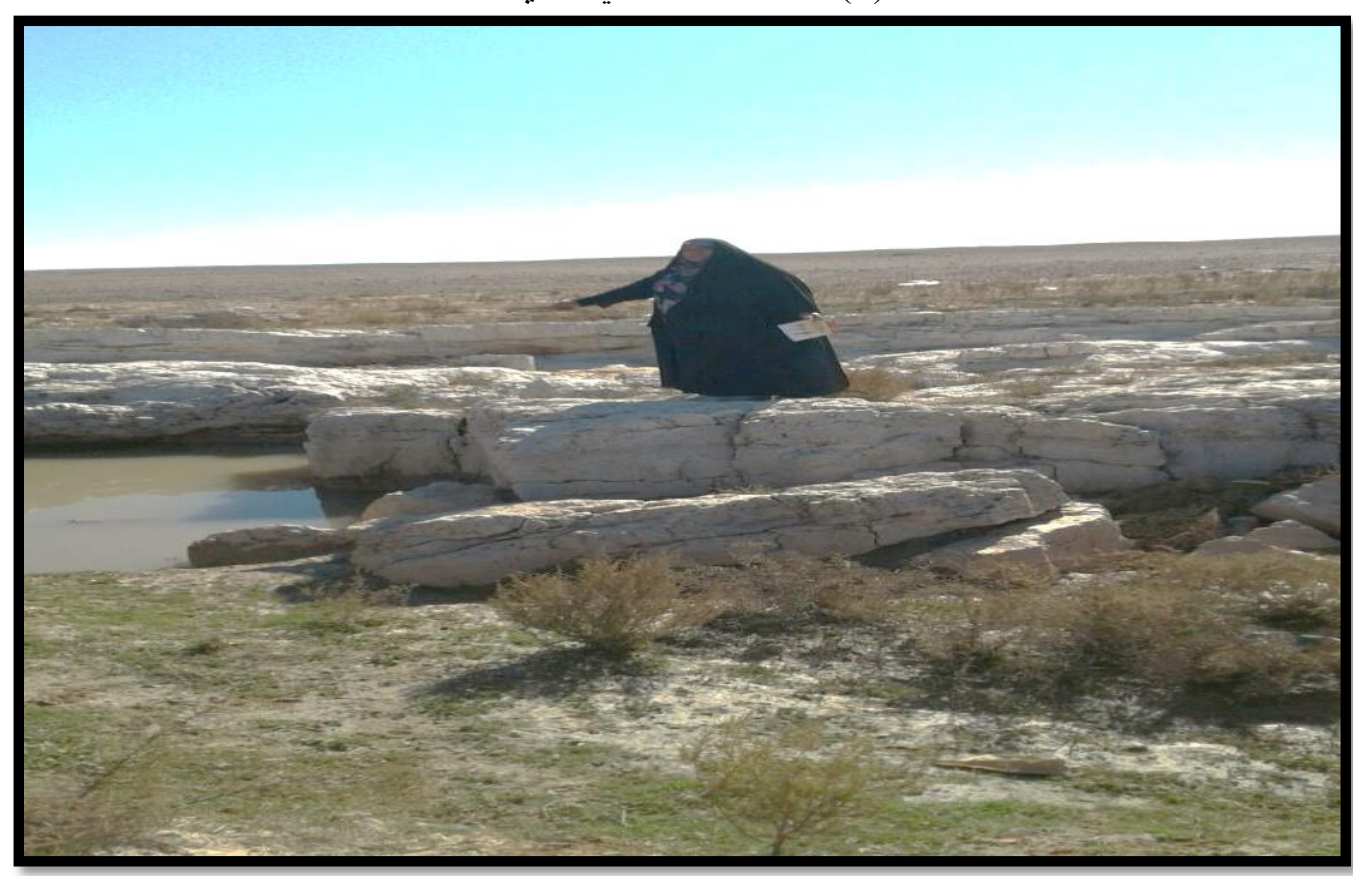

الدراسة الميدانية / التقطت بتاريخ 2019/12/28

صورة (5) عملية التكهف في وادي شويطين في منخفض شبجة

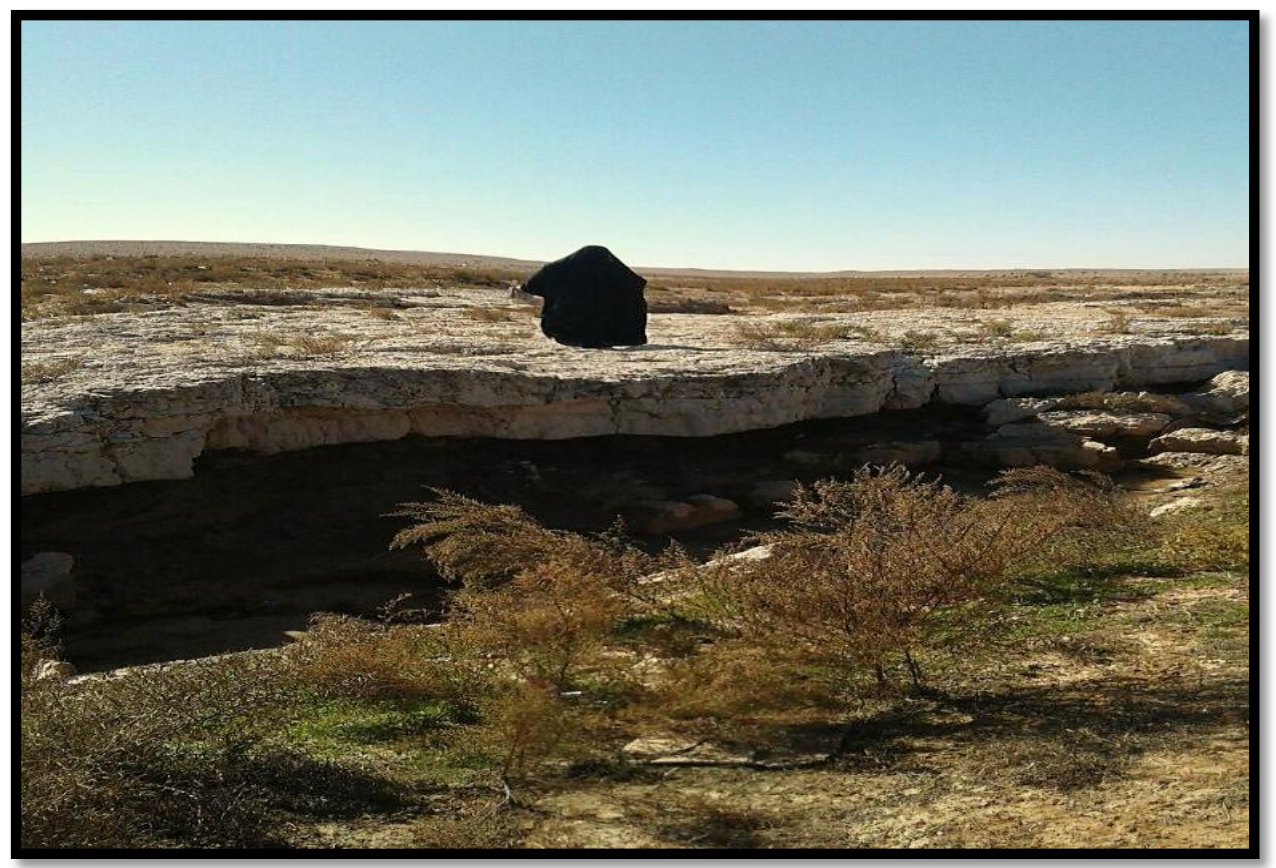

2019/12/28 الدراسة الميدانية / التقطت بتاريخ 


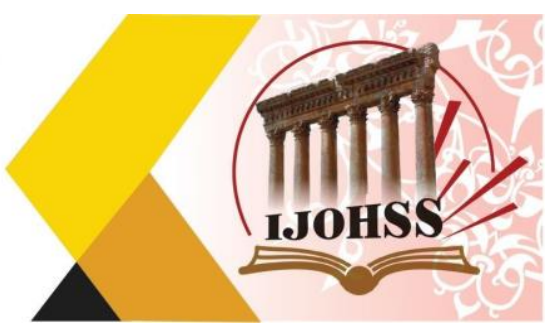

(Erosion) التعرية: 2-1-1- 1

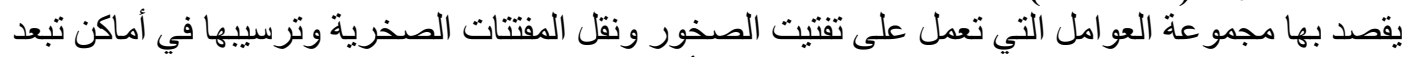

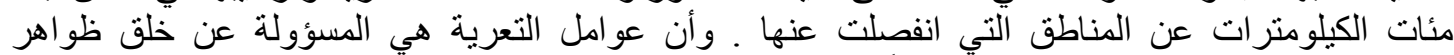

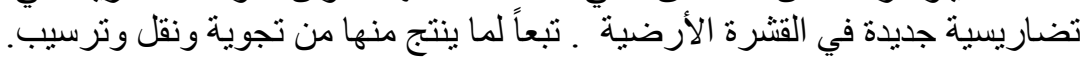

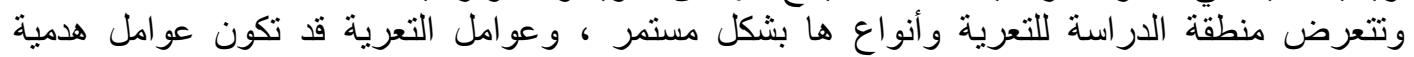

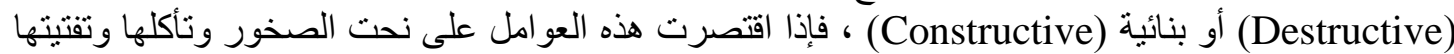

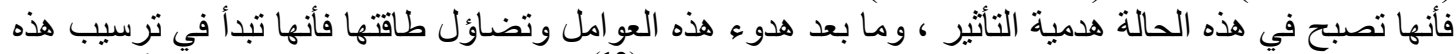

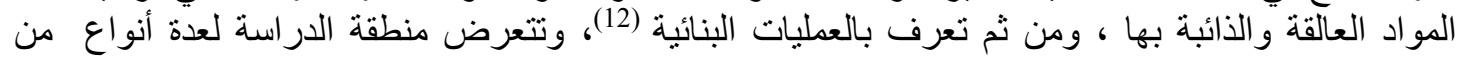

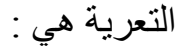

أـ التعرية الريحية Wind Erosion

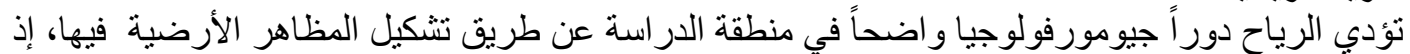

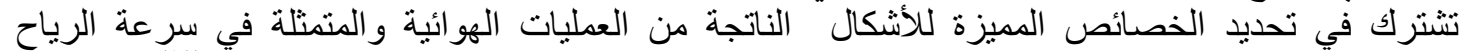

و اضطر ابها ، خشونة السطح (Surface roughness) وتلاحم التكوينات السطحية (cohesion) (13).

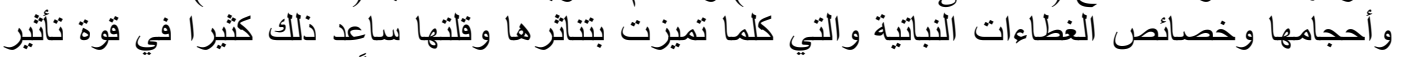

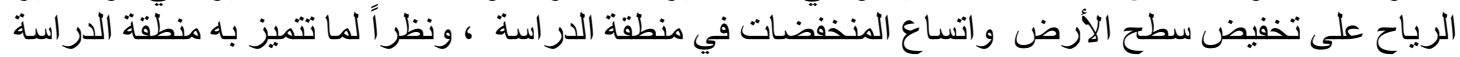

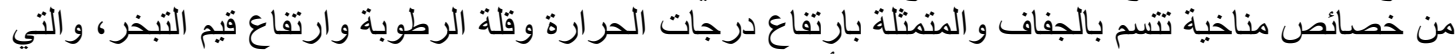

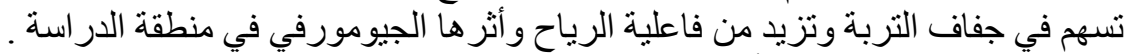

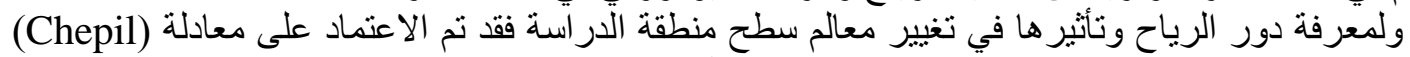

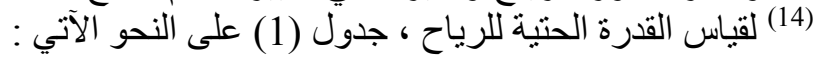

$$
\mathrm{C}=360 \frac{\mathrm{V}^{3}}{(\mathrm{PE})^{2}}
$$

C

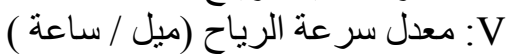
PE

$$
\mathrm{PE}=115\left[\frac{P}{T-10}\right]^{10 / 3}
$$

ت تساقط سنوي (أنج) :

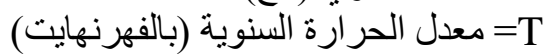

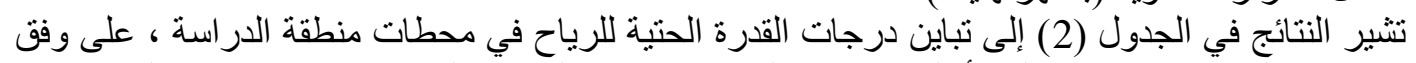

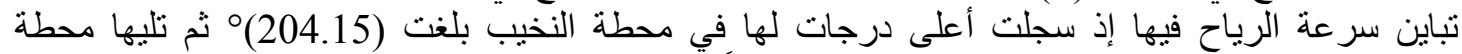

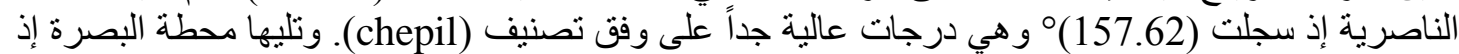

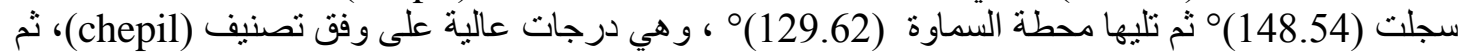

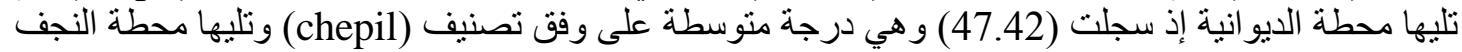

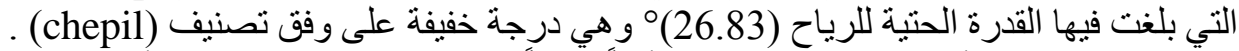

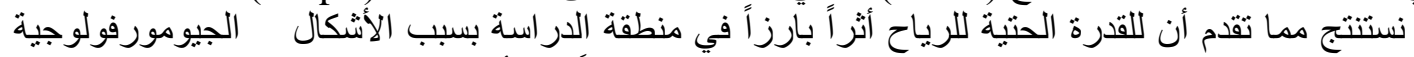

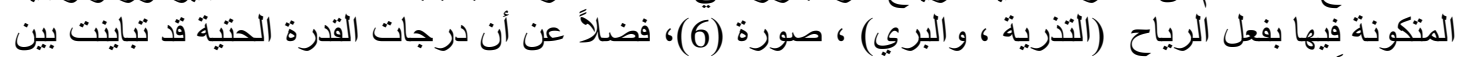

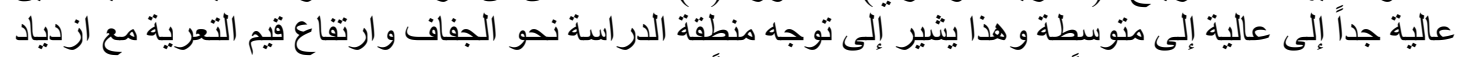

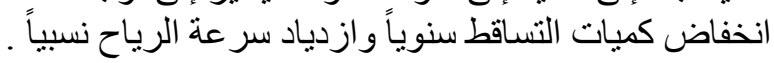



International Journal of Humanities and Social Sciences website:www.ijohss.com Email:editor@ijohss.com العدد (17) ل ISSN: $2415-4822$

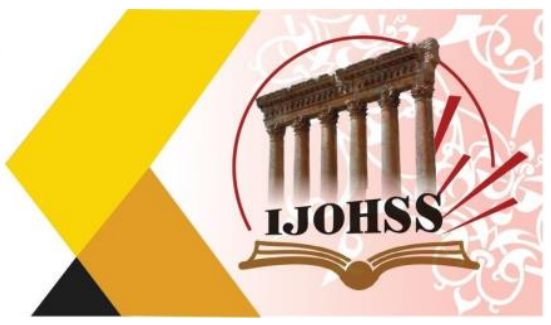

جدول (1) درجات القدرة الحتية الريحية وصفاتها وفقاً لتصنيف (chepil)

\begin{tabular}{|c|c|c|}
\hline الوصف & الدرجة & ت \\
\hline خفقيفة جداً & $\begin{array}{r}17-0 \\
35-18 \\
71-36 \\
150-72 \\
150 \text { أكثر من }\end{array}$ & $\begin{array}{l}1 \\
2 \\
3 \\
4 \\
5\end{array}$ \\
\hline
\end{tabular}

المصدر: Chepil , W.S,and sibbway ,F.H,Ambrust ,D.V,chimatic , factor for Estimatin Wind Erodibility of form fields , J.soil and water conservation, 1962 .p.p.162.

جدول (2) درجات القدرة الحتية للرياح المناخي للمدة (1985-2017)

\begin{tabular}{|c|c|c|c|c|}
\hline قانون جابل $\quad$ حسب & القدرة الحتية للرياح & سراعة الرياح ميل & المطر الفعال & المحطة \\
\hline عالية جدا & 204.15 & 11.24 & 4.61 & النخيب \\
\hline خفيف & 26.83 & 1.40 & 4.50 & النجف \\
\hline متوسط & 47.42 & 3.31 & 5.19 & الديو انية \\
\hline عالية & 129.62 & 8.62 & 5.07 & السماوة \\
\hline عالية جدا & 157.62 & 14.17 & 5.89 & الناصرية \\
\hline عالية & 148.54 & 15.44 & 6.33 & البصرة \\
\hline
\end{tabular}

(chepil) المصدر : بالاعتماد على معادلة

صورة (6) التذرية الريحية على طريق شبجة

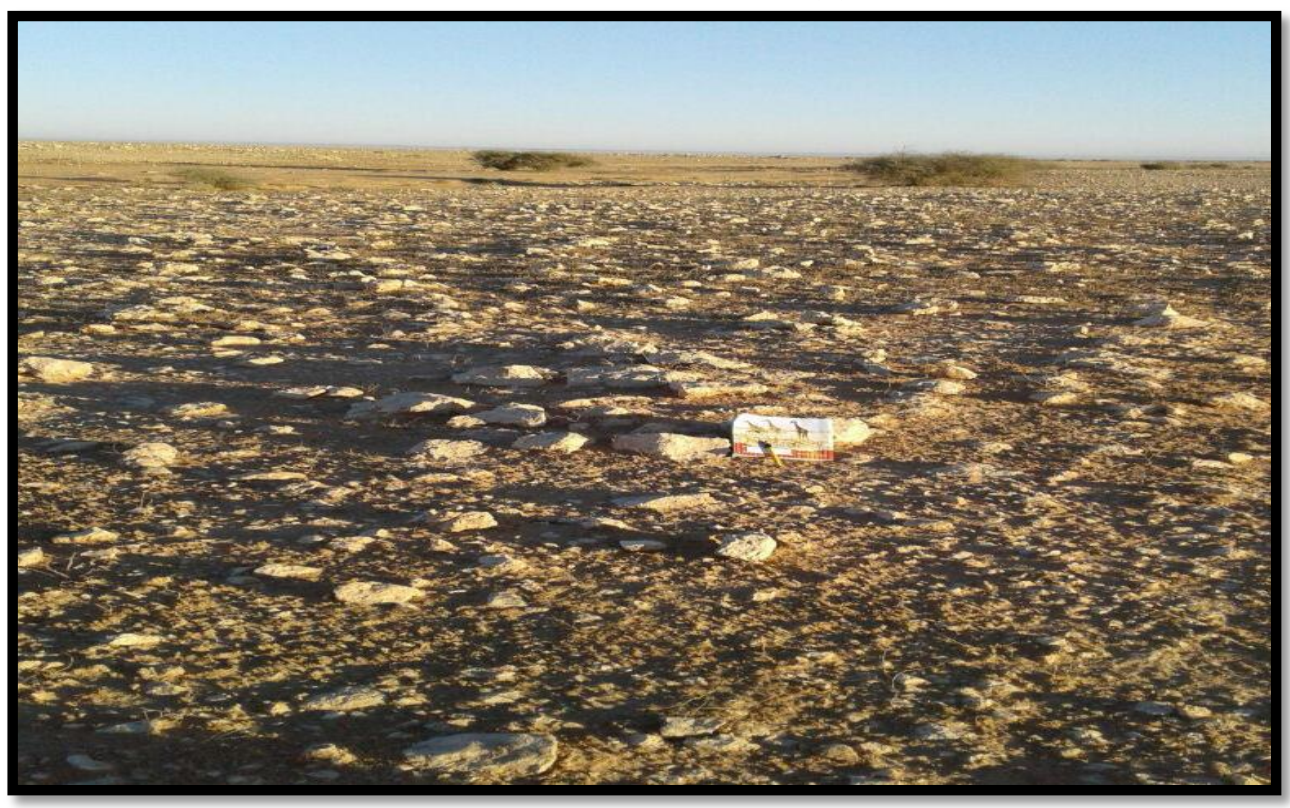

2019/12/28 الدراسة الميدانية / التقطت بتاريخ 


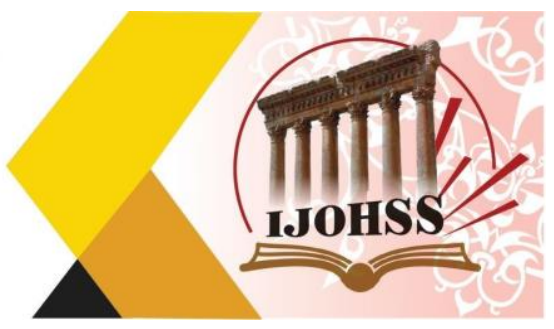

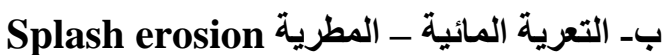
تعتمد التعرية المطرية في منطقة الدراسة على غزاية ارة الأمطار وشدتها ، وبما أن منطقة الدراسة تتسم بقلة

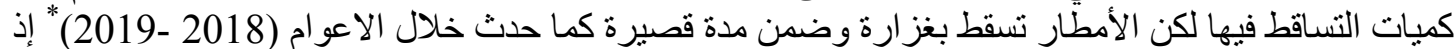

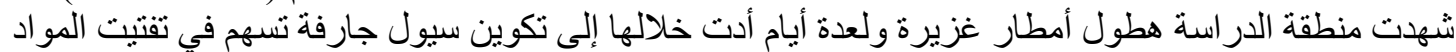

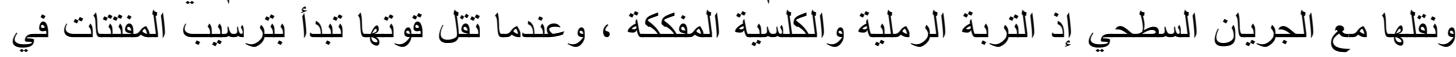

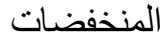

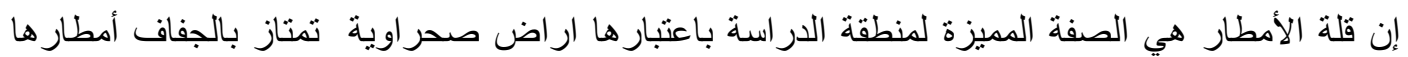

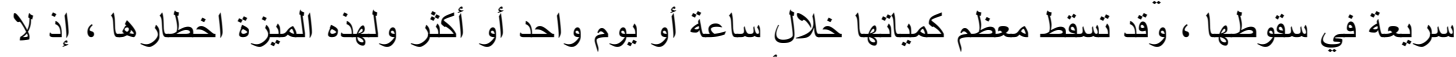

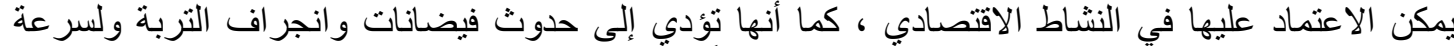

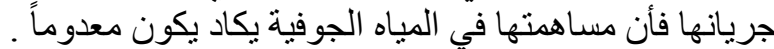

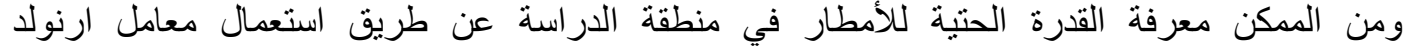
فورنير(A.F.I) و هذا المعيار معتمد من قبل منظمة الأغذية و الزر اعة العالمبة

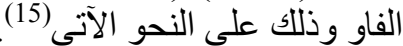

$$
\text { A.F.I }=\sum_{i=1}^{12} \frac{(p i)^{2}}{p}
$$

A.F.I

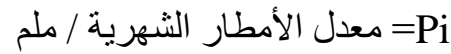

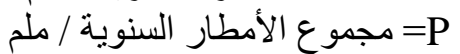
يتضح من الجدول (3) وبعد تطبيق معامل فورنير فيما يتعلق بكمبات الأمطار الساقطة على منطقة الدراسة:

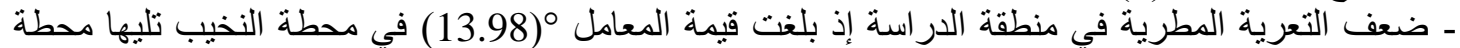

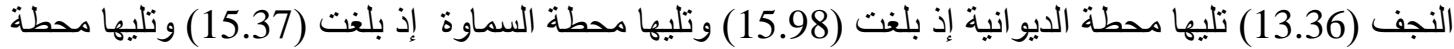
الناصرية إذ بلغت (17.52) ثم محطة البصرة إذ سجلت (10.15) ، ما يشير إلى أنها ضعيفة في ضمن تصنيف

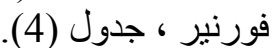
ـ لا توجد تعرية مطرية خلال شهور حزير ان ، وتموز ، و آب ، و أن قيمة المعامل (صفر) بسبب انقطاع سقوط

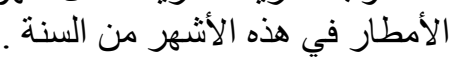

جدول (3) القدرة الحتية للأمطار حسب معادلة ارنولا فورنير اندكس Arnold Fournner Index

\begin{tabular}{|c|c|c|c|c|c|c|c|c|c|c|c|c|c|}
\hline الكلي & كانول الأول & تثرين & تشرين & أيلول & آب & تموز & حزير ان & أيار & نيسان & آذار & شباط & كانانون & الأشهر/ \\
\hline 13.06 & 2.59 & 2.87 & 0.46 & 0.00 & 0.00 & 0.00 & 0.00 & 0.06 & 2.10 & 2.59 & 1.61 & 0.79 & النخيب \\
\hline 13.36 & 2.32 & 2.96 & 0.26 & 0.00 & 0.00 & 0.00 & 0.00 & 0.10 & 1.78 & 1.51 & 1.78 & 2.65 & النجف \\
\hline 15.98 & 2.27 & 3.60 & 0.18 & 0.00 & 0.00 & 0.00 & 0.00 & 0.06 & 1.96 & 1.36 & 1.69 & 4.85 & الديو انية \\
\hline 15.37 & 1.94 & 3.26 & 0.23 & 0.00 & 0.00 & 0.00 & 0.00 & 0.16 & 0.86 & 2.78 & 1.88 & 4.25 & السماوة \\
\hline 17.52 & 3.19 & 2.84 & 0.37 & 0.01 & 0.00 & 0.00 & 0.00 & 0.10 & 1.63 & 3.49 & 1.77 & 4.13 & الناصرية \\
\hline 20.15 & 5.23 & 2.43 & 0.23 & 0.00 & 0.00 & 0.00 & 0.00 & 0.09 & 1.36 & 3.23 & 2.19 & 5.39 & البصرة \\
\hline
\end{tabular}


المبلة المولية اللملوم الآسسانية والإمتصاعية International Journal of Humanities and Social Sciences website:www.ijohss.com Email:editor@ijohss.com ISSN: $2415-4822$

العدد (17) ل Volume (17) December 2020

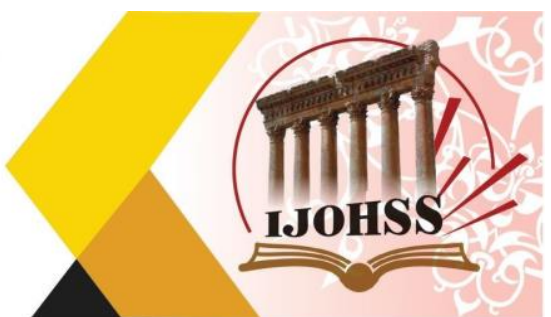

جدول (4)تصنيف (Fournner) لقياس القدرة الحتية للأمطار

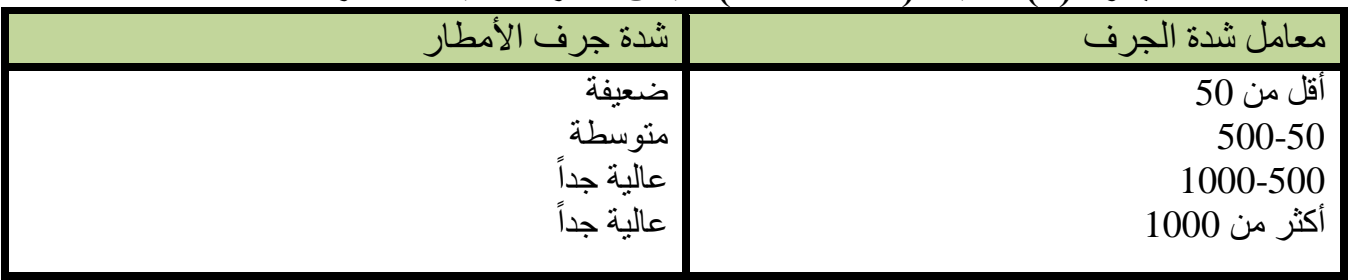

Cliffard Embeton , Jonn Thornes, process in geomorphology , المصدر

Edward Arnold ITd, London ,1920,p.215.

ج - التعرية الصفائحية (Sheet Erosion) ينشأ هذا النوع من التعرية في الأراضي المستوية خفيفة الانحدارات والتربة التربة ذات التهات النفاذية ، إذ تعمل الأمطار

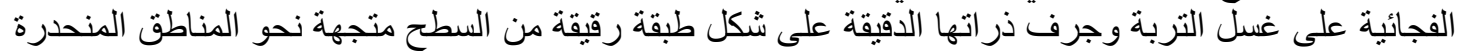

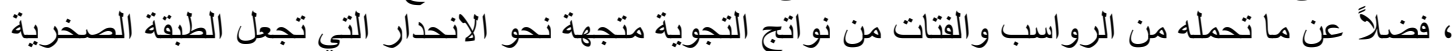

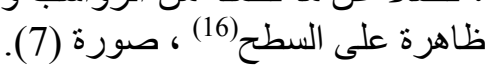

دـ التعرية الأخدودية والجدولية (Rill \& Gully Erosion)

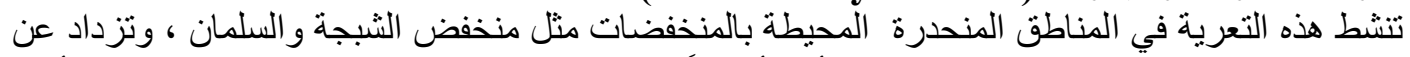

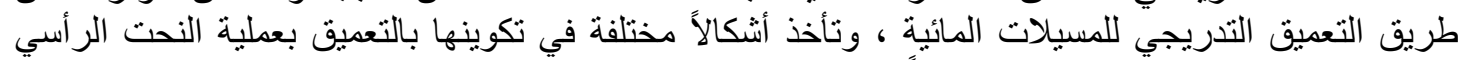

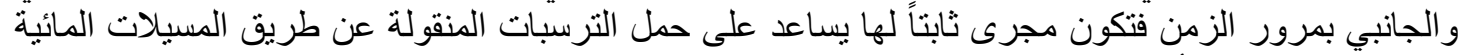

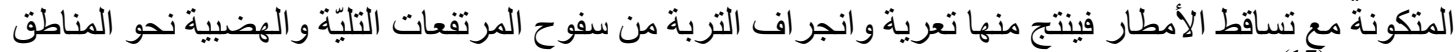

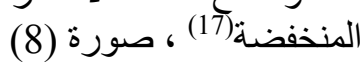

صورة (7) التعرية الصفائحية في وادي السجر في منخفض شبجة

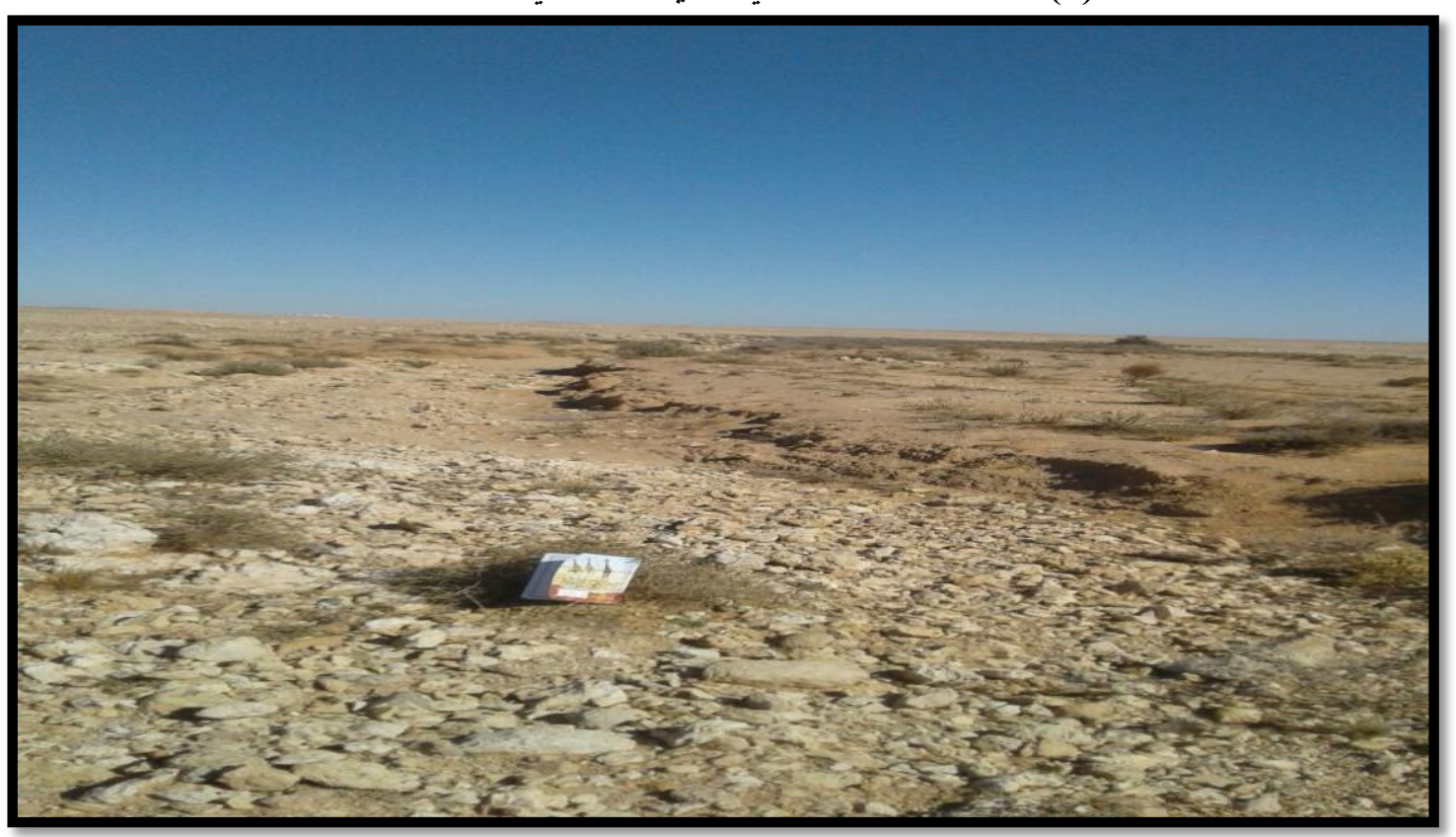

2019/12/28 الدراسة الميدانية / التقطت بتاريخ 
المجلة اللحولية اللملوم الآنسانية والإمتماعية International Journal of Humanities and Social Sciences website:www.ijohss.com Email:editor@ijohss.com ISSN: 2415 - 4822

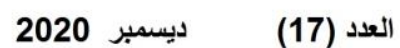
Volume (17) December 2020

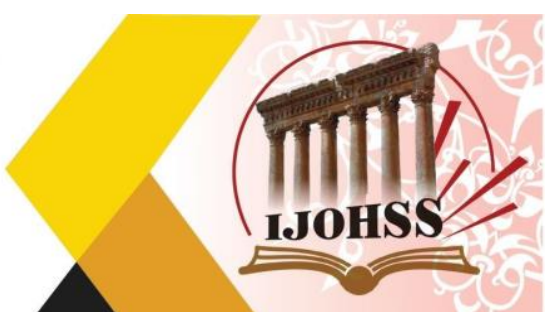

صورة (8) أحد المجاري المائية في بطون الأودية في فيضة الصوكعة في منخفض الثبجة

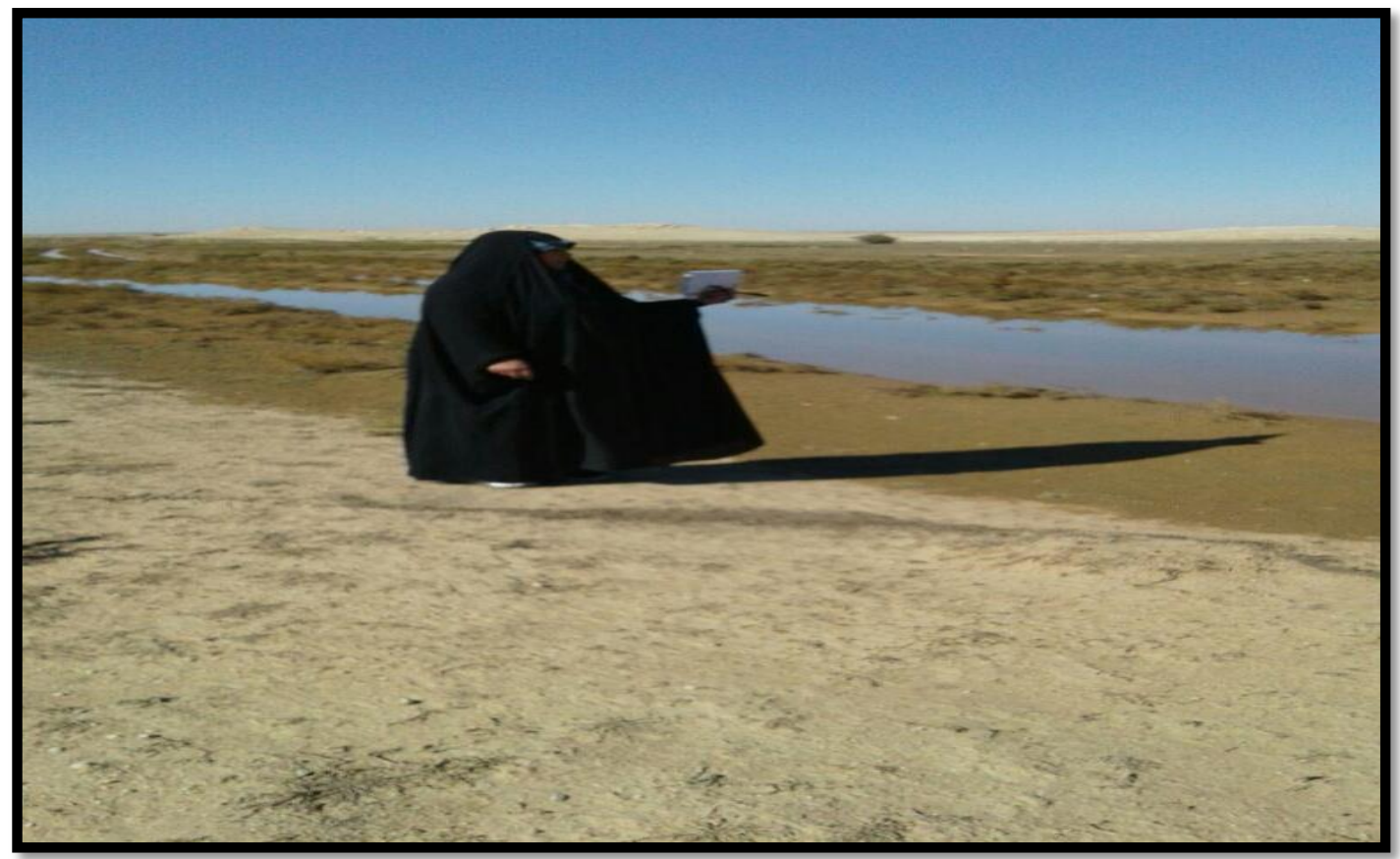

2019/12/28 الاراسة الميدانية / التقطت بتاريخ

(Mass Wasting) الانهيارات الأرضية):3-2-1- 1

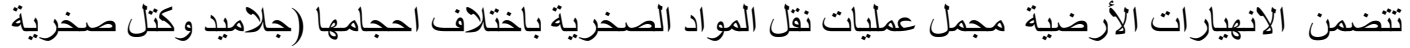

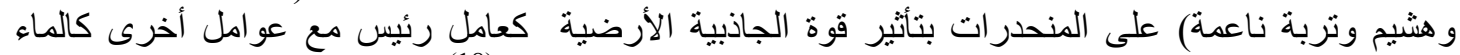

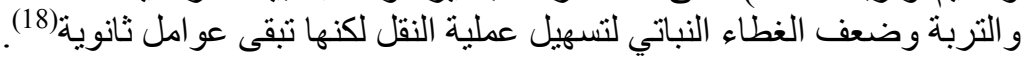

أـ تساقط الصخور (Rocks Fall)

حركة سريعة جداً لمو اد سطح الأرض فوض فوق منحدرات شديدة الميل كالجروف ، وقد نكون المواد المتساقطة

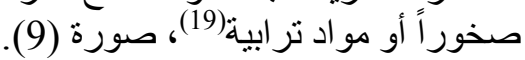

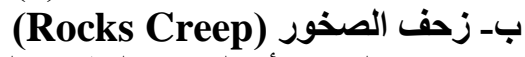

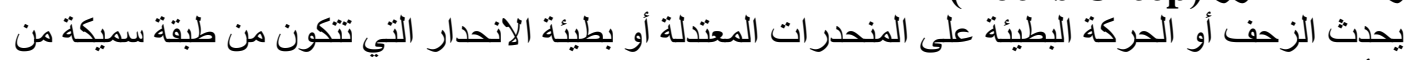

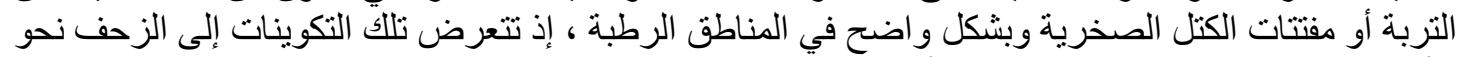

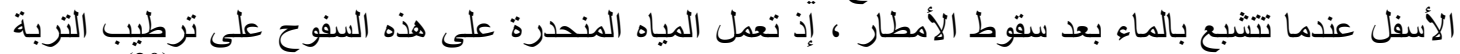

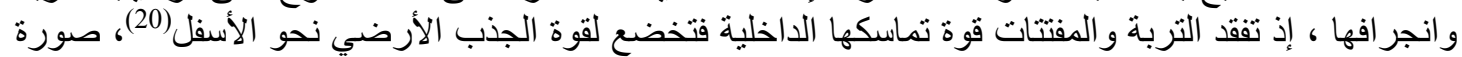




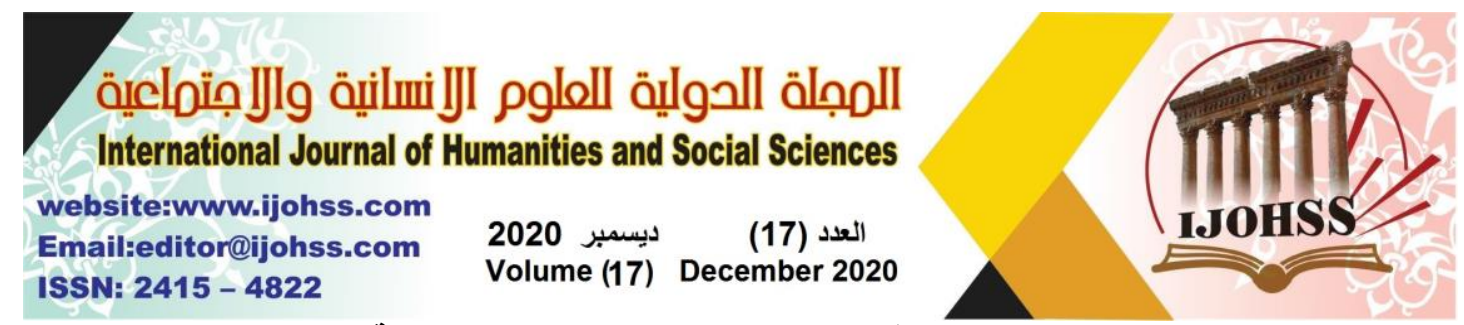

صورة (9) تساقط الصخور على طريق منخفض الثبجة

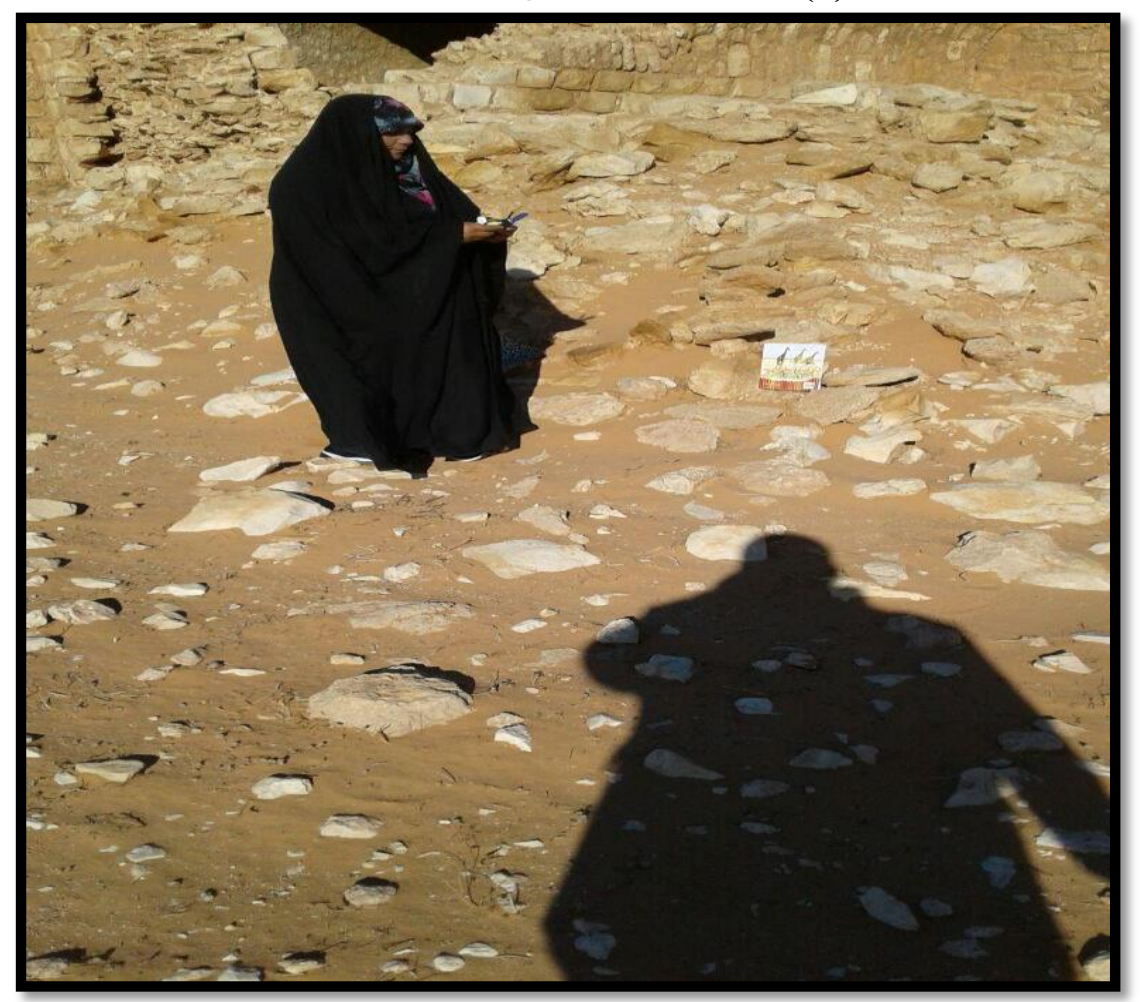

الدراسة الميدانية / التقطت بتاريخ 2019/12/28

صورة (10) زحف الصخور في منخفض السلمان

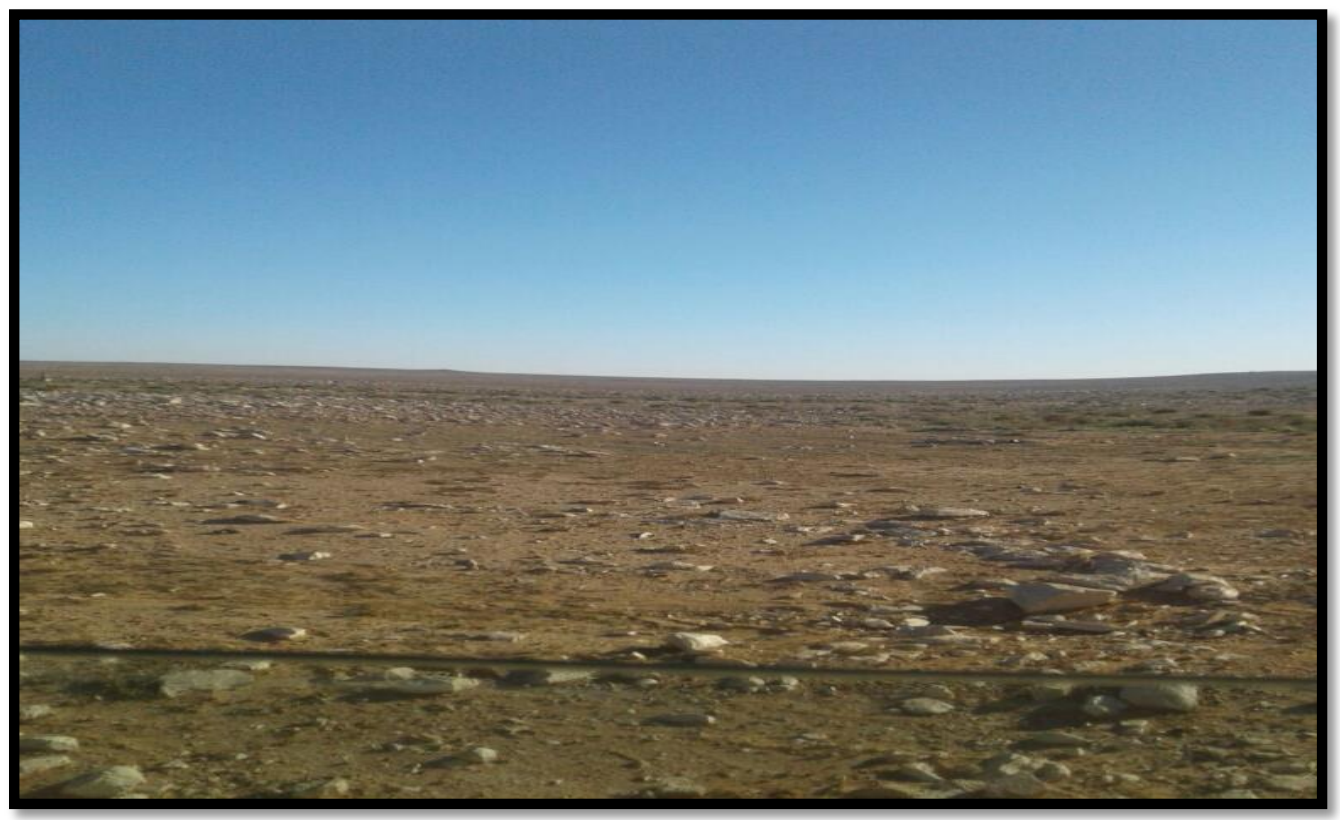

الاراسة الميدانية / التقطت بتاريخ 2020/12/23 


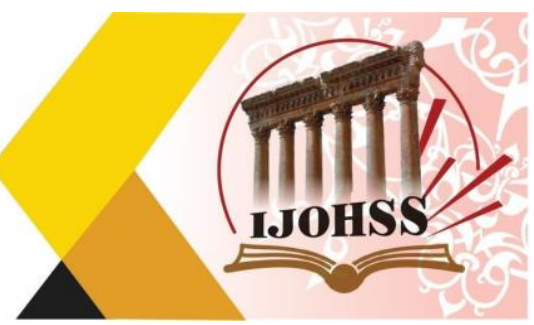

(القوة البناءة (Aggradations Processes):1-1

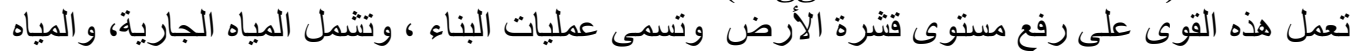
الباطنية ، و التبار ات ، و المد ، و الأمواج ، و الرياح ، و والثلاجات ، و وكل الكائنات العضوية الثية بما فيها الإنسان و العمليات الباطنية) (21).

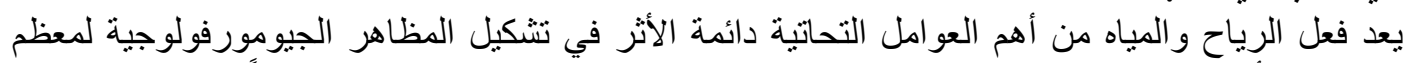

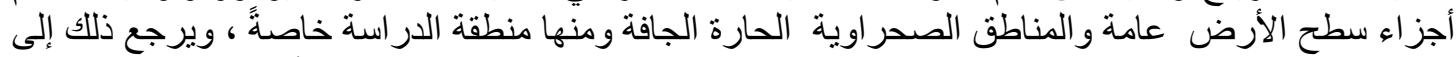

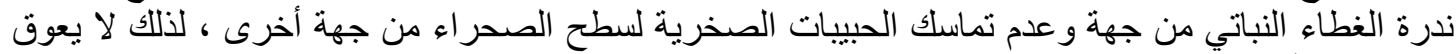

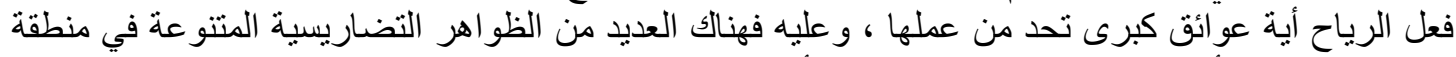

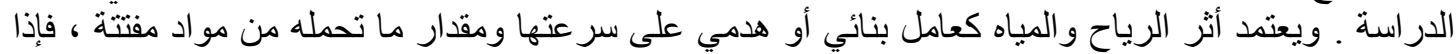

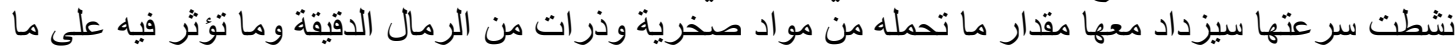

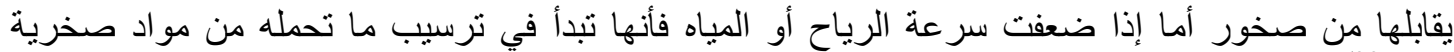
مفتتة(22) ومو اد طينية و غرينية .

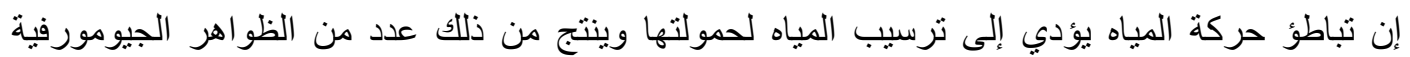

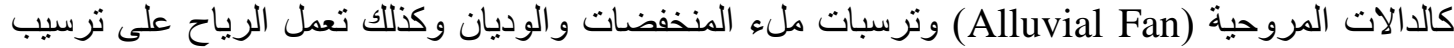

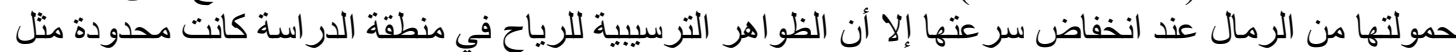

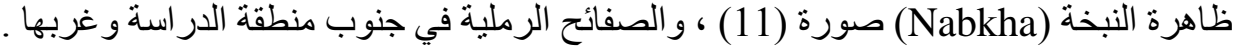

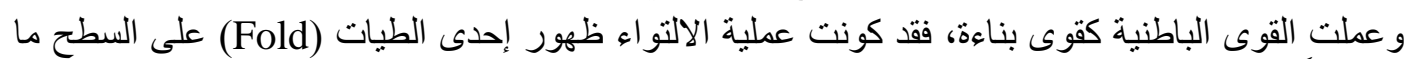

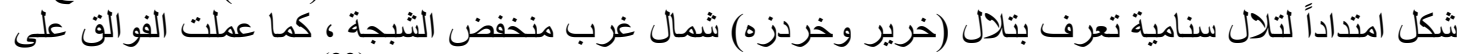

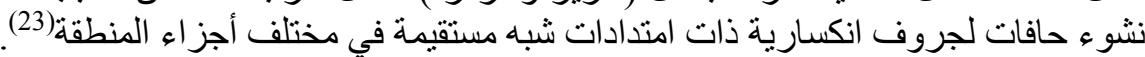
2-1 الوحدات الجيومورفولوجية (Geomorphic Units): تتنو ع الوحدات الجيومورفولوجية في منطقة الدراسة على وفية وفق تباين القوى و العمليات التي أسهمت وتسهر في نشأتها وتكو ينها عبر مر احل تطور هات الجيا. تم تمييز الوحدات الجيومورفولئوجية اعتماداً على تفسير المرئية الفضائية والصور النية الجوية والخرائط

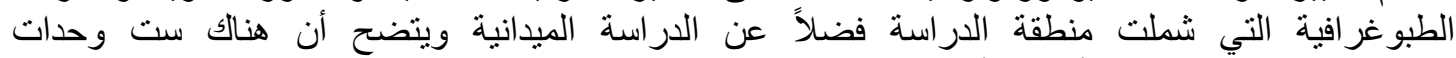

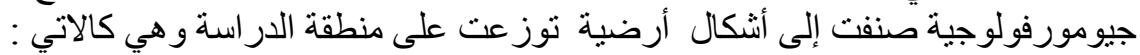
صورة (11) ظاهرة النبخة في طريق شبجة

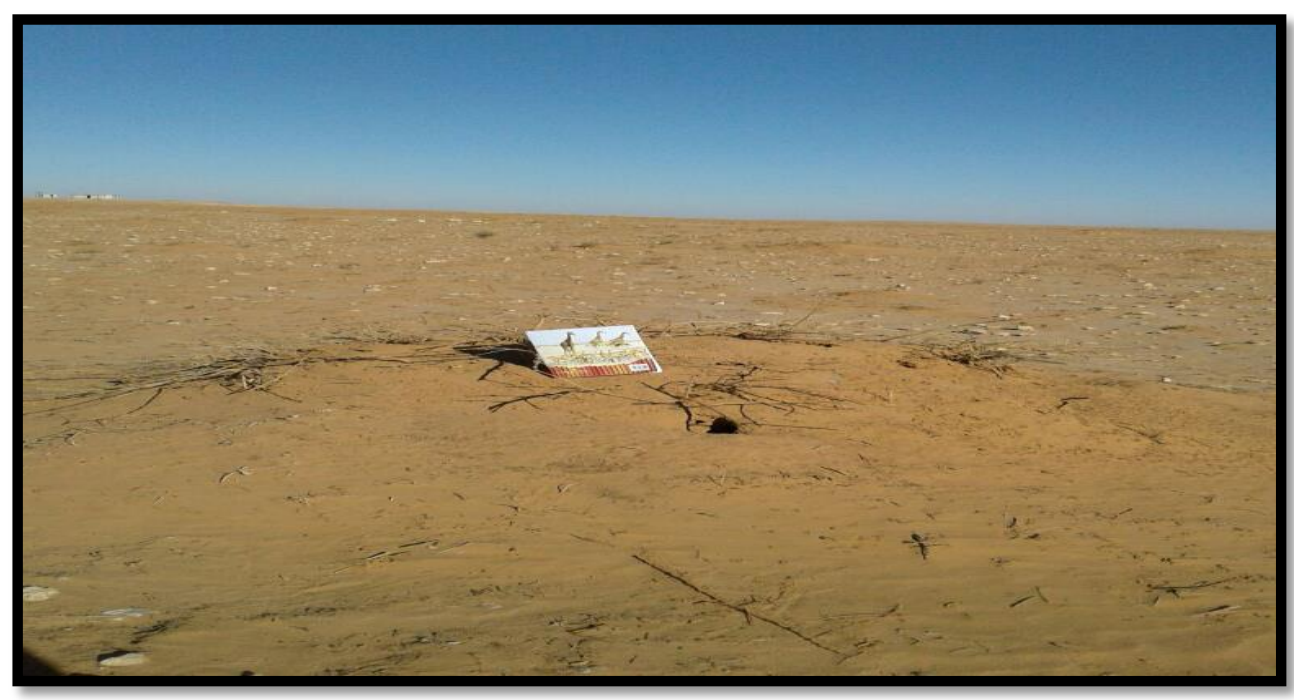

الدراسة الميدانية/ التقطت بتاريخ 2019/12/28 


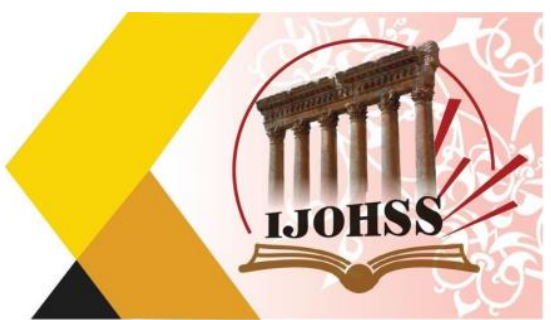

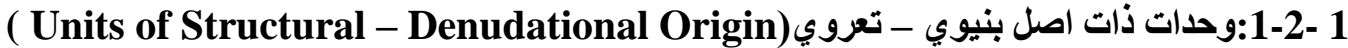

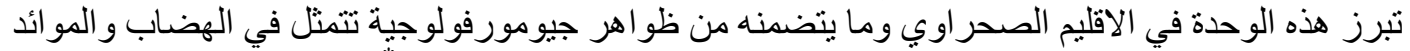

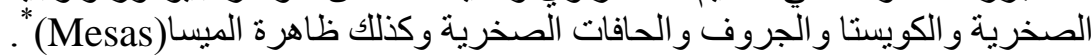

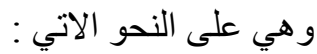
(Plateau) (الهزضبة:1-1-2- 1

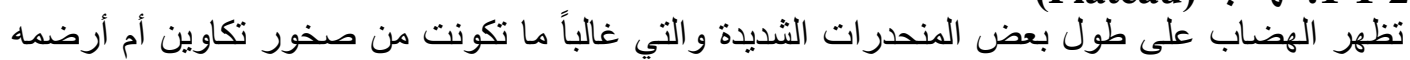

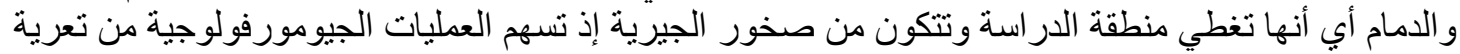

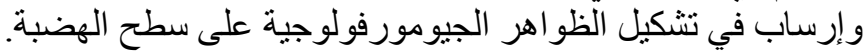

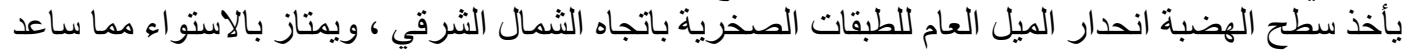

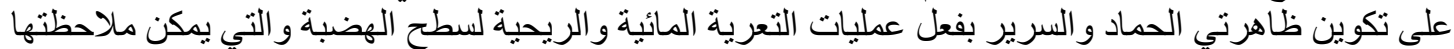

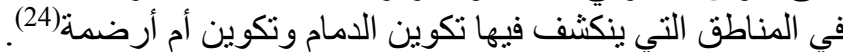

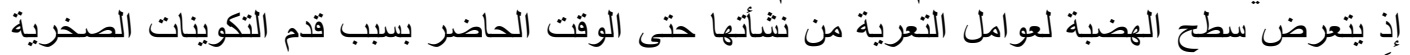

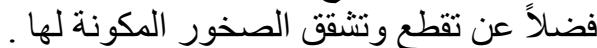

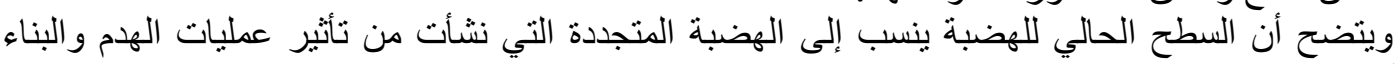

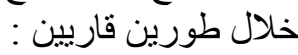
بدأ الطور الأول بعد نهوض الأوليكوسين وكوّن الهضبة الأقدم ، وتميز هذا الطور بسيادة العمليات التعروية

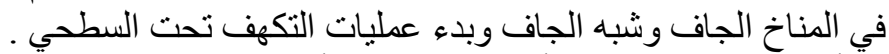

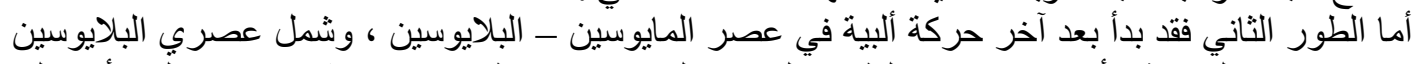

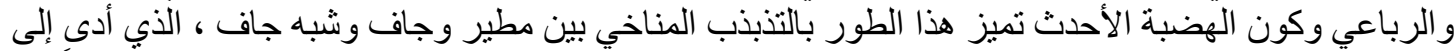

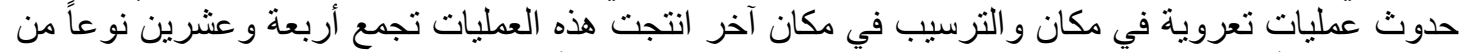

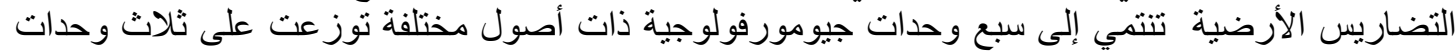

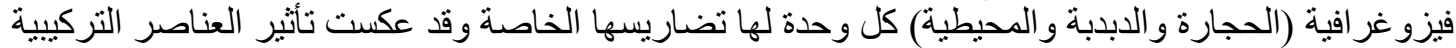
و الصخارية و المناخية(25).

(Cuesta): 2-1-2-1

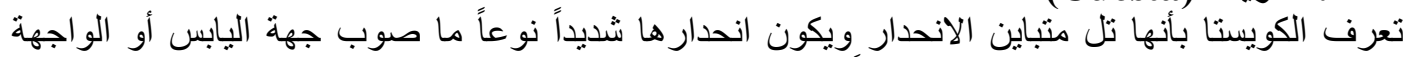

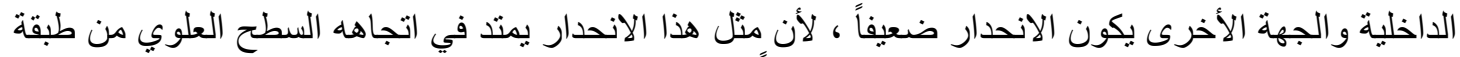

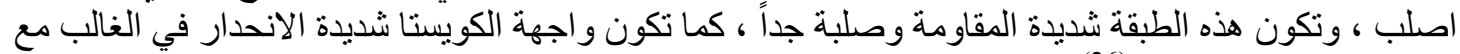

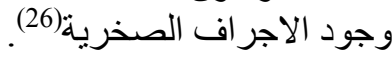

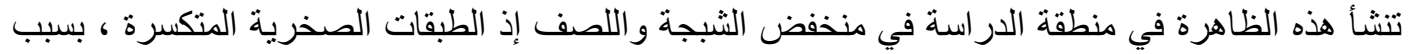

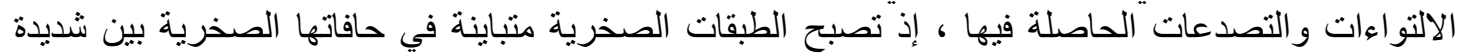
الانحدار ومعتدلة الانحدار ، وتظهر الكويستا كذللك في منخفض السلمان ومنخفض الهدانية وفي الأجز اء الغربية

(Butte)(البيوت 3-1-2- 1

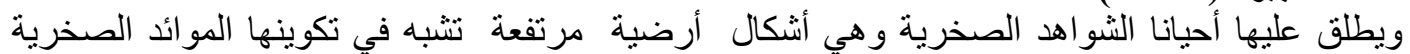

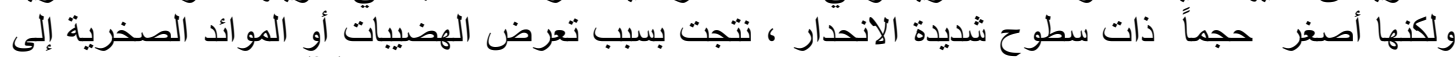

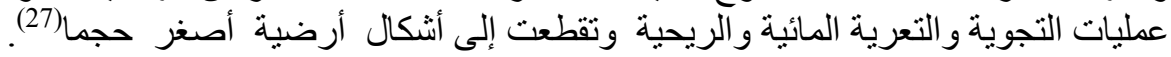

4-1-2-1 الثواهد الصخرية ( Buttees )

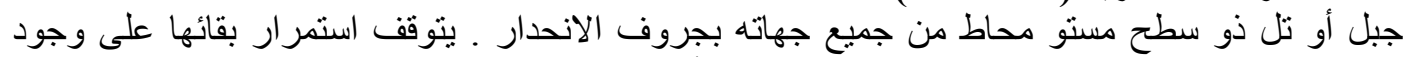

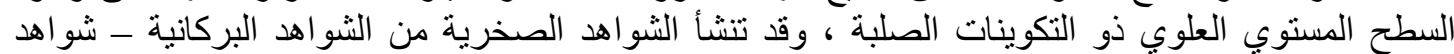

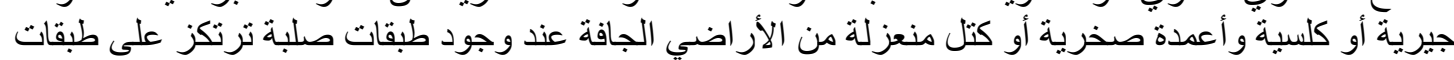

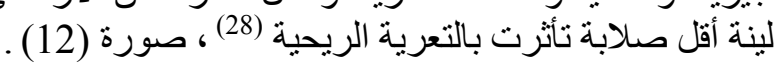




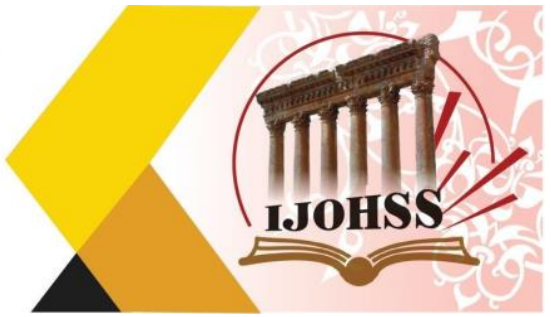

صورة (12) الشواهد الصخرية في السلمان

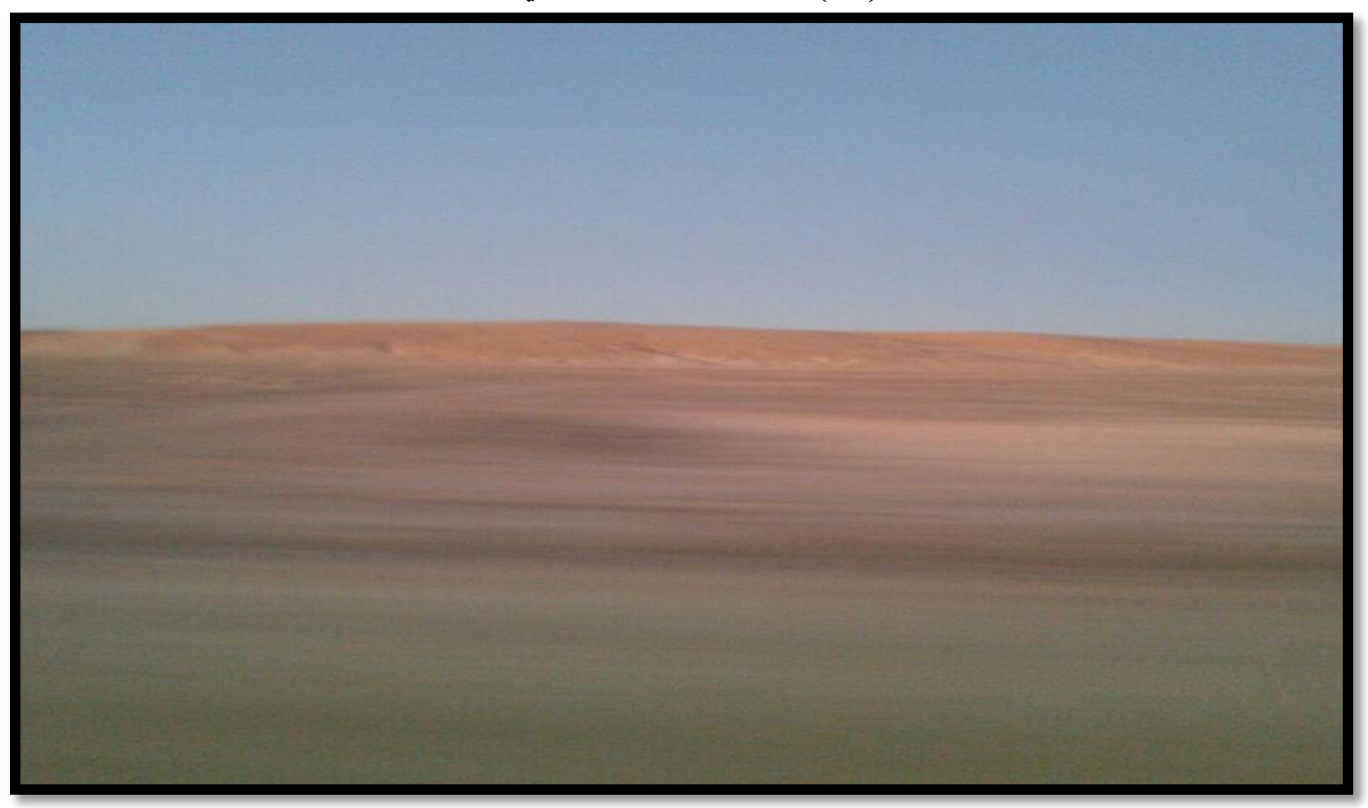

2019/12/26 الاراسة الميدانية التقطت بتاريخ

5-1-2-1

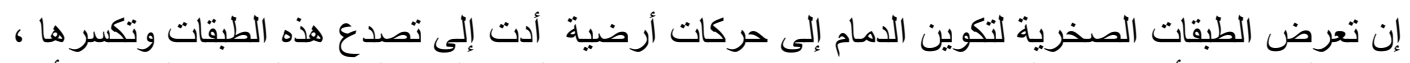

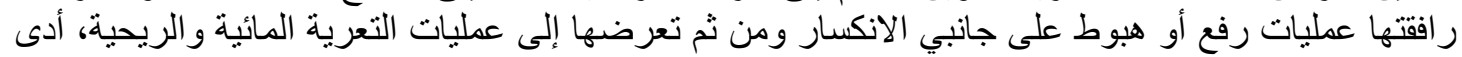

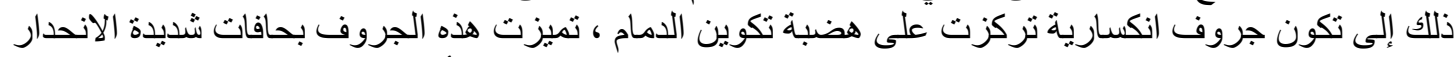

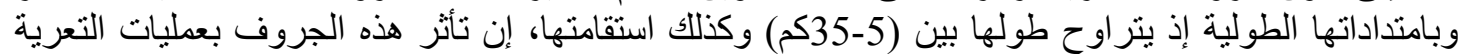

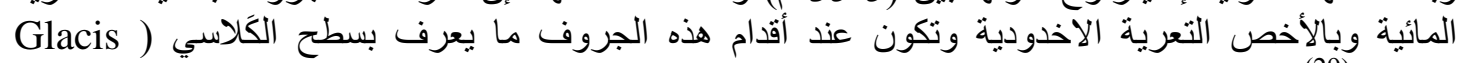
(29) (Plane

2-2-1

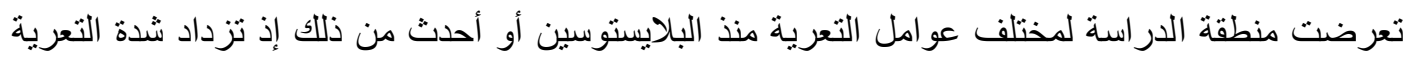

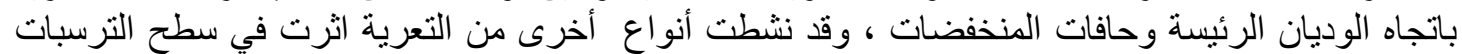

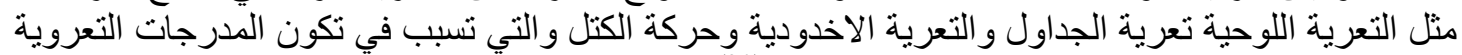

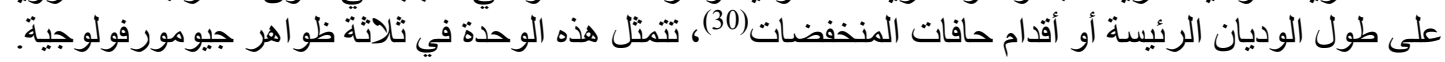

\section{Podiment البيدمنت 1-2-2-1}

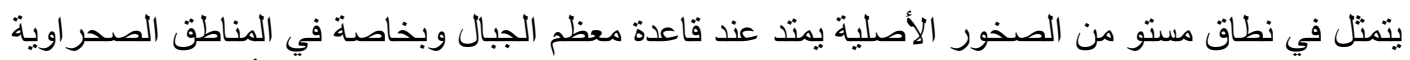

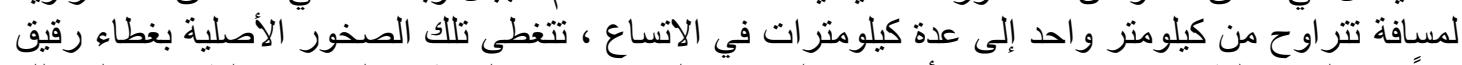

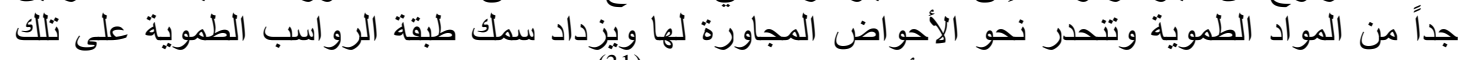

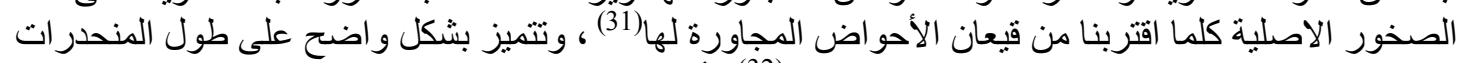

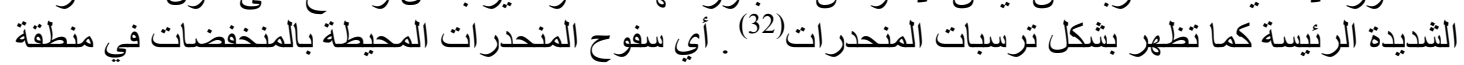

Bad lands 2-2-2-1

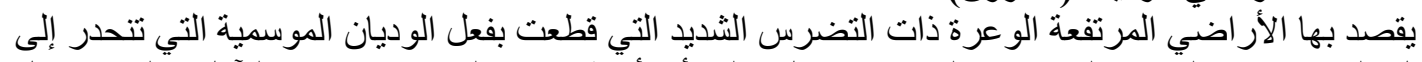

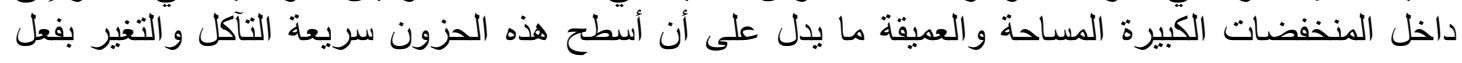




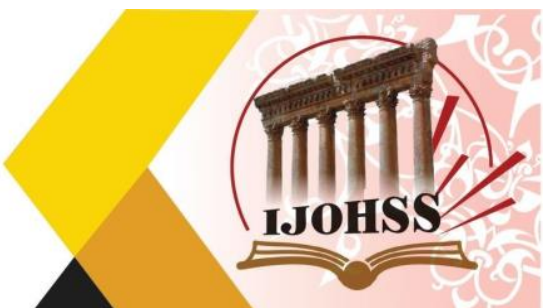

التعرية المائية فتكون عملية الانهيار لتلك الجروف بهيأة حفر عميقة وكبيرة الحجم يقدر طول الو احدة منها بنحو

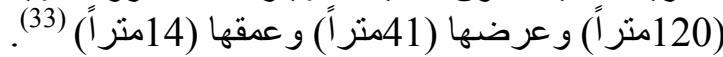

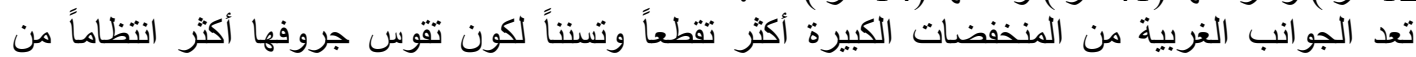

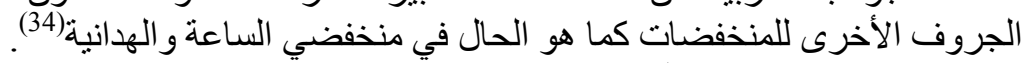

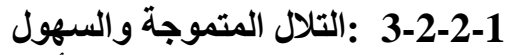

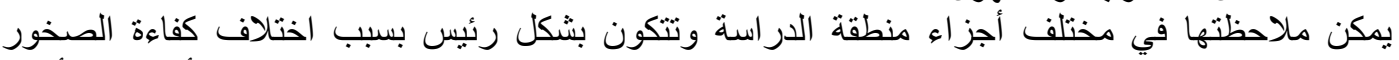

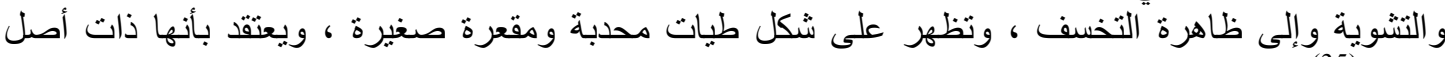
تكنوني (35).

(Unit of Depositional Origin) وحدات ذات أصل ارسابي الارحي (35:2-1 تعد الأشكال الأرضية الترسييية هي الأشكال الثائعة لتلكاتك الوحدات ذات الترات الأصل النهري أو الطموي

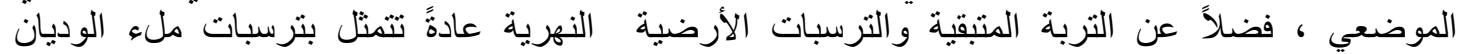

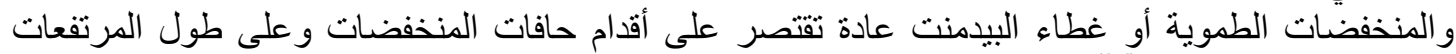
وكذللك الدالات المروحية:

1-3-2-1

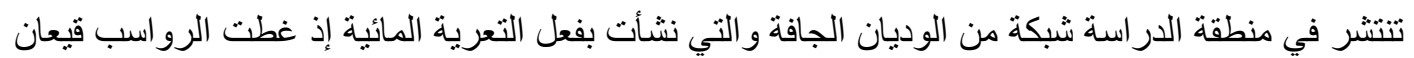

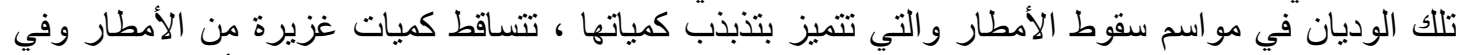

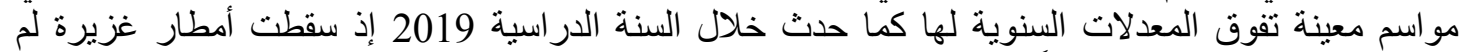

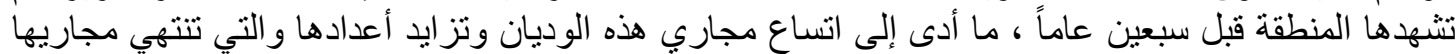

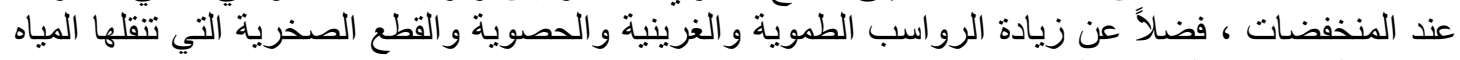

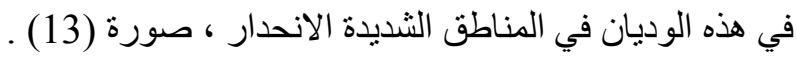

صورة (13) رواسب قيعان وادي أبو طلاح

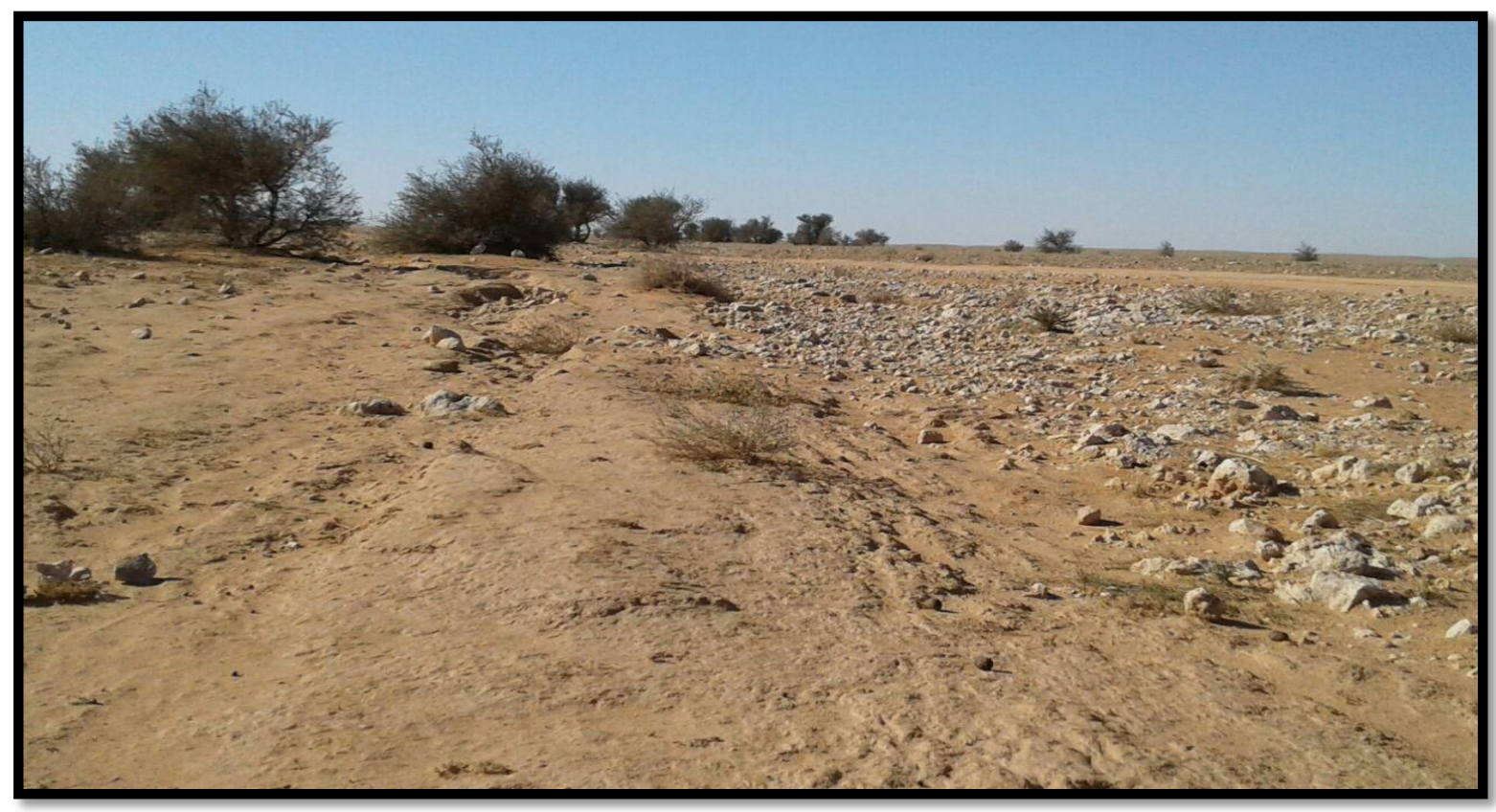

الاراسة الميدانية/ التقطت بتاريخ 2019/12/28 


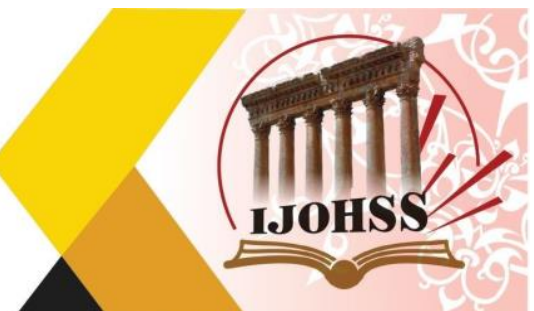

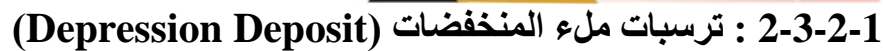

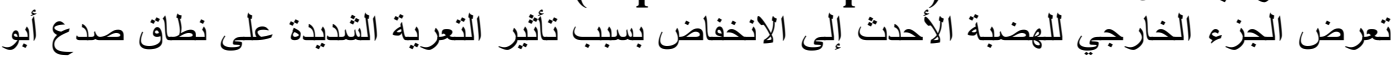

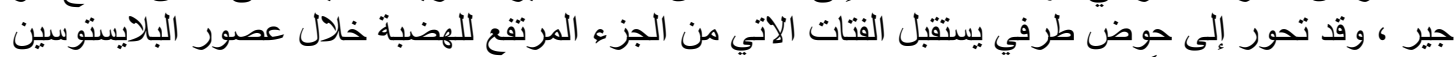

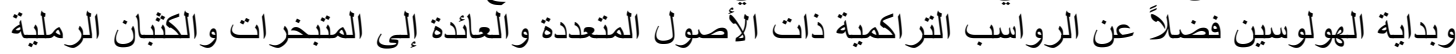

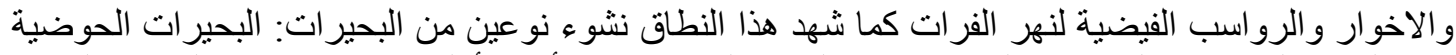

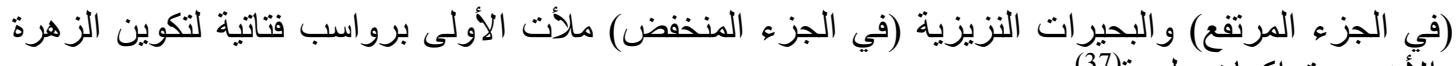

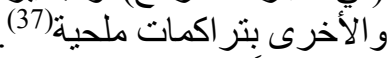

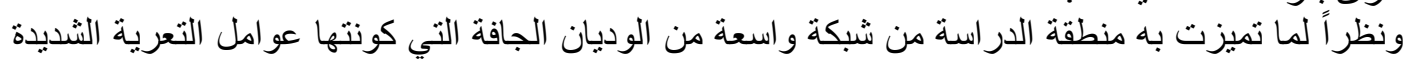

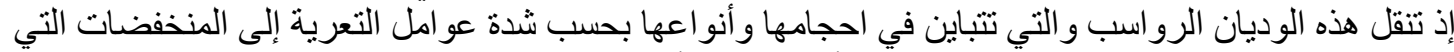

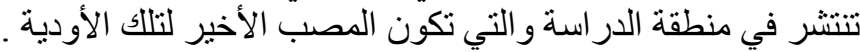

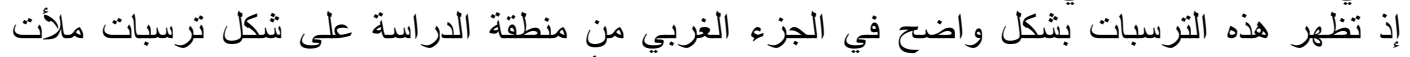

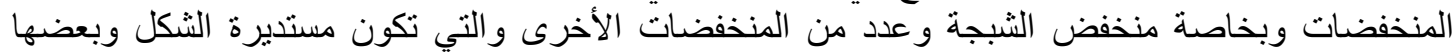
طولي بسبب عمليات التكهف.

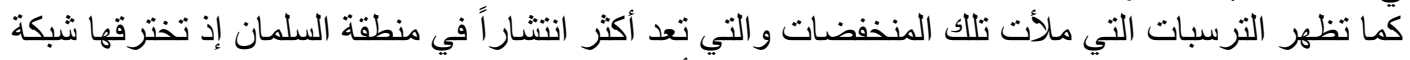

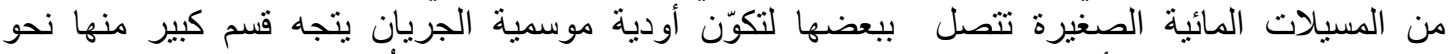

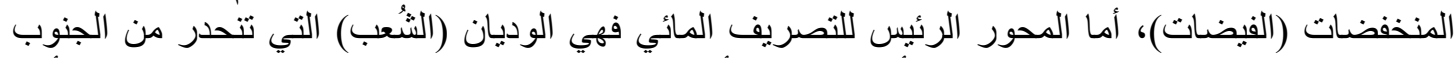

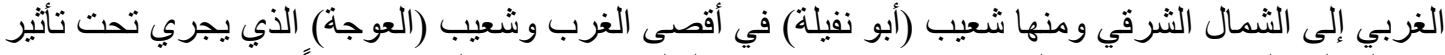

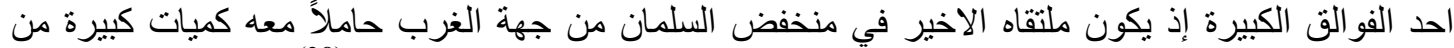

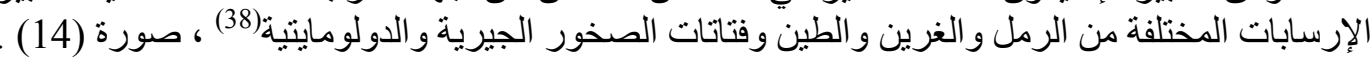

صورة (14) ترسبات ملئ المنخفضات (فيضة الحقل)

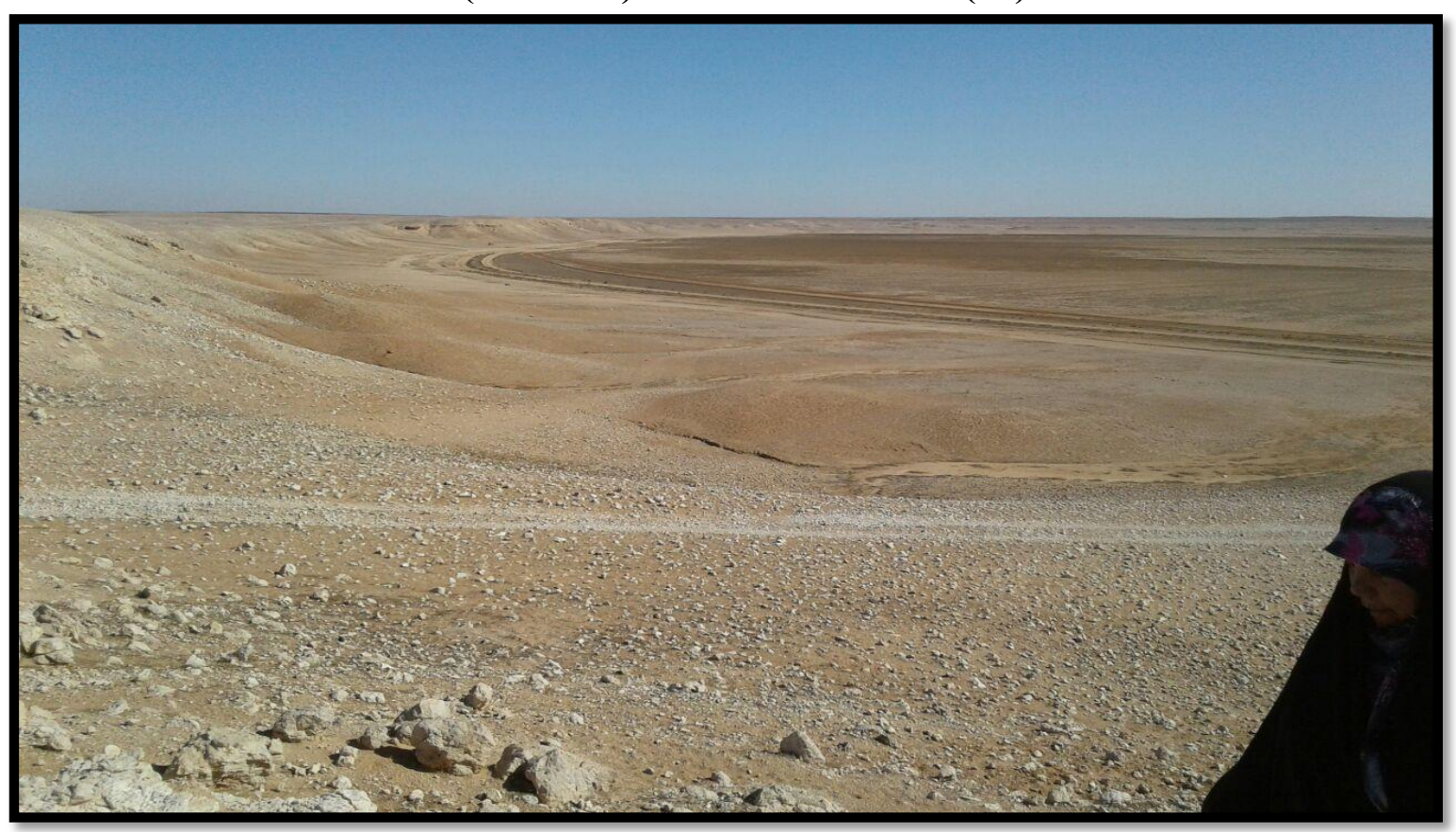

الاراسة الميدانية/ التقطت بتاريخ 2019/12/28

(Alluvial Fans) 3-3-2-1

تعرف الدالة المروحية بأنها ترسبات نهرية ذات شكل قمعي تكونت بوساطة الأنهر التي تفقد مياهها سرعة 


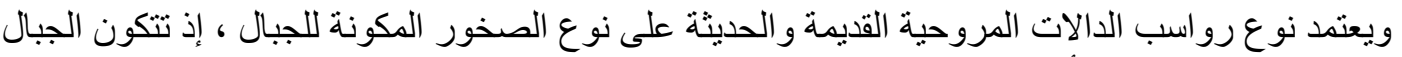

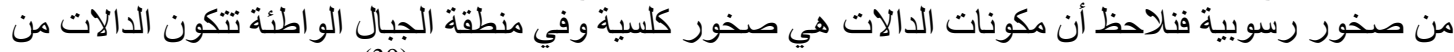
حصى مختلف الصخارية وذللك لتكثف طبقات صنات صخرية مختلفة التكوين في الجبال (39).

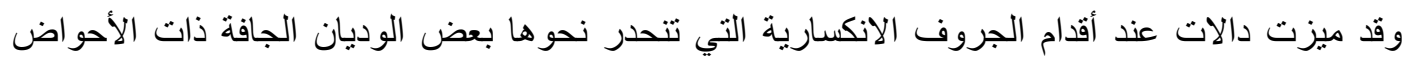

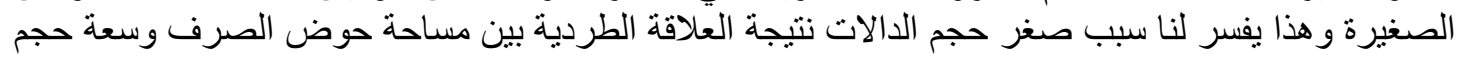

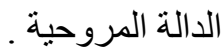

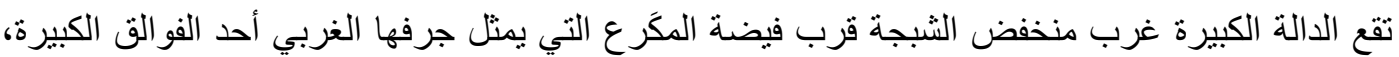

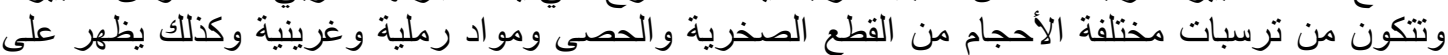

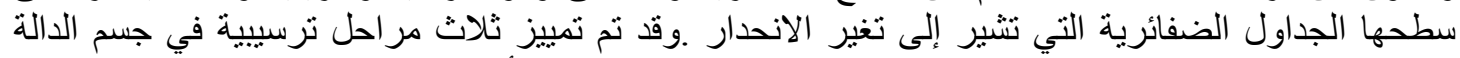

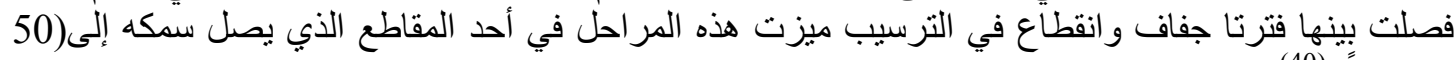

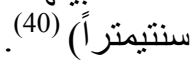

Units of Eolian Origin 4-2-1 وحدات ذات اصل ريحي)

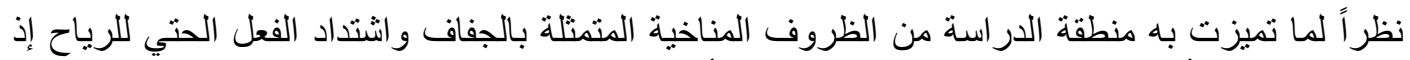

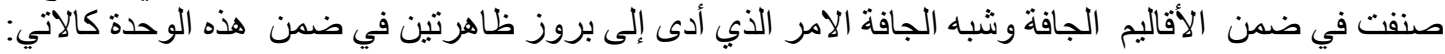
: 4-2-1 1

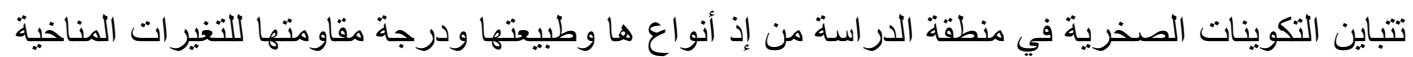

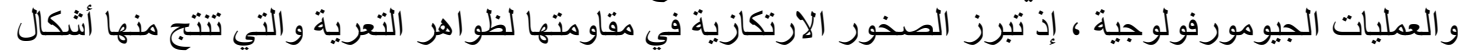

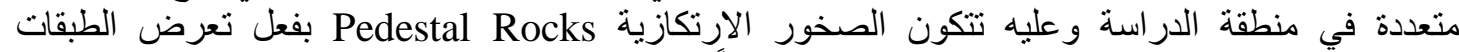

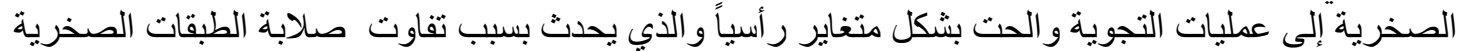

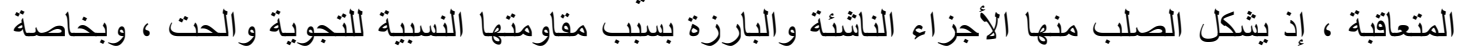

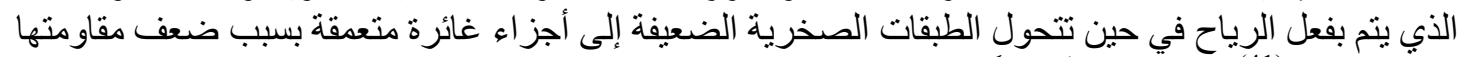

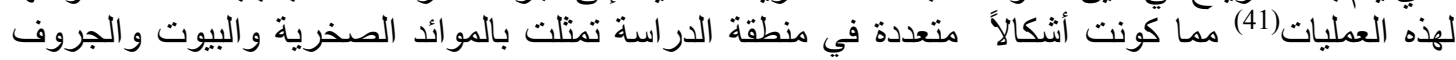
الانكسارية .

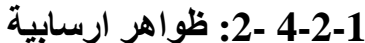

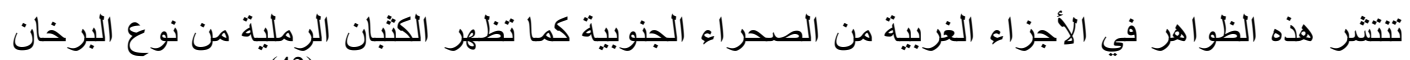

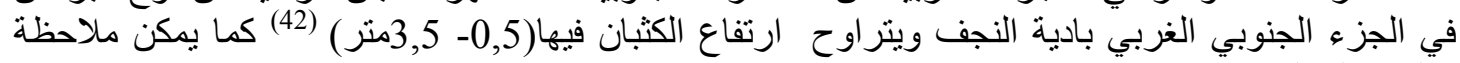

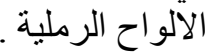

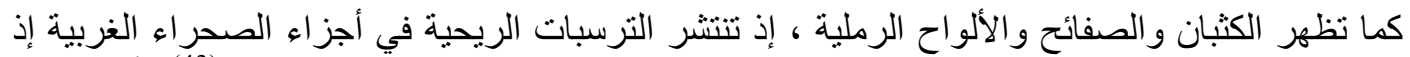

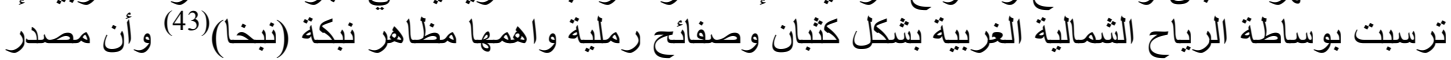

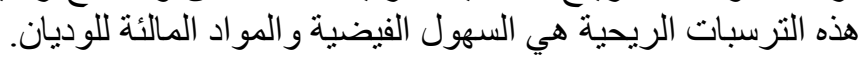

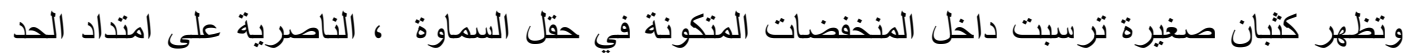

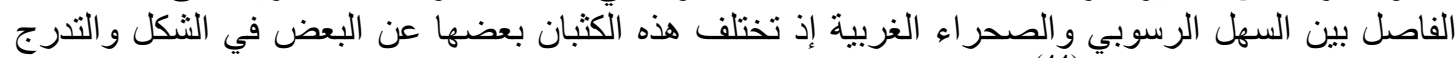
الحجمي و الانحر اف و التفلطح (44).

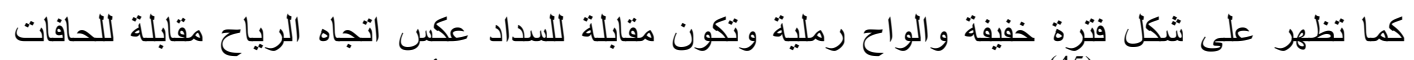

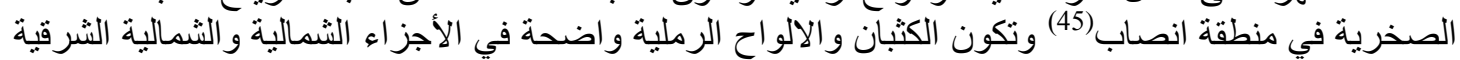

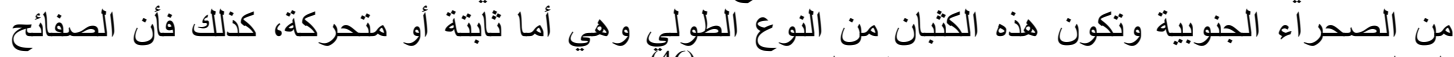

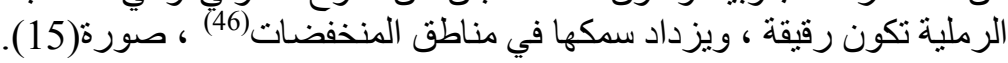

5-2-1 تسود في ضمن هذه الوحدة ظواهر ذات أصل إذابي تتمثل في ظواهر الكارست التي تظهر الأقاليم التي 

International Journal of Humanities and Social Sciences website:www.ijohss.com Email:editor@ijohss.com ISSN: 2415 - 4822
العدد (17) (17) Volume (17) December 2020

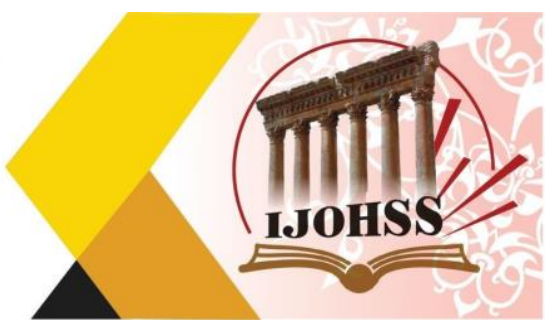

يكون التأثير الكيميائي للماء الباطني و اضحاً فيها والتي تتكون من صخور جيرية قريبة من سطح الأرض (47). صورة (15) ظواهر ارسابية في منخفض وني السلمان

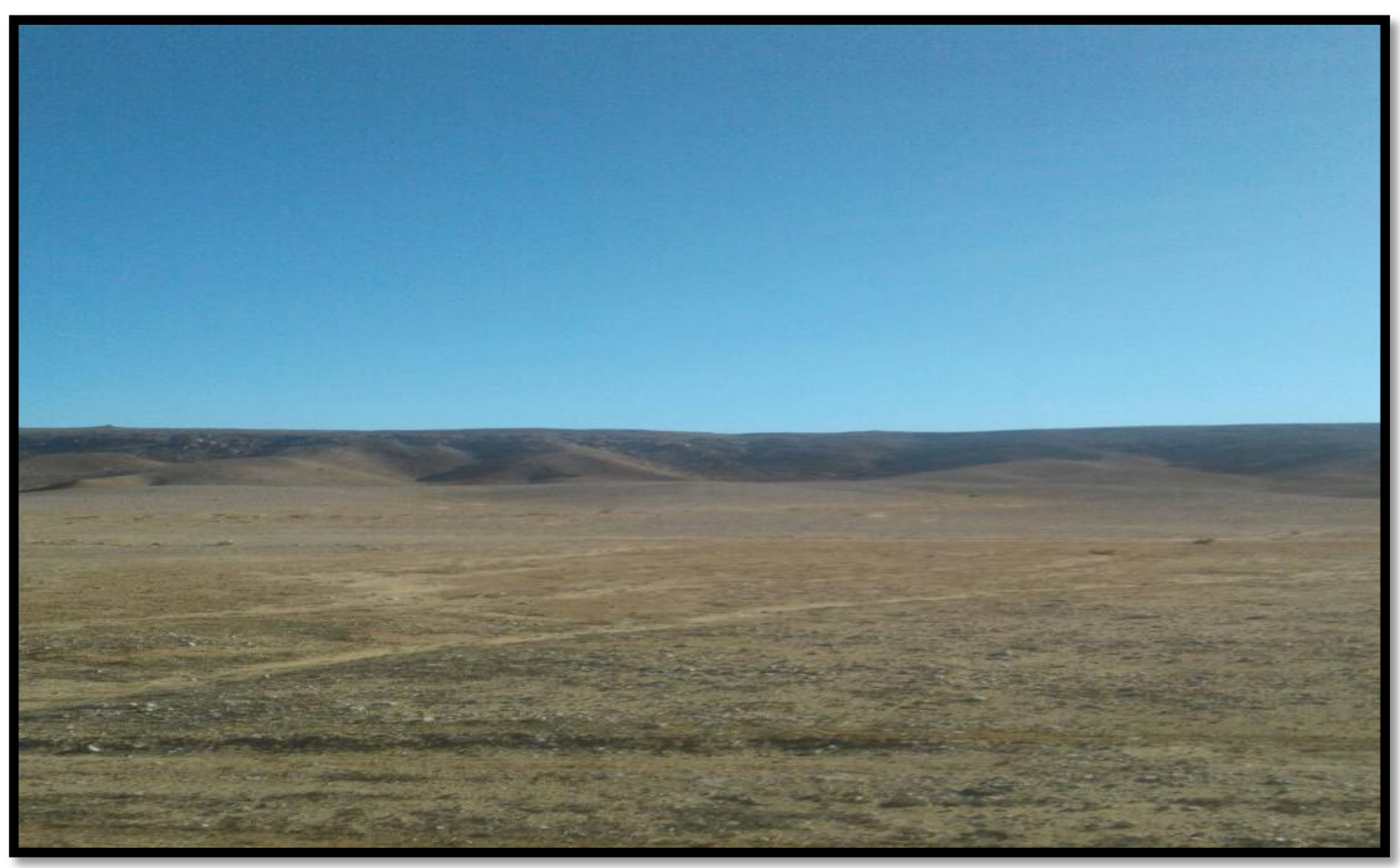

2019/12/28 الدراسة الميدانية/ التقطت بتاريخ

إذ يعد وجود صخور قابلة للذوبان و غور كميات من المياه عبر نطاق شديد النفاذية من العو امل الرئيسة في

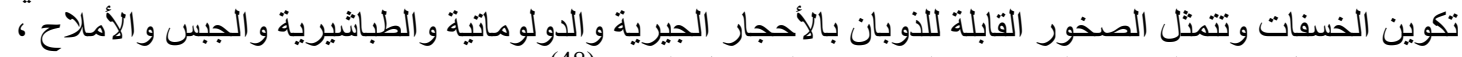
في حين تتمثل نطاق النفاذية بالصدو ع و التشققات و الفو اصل الصن الطبقية (48).

وحتى تستجيب تلك الصخور لعمليات التحلل والتفكك بالمياه اعتماداً على ذلك فإن ظروف تطور ظاهرة

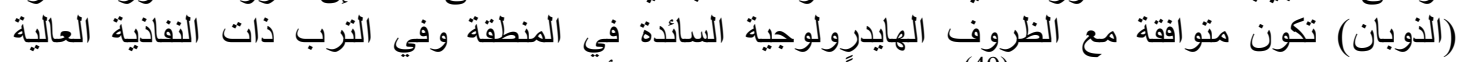

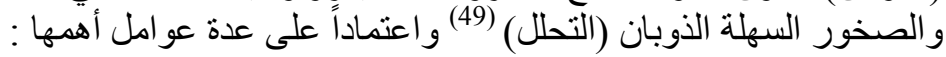

1- التكوينات الصخرية القابلة للذوبان بالقرب من سطح الأرض وبخاصة الصخور الجيرية . 2- وجود الفو اصل و التشققات في الطبقات الصخرية ، و الذي يؤدي إلى سر عة المياه الباطنية خلال تكويناته

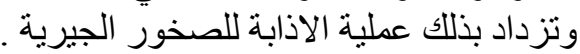

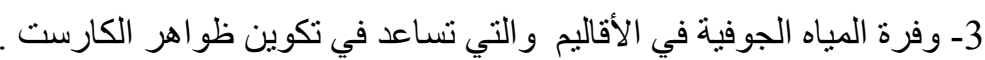

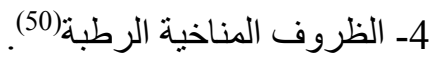

وقد تمخضت عن ظاهرة الكارست التي تميز منطقة الدر اسة ، وجود التاد الاخداديد و الحفر في اماكن متعددة منها،

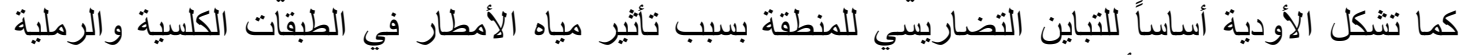

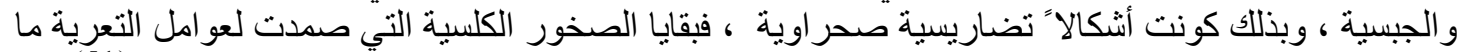

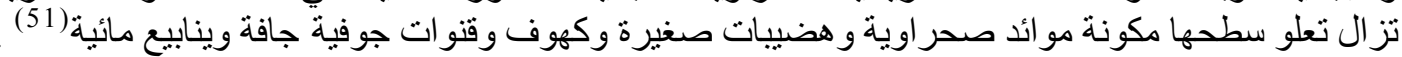

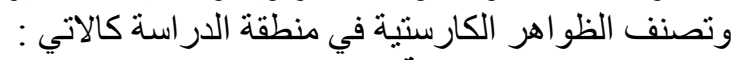

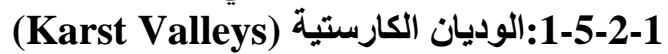

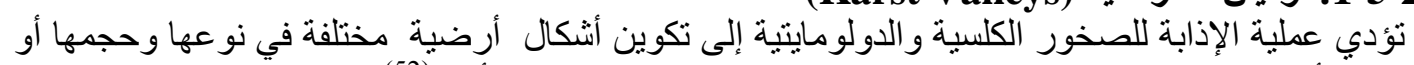
سعتها من أشكال محفورة على الصخور السطحية إلى منخفضات مختلفة الأبعاد (52). 


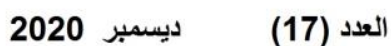

ISSN: 2415 - 4822
Volume (17) December 2020

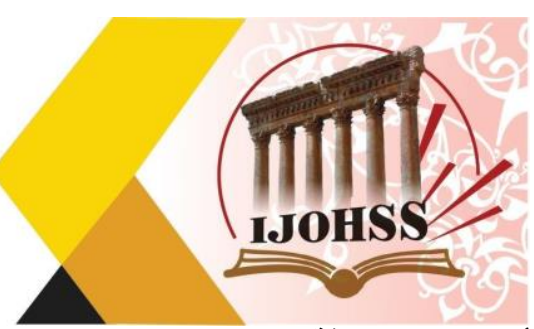

أـ الوديان الجافة (Dry Valleys)

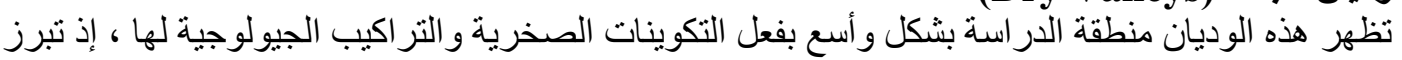

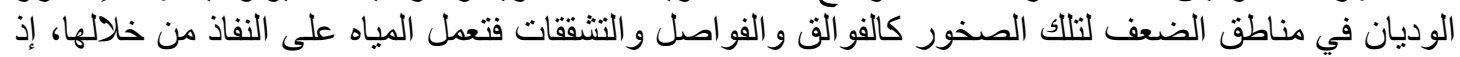

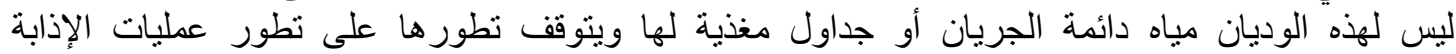
karstprocess

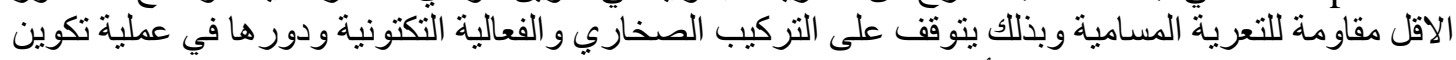

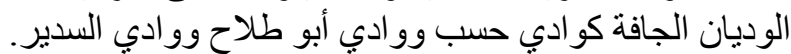

بـ الوديان العمياء (Blinds Valleys)

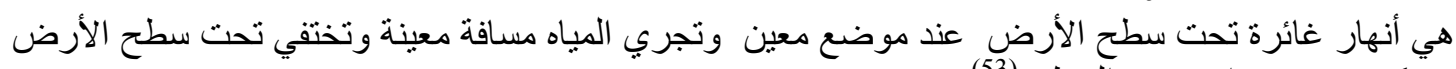
في كهوف و فجوات فائرة تحت السطح (53).

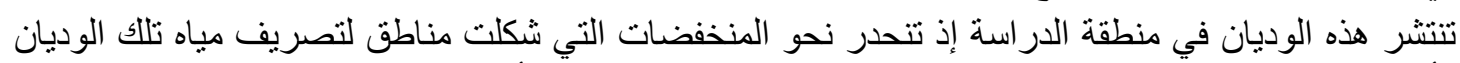

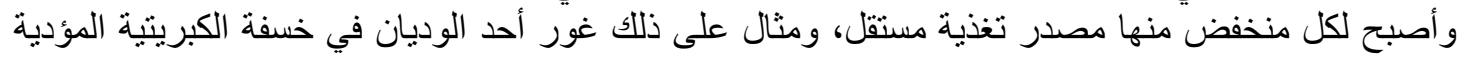

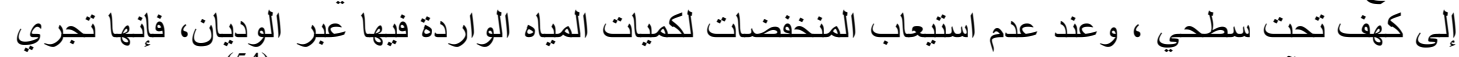

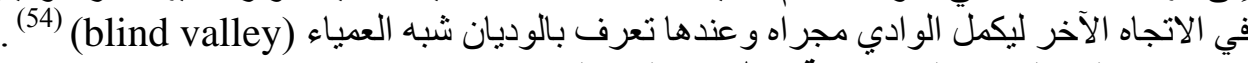

(المنخفضات الصحراوية وظواهر التخسف (Poljes \& Dolins):2-5-1

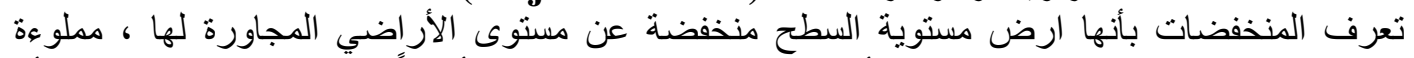

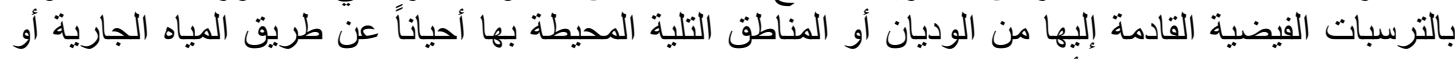

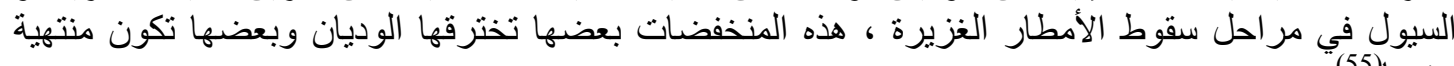
عندها:55). وتنتشر هذه المنخفضات في منطقة الدراسة بشكل كبير إذ تعد من أكثر المظاهر الجيومورفولوجية في في إديا

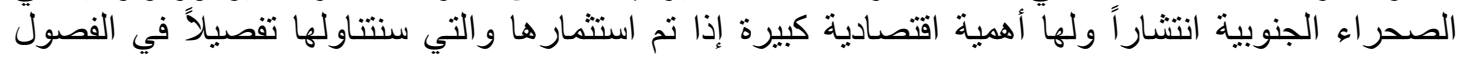

يعد وجود صخور قابلة للذوبان وغور كميات و افية من المياه عبر نطاق شديد النفاذية من العوامل الرئيسة

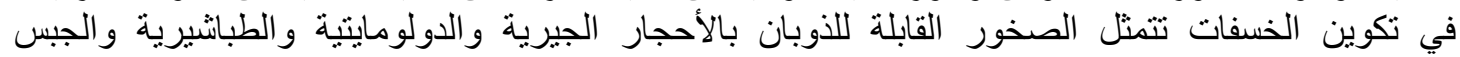

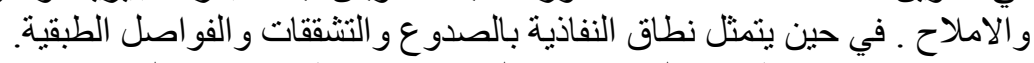

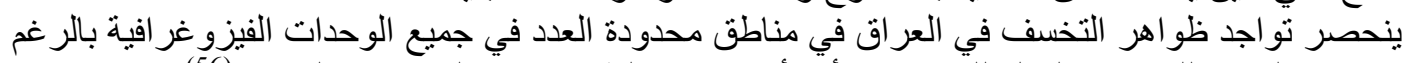

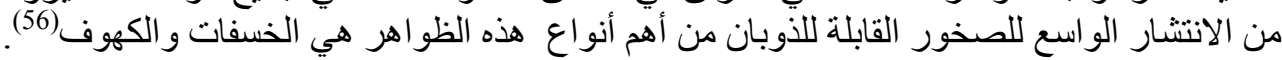

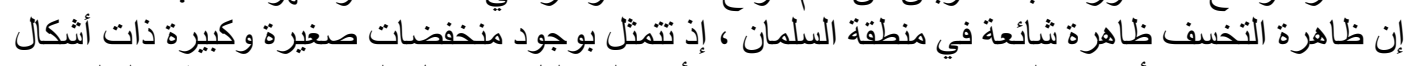

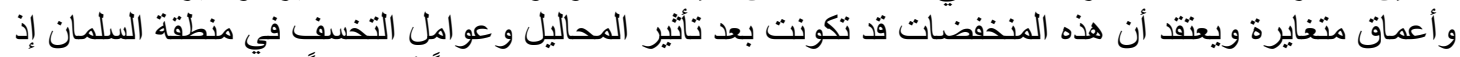

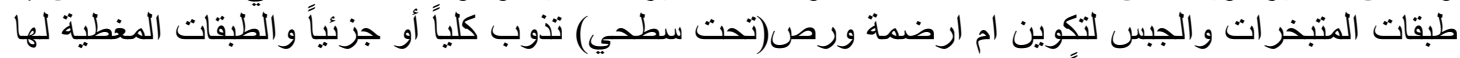

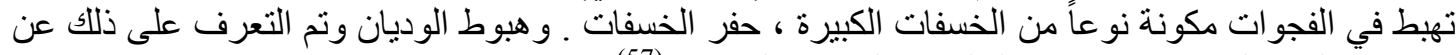

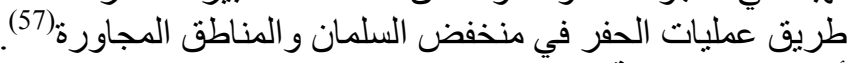
أـ الحفر البالوعية (Sink holes)

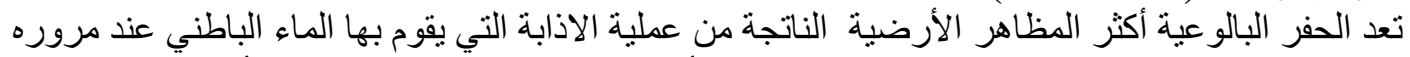

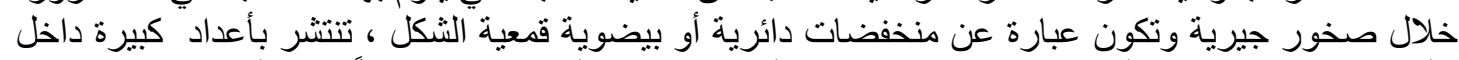

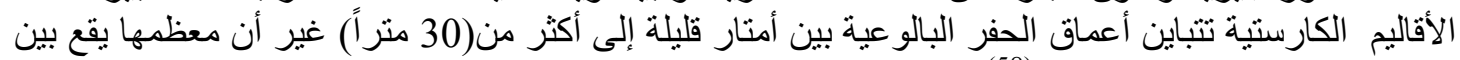

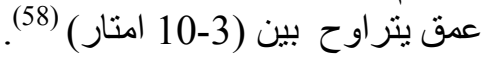

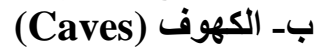

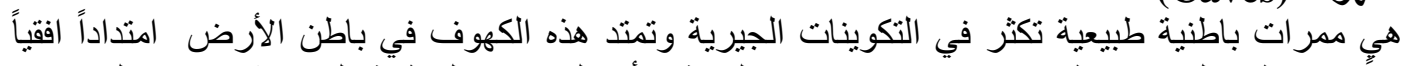

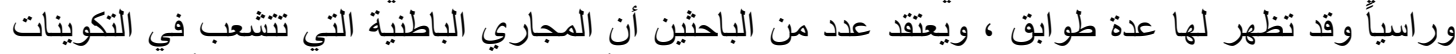

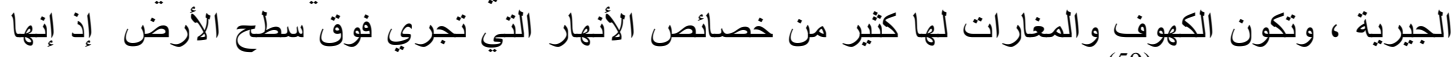
تؤدي إلى النحت و الهدم (59) 

International Journal of Humanities and Social Sciences website:www.ijohss.com Email:editor@ijohss.com ISSN: $2415-4822$

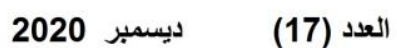
Volume (17) December 2020

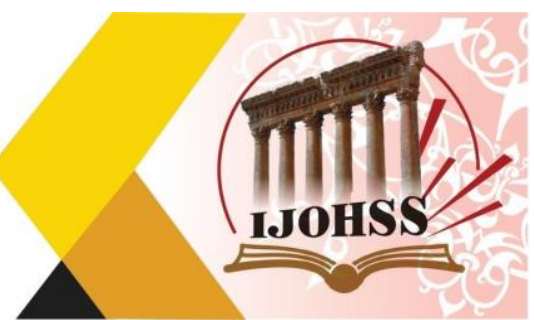

جـ - ندب الإذابة (Solution pits)

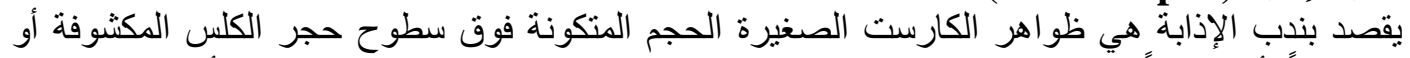

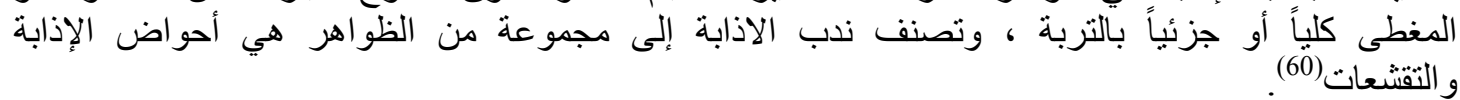

Geomorphological Units of man-made 6-2-1 وحدات جيومورفولوجية من عمل الانسان يؤدي الانسان دوراً فاعلاً في هذه الوحدة في تغيير معالم سطح الأرض فئر ويظهر ذللك واضحاً في منطقة

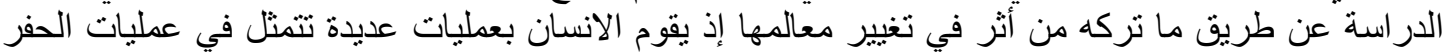

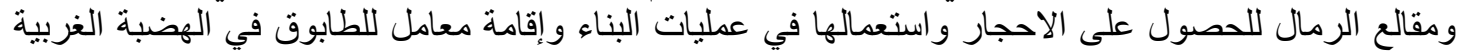
صورة (16) مقالع الرمال في بادية النجف

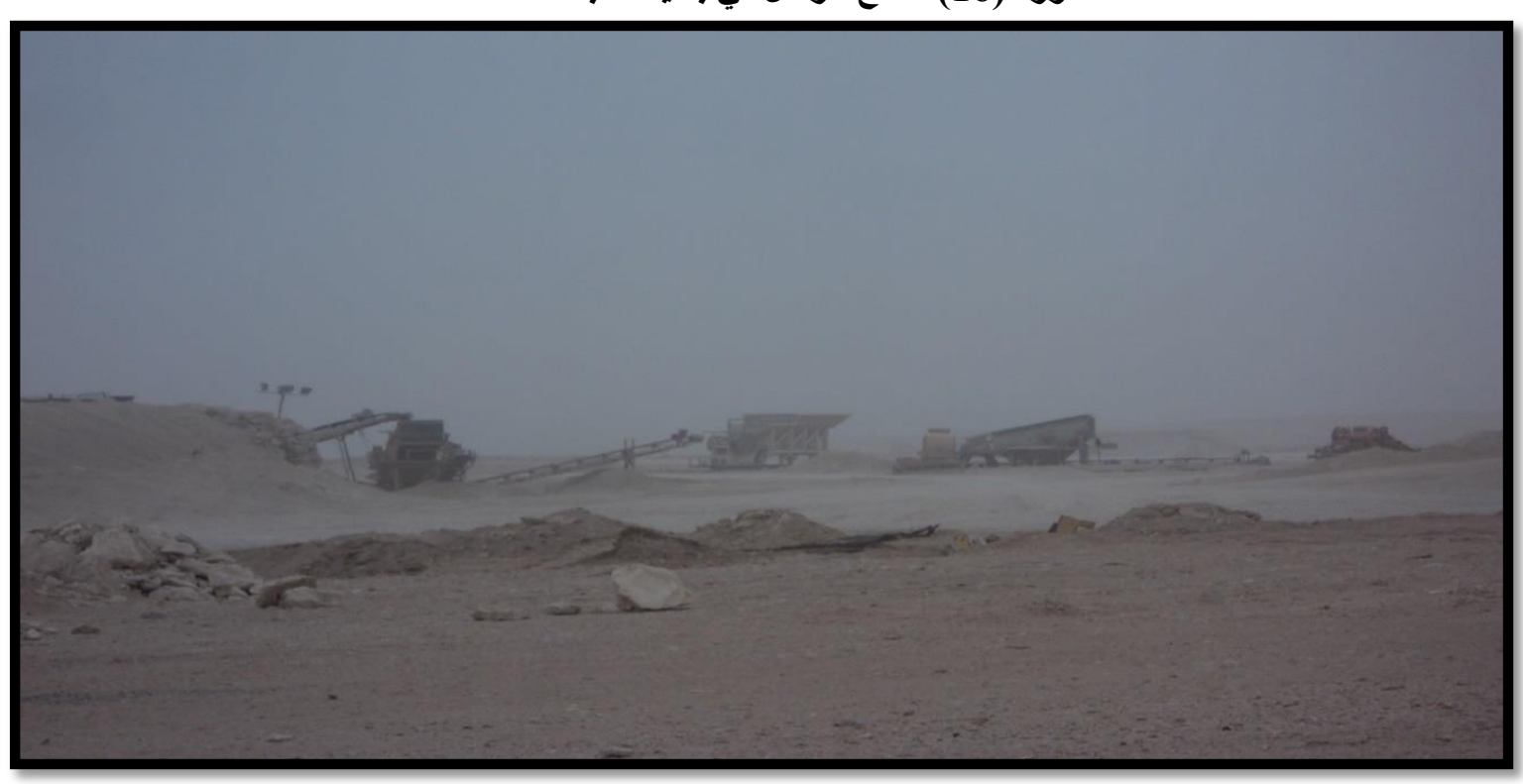

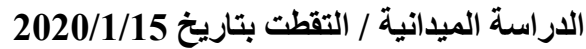

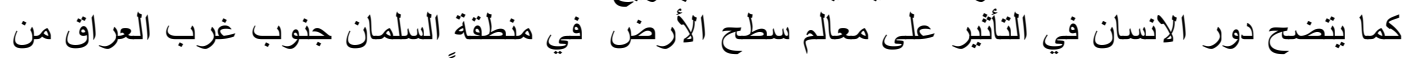

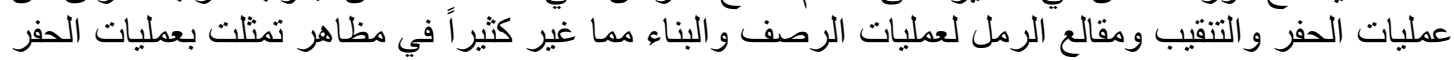
إن اغلب بيئات العالم قد تأثرت بالإنسان بدرجات متفاوتة إذ يؤدي الانسان دور ألناً هاماً في النأثير في العمليات

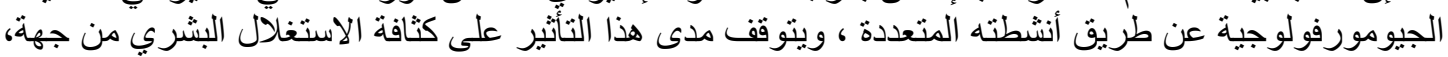

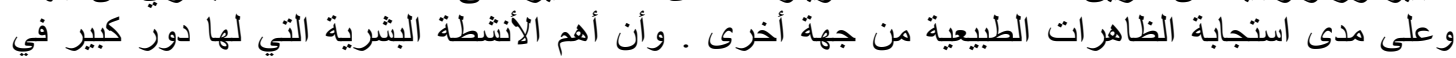

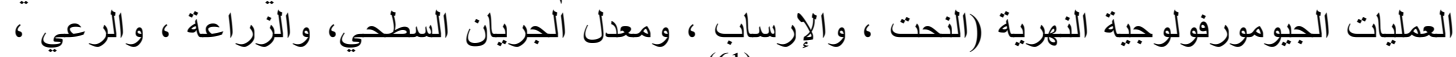

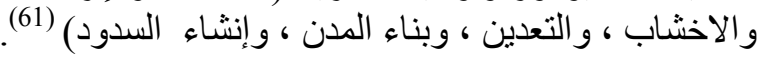
3-1 بظهر عن طريق نموذج الارتفاع الرقمي DEM وتحليل الفيل المرئية الفضائية لمنطقة الدراسة ، أن الفواصل

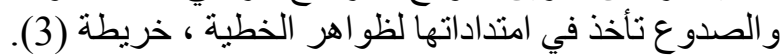

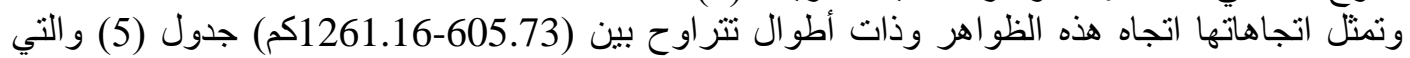

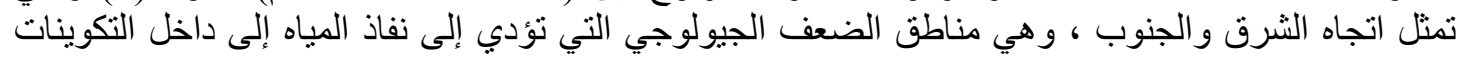

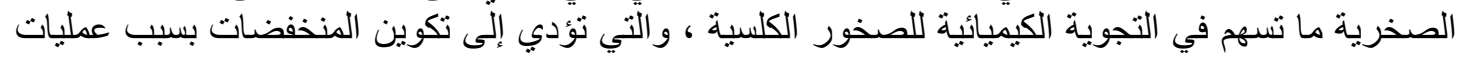




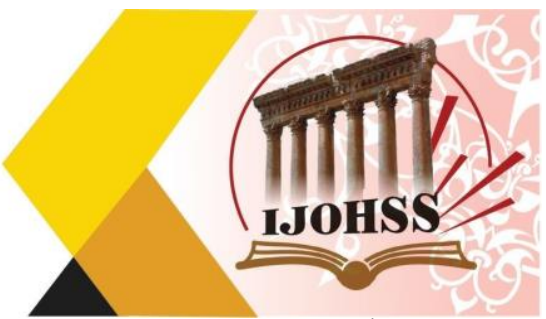

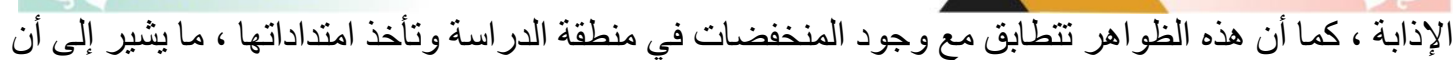

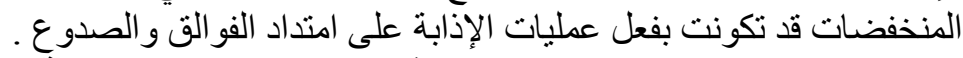

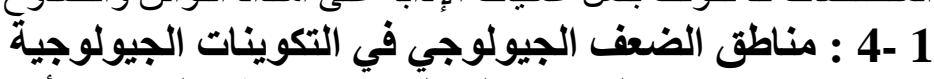

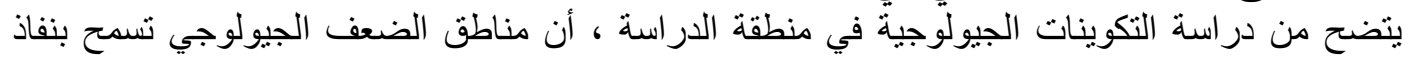

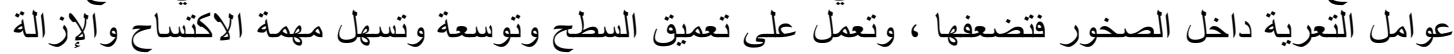
الهو ائية إنل

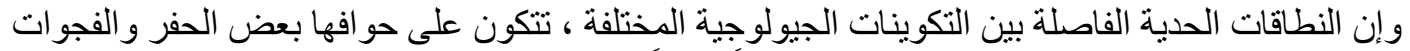

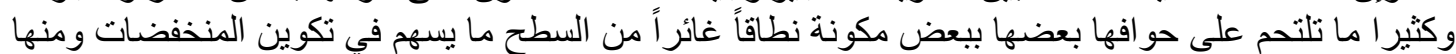

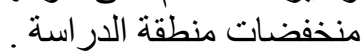

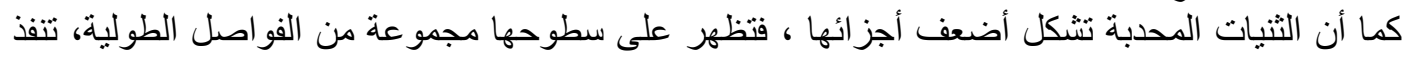

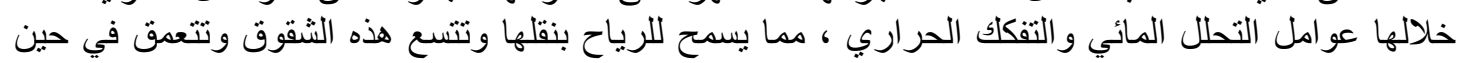

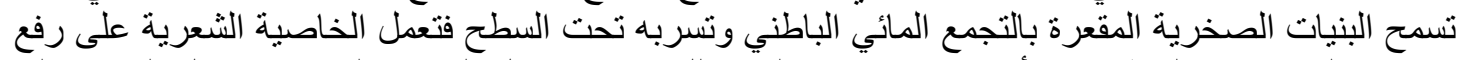

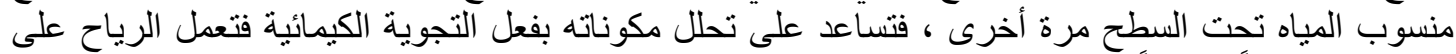

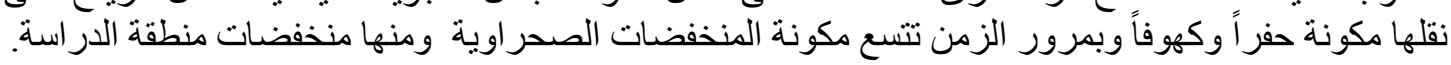


المجلة اللحولية اللملوم الآنسانية والامتماعية International Journal of Humanities and Social Sciences website:www.ijohss.com Email:editor@ijohss.com

العدد (17) ل

ISSN: 2415 - 4822

Volume (17) December 2020

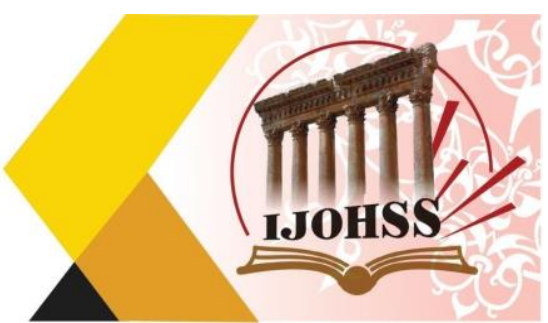

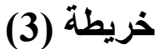

الظواهر الخطية في منطقة الاراسة

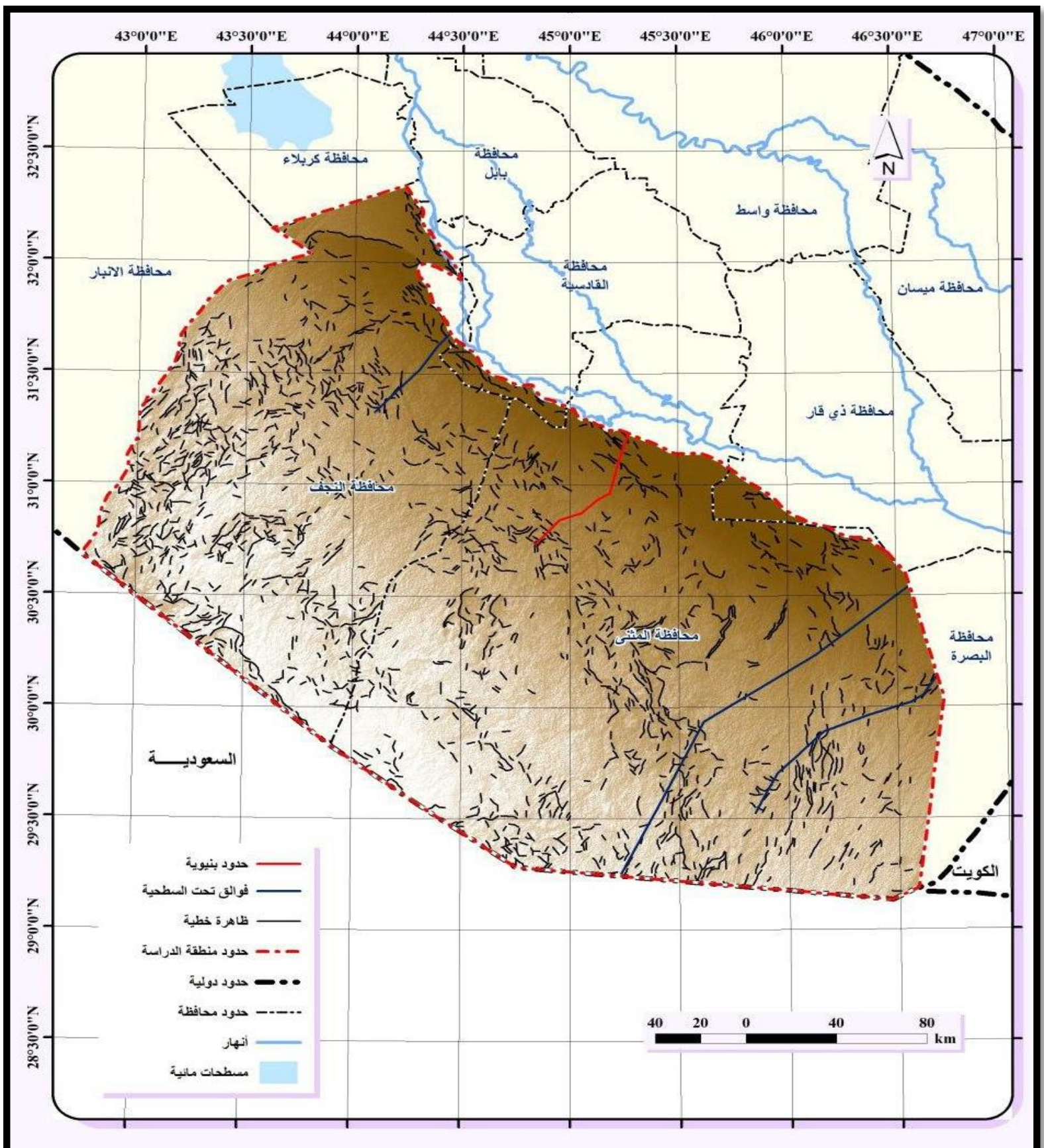

المصدر: عمل الباحث بالاعتماد على برنامج Geomatica 2013 ومخرجات برنامج Arc Gis 10.3. 
2020 ديسمبر

العدد (17)

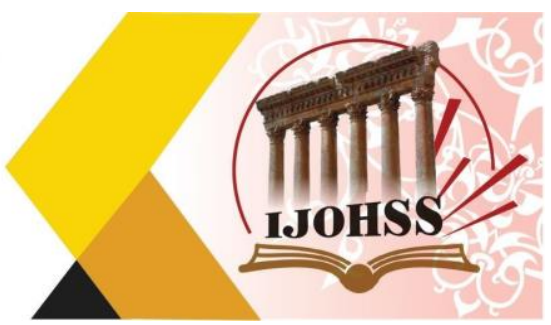

جدول (5) الظواهر الخطية وامتداداتها في منطقة الدراسة

\begin{tabular}{|c|c|c|}
\hline مجموع الأطو ال (كم) & اتجاه الظو اهر الخطية & ت \\
\hline 971.02 & الشمال & -1 \\
\hline 750.86 & الشمال الشرقي & -2 \\
\hline 605.73 & الثرق & -3 \\
\hline 1149.44 & الجنوب الثرقي & -4 \\
\hline 1261.16 & الجنوب & -5 \\
\hline 1160.46 & الجنوب الغربي & -6 \\
\hline 591.24 & 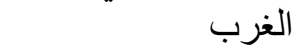 & -7 \\
\hline 770.79 & الشمال الغربي & -8 \\
\hline
\end{tabular}

المصدر: نموذج الارتفاع الرقمي DEM ومخرجات برنامج 10.3 ARC Gis

الاستنتاجات

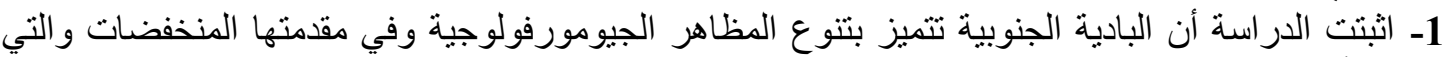

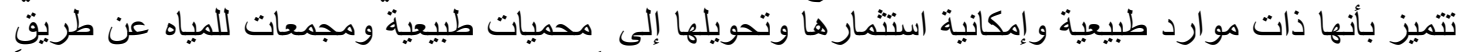

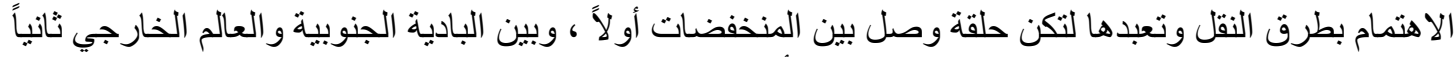

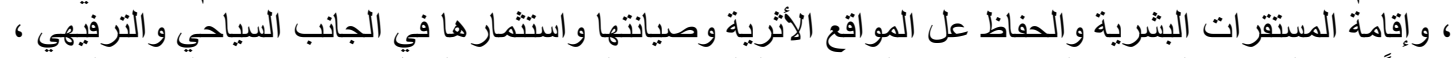

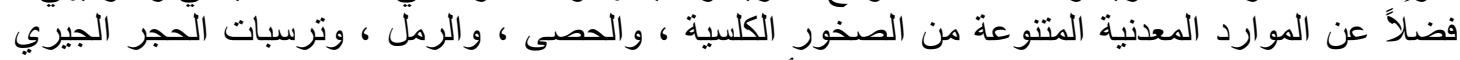

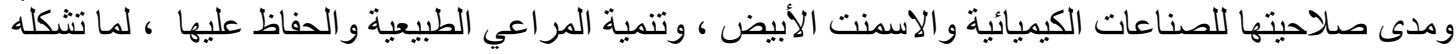

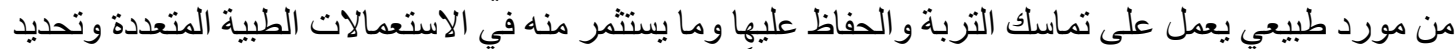

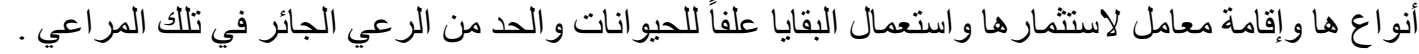

2- أوضحت الدر اسة أن القدرة الحتية للرياح قد تباينت في محطات منطقة الدر اسة وفقاً لتباين سرعة الرياح فيها

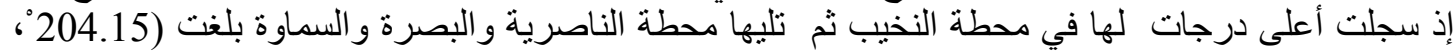

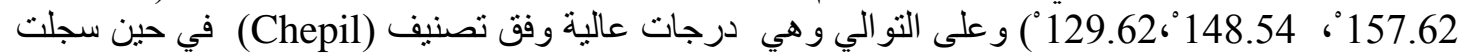

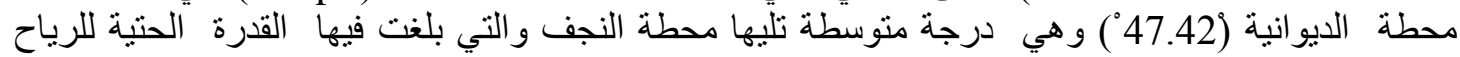

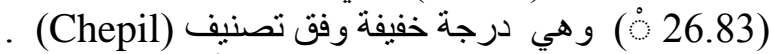

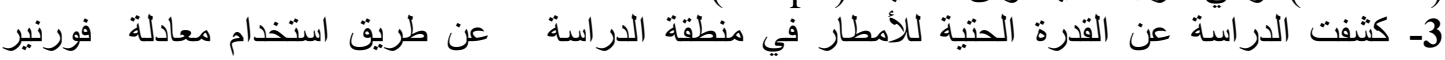
(Arnold Eournner lndex)

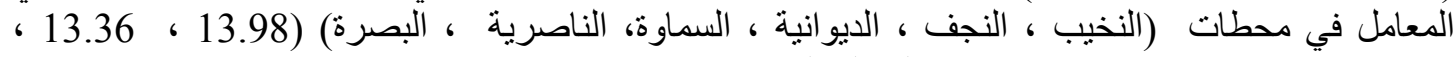

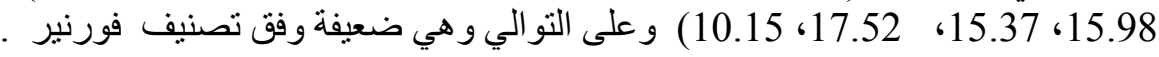

التوصيات 1- إقامة محطات هيدرولوجية متخصصة لقياس الأمطار والتنبؤ بأوقات حدوثها وحساب الجريان السطحي

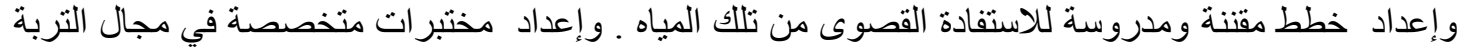

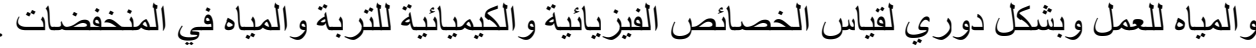

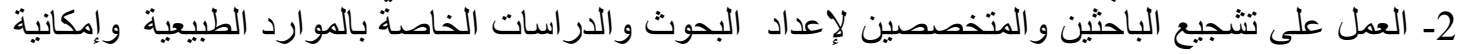

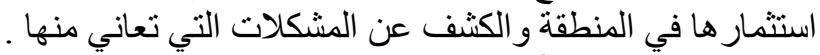

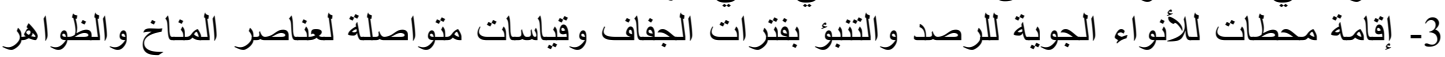


4- العمل على تتمية المر اعي الطبيعية والحفاظ عليها وتحديد استثمارها ، فمنها ما يستثمر في المجال الطبي

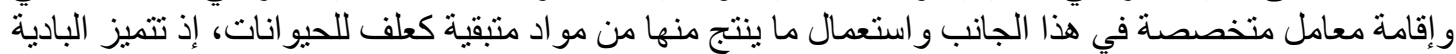

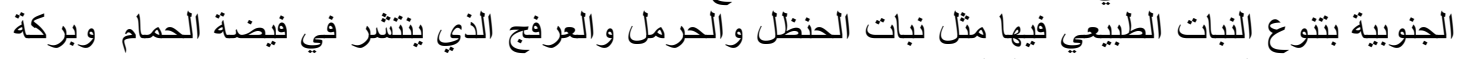

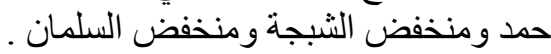

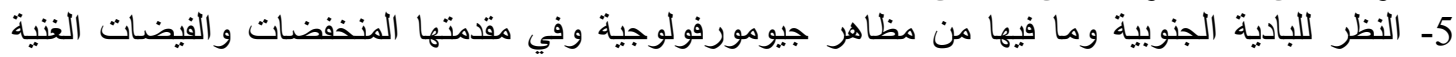
بالموارد الطبيعية كوحدة جيومورفولوجية هيدرولوجية منكاملة قابلة للتنمية والاستثمار بما يحقق الانتعانش الاقتصادي للبلد . الطئ.

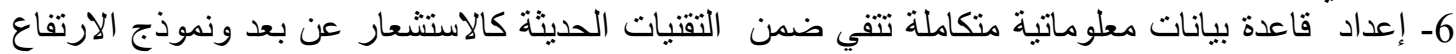

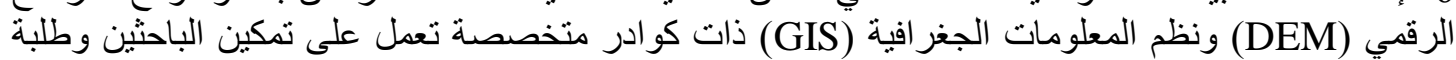
العلم وتأهليهم في هذه المجالات .

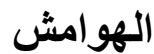

1. وزارة التخطيط ، الجهاز المركزي للإحصاء ، المجموعة الإحصائية السنوية (بيانات غير منشورة) ، 2016

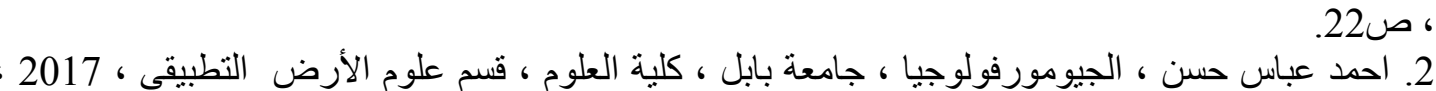
ص.3.

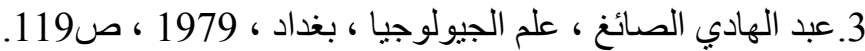

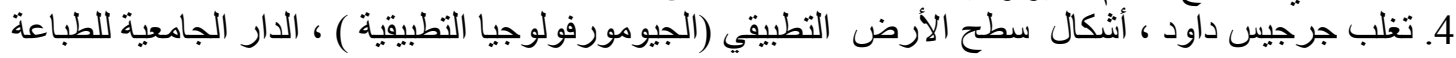
و النشر و الترجمة ، البصرة ،

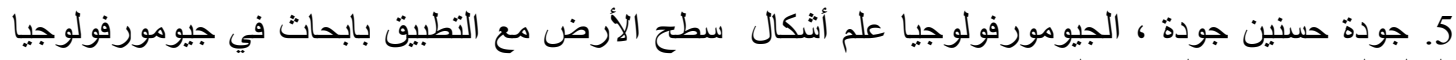

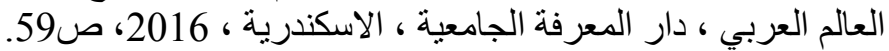

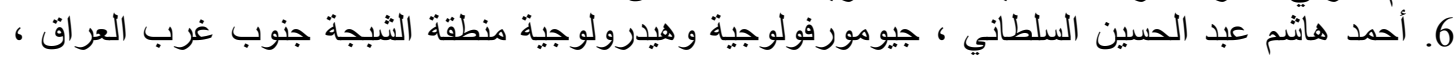

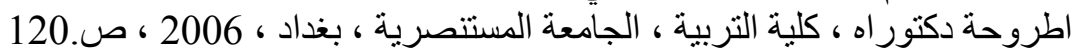

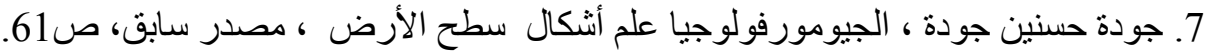
8. ميشيل كامل عطا اله ، اساسيات الجيولوجيا ، ودئ دار المسيرة للنشر و التوزيع و الطباعة ، عمان ، ط1 ، 2000،

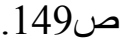

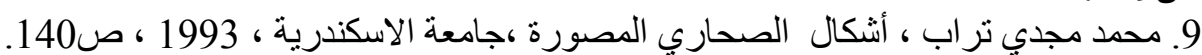

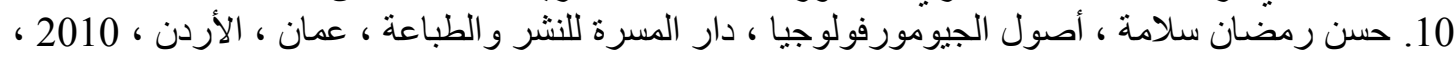
ص ص 108

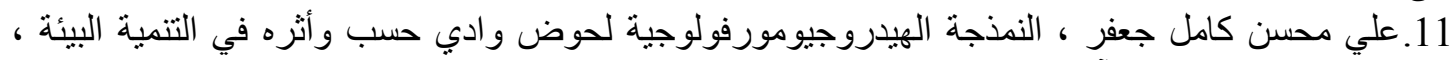

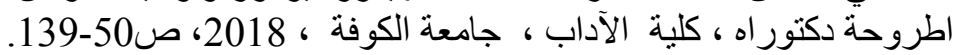

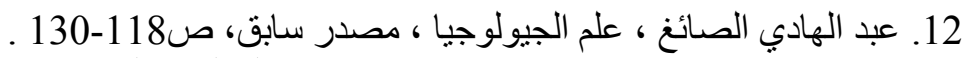

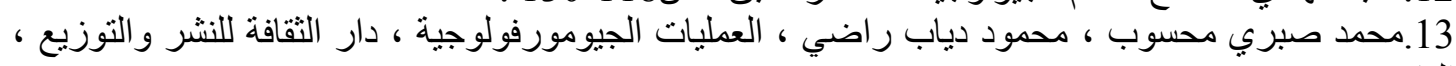

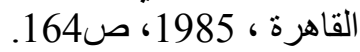

14. Chepil , W.S, and sibbway ,F.H,Ambrust ,D.V,chimatic , factor for Estimating Wind Erodibility of form fields, J.soil and water conservation, 1962 .p.p.162-165. 2019/12/15 الدر اسة الميدانية 15. قصي عبد المجيد السامر ائي ، عبد مخور نجم الريحاني ، جغر افية الأراضي الجافة ، جامعة بغداد، 1990

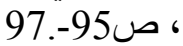

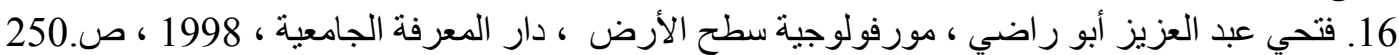

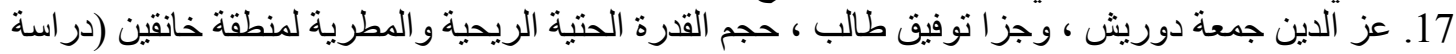

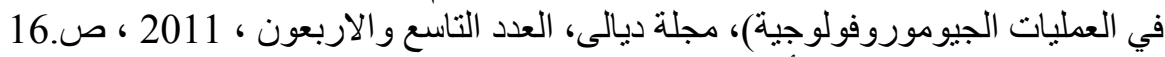

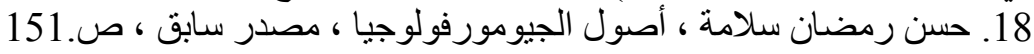


العدد (17) ديسمبر 2020

Volume (17) December 2020

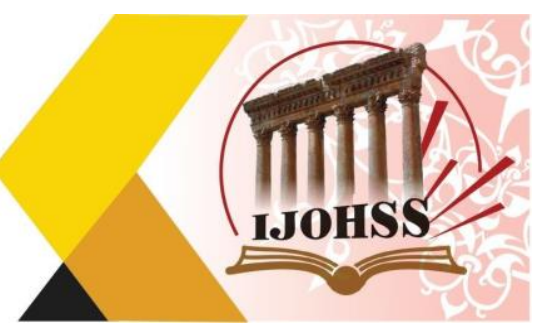

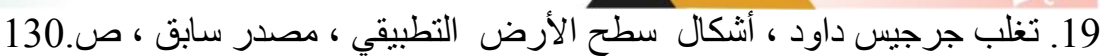

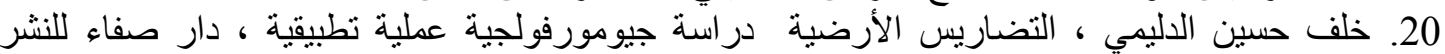

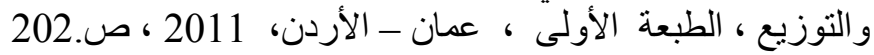

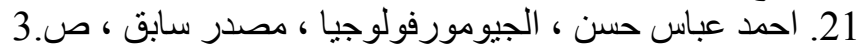

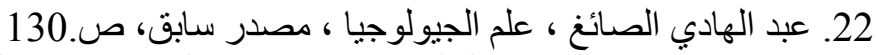

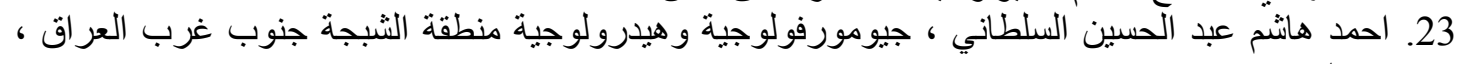

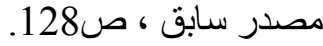
(Mesas) * صخرية وتمتاز باستو اء السطح وبثدة الانحدار إلى درجة الجروف الهياً الصخرية ـ حسن رمضان سلامة ، مصدر سابق ، ص240. 24. المنشأة العامة للمسح الجيولوجي و التعدين ، تقرير عن لوحة البريت ، ان جي 38-1990 جي ام /31 مقياس 250000/1

25. Khaldoun A. ma'ala , Geomorphology, Iraqi Bull, Geol- MIN .Special lssue , 2003 : Geology of Iraqi Southren Desert, p.8.

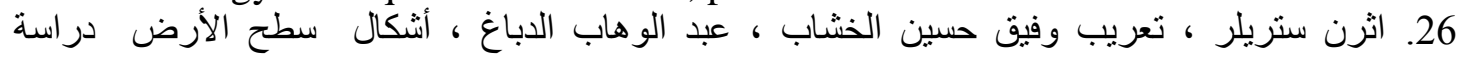

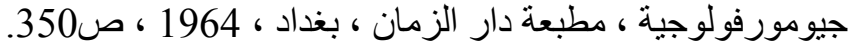

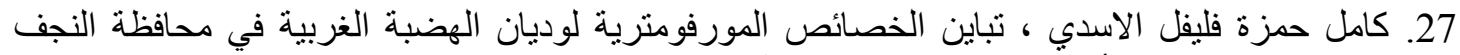

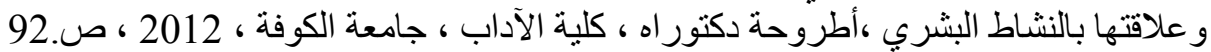

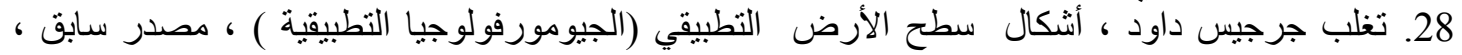
ص181.-180 صنام 29. أحمد هاثم عبد الحسين السلطاني ، جيومورفولوجية وهيدرولوجية منطقة الثبجة جنوب غرب العراق ،

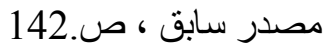

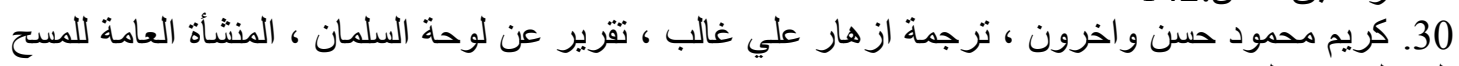

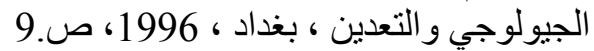

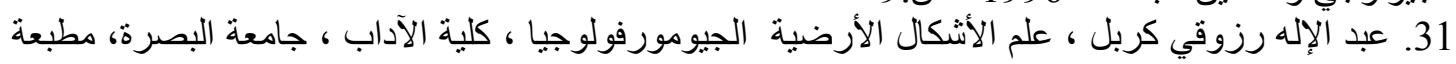
جامعة البصرة ، 262.

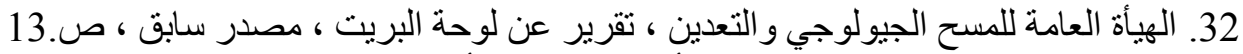

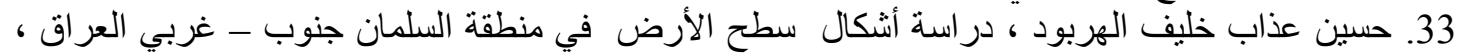

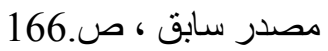

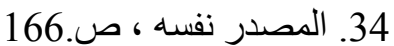

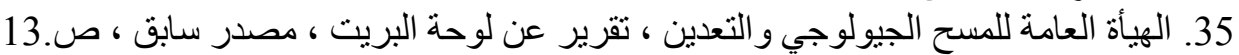

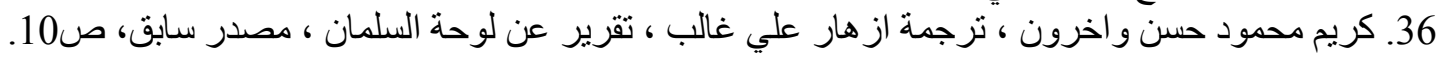

37.Khaldoun Ama'ala . Geomorphology, Iraqi Bull,Goel-min,special 1ssue, 2003:Geology of Iraqi southern Desert,p,8.

38. حسين عذاب خليف الهربود ، دراسة أنثكال سطح الأرض في منطقة السلمان جنوب - غربي العراق ،

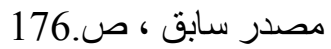

39. نوري محسن حمزة واخرون، واخدون خارطة العراق الجيولوجية ،لوحة رقم (3) الطبعة الأولى ، المنشأة العامة

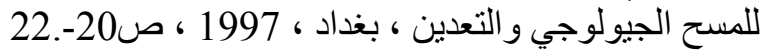
40. أحمد هاثتم عبد الحسين السلطاني ، جيوموروفئولوجية و هيدرولوجية منطقة الثبجة جنوب غرب العراق ،

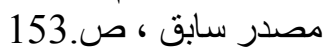
41. حسن رمضان سلامة ، أصول الجيومورفولوجيا ، مصدر سابق ، ص.94 


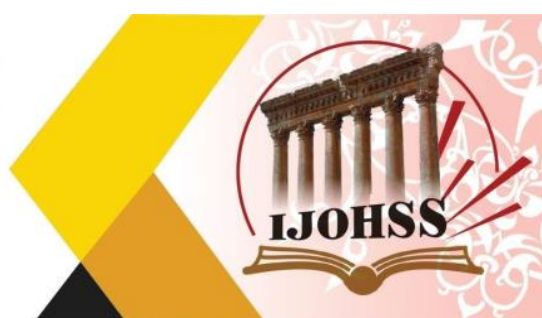

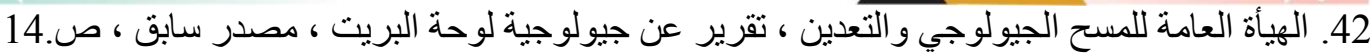

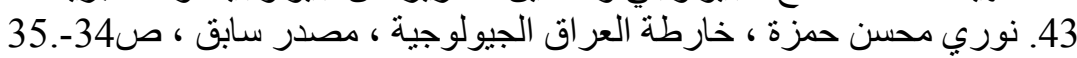

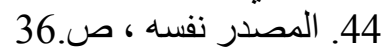

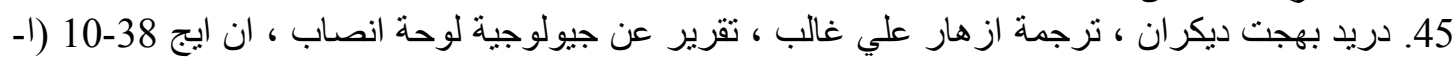

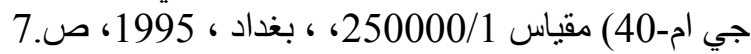

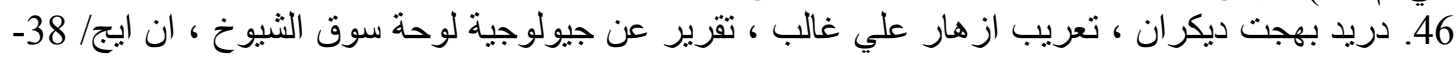

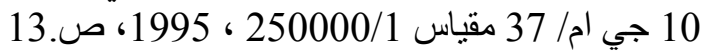

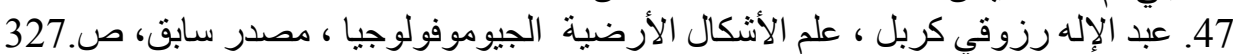

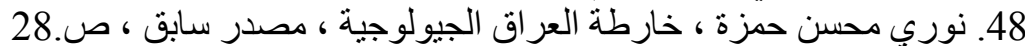

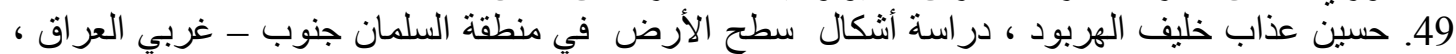

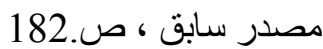

50. عبد الإله رزوقي كربل ، علم الأشكال الأرضية الجيوموفولوجيا ، مصدر سابق ، ص.327 الطيان

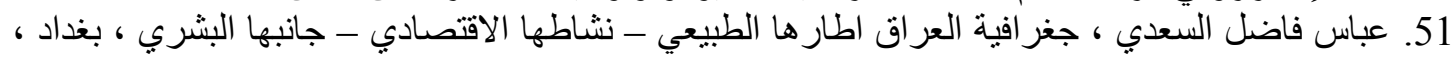

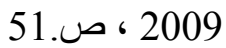

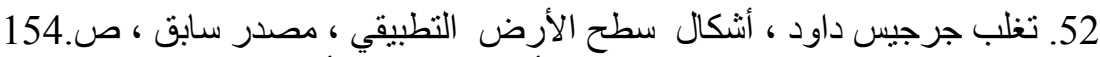

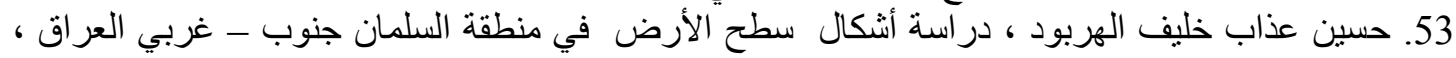

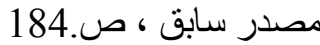
54. أحمد هاثم عبد الحسين السلطاني ، جيومورفولوجية وهيدرولوجية منطقة الثبجة جنوب غرب العراق ،

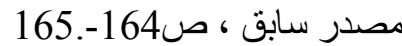

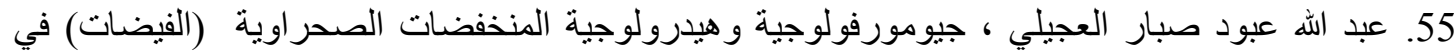

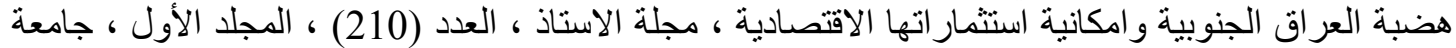

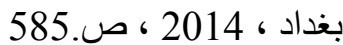

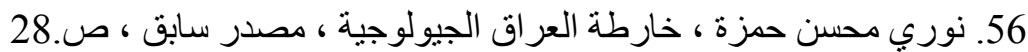
57. Al-Mubarak, M.A.\& Amin R.M, 1983, Report on the region Geological Mapping of the Eastern Part of the Western Desert and the Western Part of Southern Desert, GEOSURV, Report No. 1380, Baghdad,p.11.

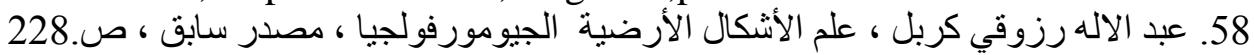

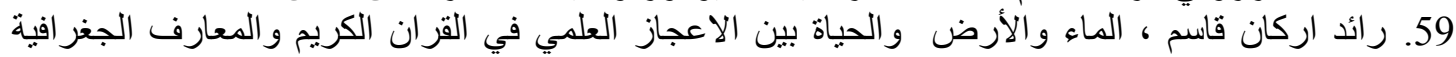

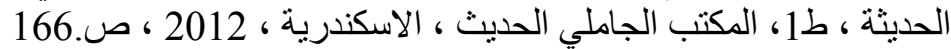

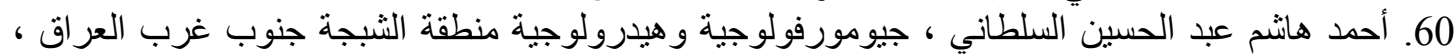

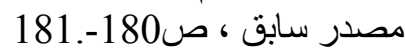
61. عبد الحميد احمد كليو ، الانسان كعامل جيومورفولوجي دوره في العمليات الجيومورفولوجية النهرية ،

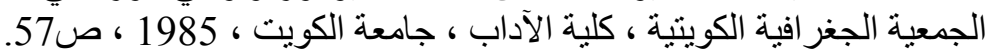

1. أبو راضي ، فتحي عبد العزيز ، مورفولوجية سطح الأرض ، دارئ دار المعرفة الجامعية ، 1998.

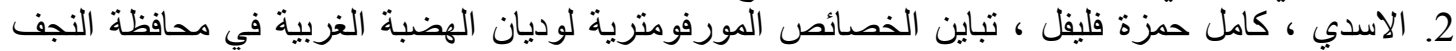

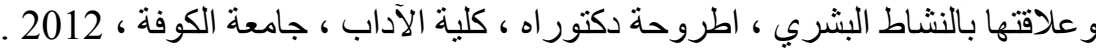

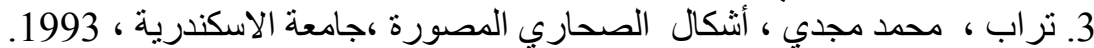

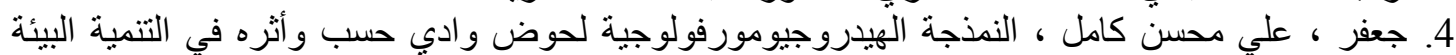

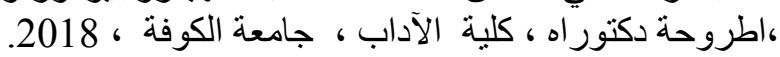

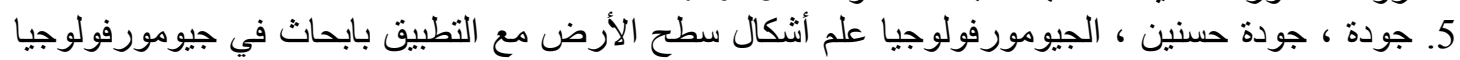
العالم العربي ، دار المعرفة الجامعية ، الاسكندرية ، 2016. 


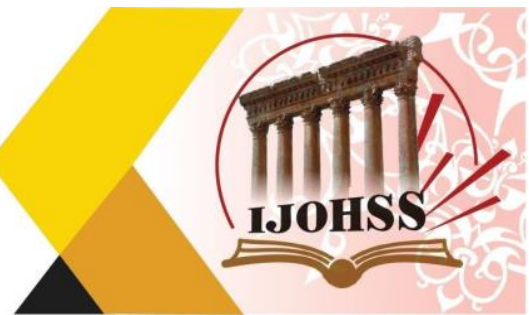

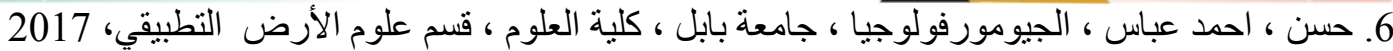

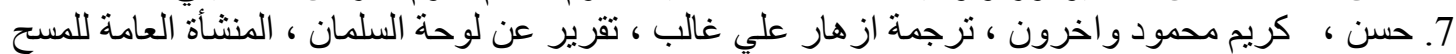

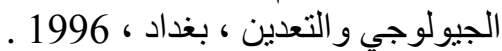

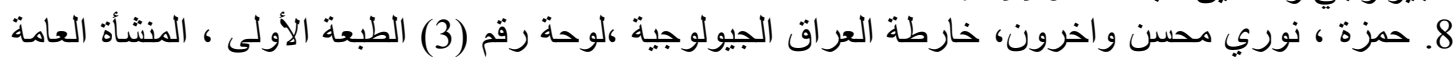

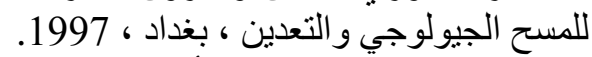
9. داود ، تغلب جرجيس ، أنثكال سطح الأرض النغ التطبيقي (الجيومورفولوجيا التطبيقية) ، الدار الجامعية

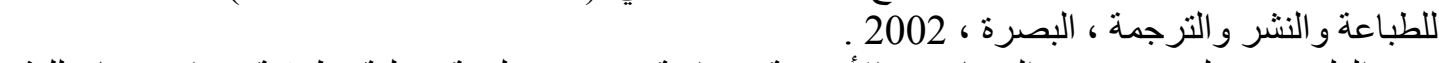

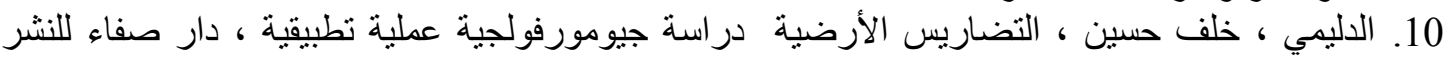

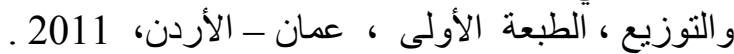

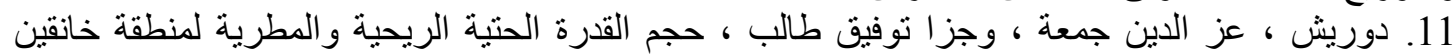

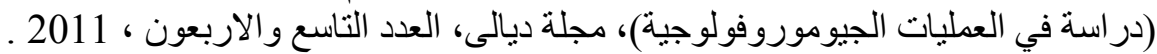

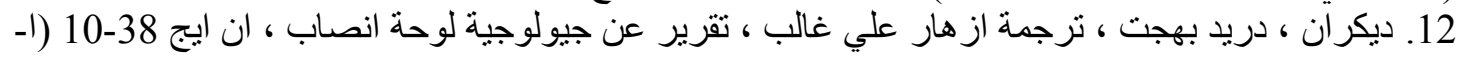

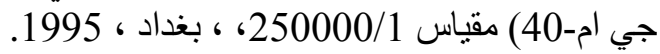

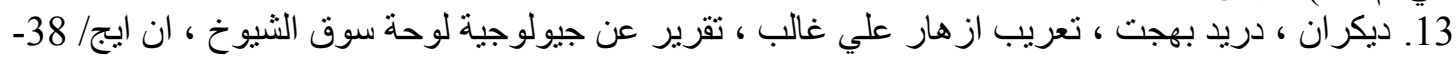

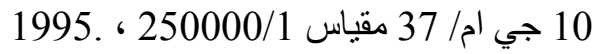
14. السامر ائي ، قصي عبد المجيد ، عبد مخور نجم الريحاني ، جغر افية الأراضي الجافة ، جامعة بغداد، .1990

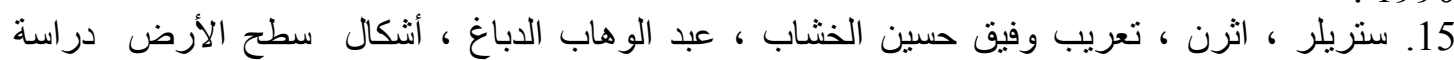

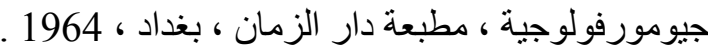

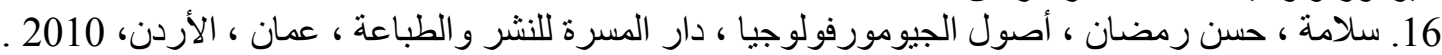

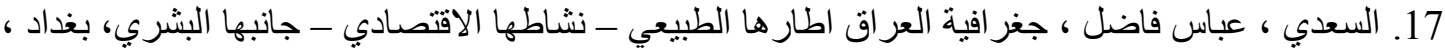

18. السلطاني ، أحمد هاثشم عبد الحسين ، جيومورفولوجية و هيدرولوجية منطقة الثبجة جنوب غرب العزب العراق ،

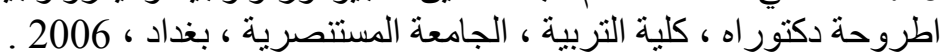

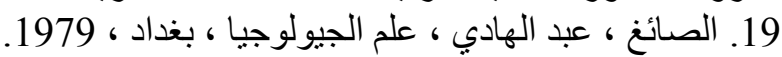

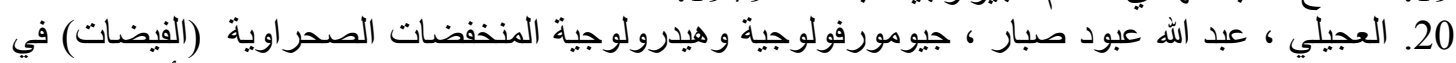
هضبة العر أق الجنوبية وامكانية استثمار اتها الاقتصادية ، مجلة الاستاذ ، العدد (210) ، المجلد الأول ، جامعةً

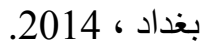
21. عطا الله ، ميشيل كامل ، اساسيات الجيولوجيا ، دار المسيرة للنشر والتوزيع والطباعة ، عمان، ط1، .2000 22. قاسم ، رائد اركان ، الماء والأرض والحياة بين الاعجاز العلمي في القران الكريم و المعارف الجغرافية

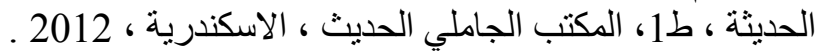

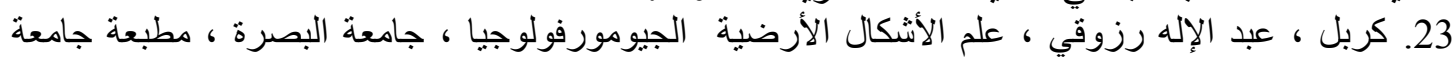

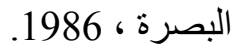
24. كليو ، عبد الحميد احمد ، الانسان كعامل جيومورفولوجي الإبه دوره في العمليات الجيومورفولوجية النهرية ،

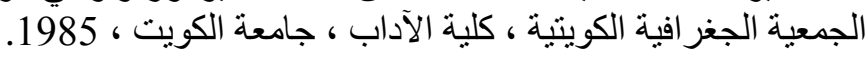

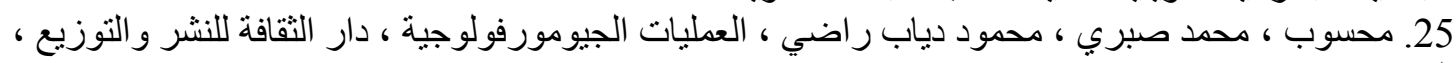

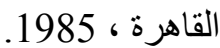
26. الهربود ، حسين عذاب خليف ، دراسة أثنكال سطح الأرض في منطقة السلمان جنوب ـ غربي العراق ،

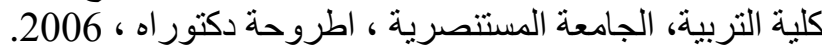
27. الهيأة العامة للمسح الجيولوجي والتئية التعدين ، تقرير عن لوحة ، التهة البريت ، ان جي 38-1 جي ام /31 مقياس

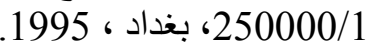




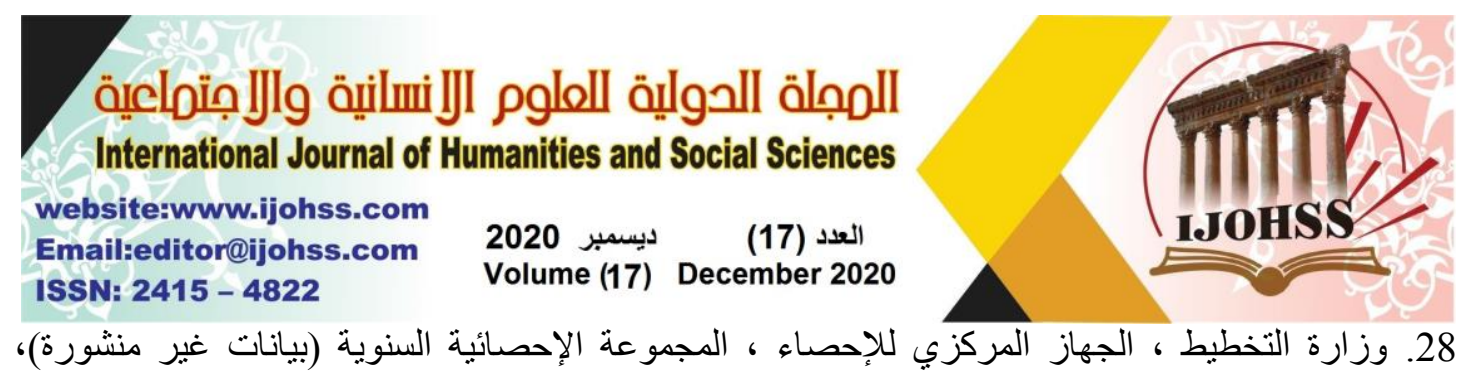

.2016

\section{References}

1-Abu Radi, Fathy Abdel Aziz, Morphology of the Earth's Surface, University Knowledge House, 1998.

2-Al-Asadi, Kamel Hamza Fleifel, Variation of Morphometric Characteristics of the Valleys of the Western Plateau in Najaf Governorate and their Relation to Human Activity, PhD thesis, Faculty of Arts, University of Kufa, 2012.

3-Trapp, Mohamed Magdy, Asks Al-Sahari Pictures, Alexandria University, 1993.

4-Jafar, Ali Mohsen Kamel, Hydrogeomorphological Modeling of Wadi Hassab Basin and its Impact on Environmental Development, PhD Thesis, Faculty of Arts, University of Kufa, 2018.

5-Gouda, Gouda Hassanein, Geomorphology of the geomorphology of the Earth's surface with application in research in the geomorphology of the Arab world, University Knowledge House, Alexandria, 2016.

6-Hassan, Ahmed Abbas, Geomorphology, University of Babylon, Faculty of Science, Department of Applied Geosciences, 2017.

7-Hassan, Karim Mahmoud and others, translated by Azhar Ali Ghalib, Report on Salman's Board, General Establishment for Geological Survey and Mining, Baghdad, 1996.

8-Hamzah, Nuri Mohsen and others, Iraq Geological Map, Plate No. (3) First Edition, The General Establishment for Geological Survey and Mining, Baghdad, 1997.

9-Daoud, Ghalib Zarzis, Applied Earth Surface Forms (Applied Geomorphology), University House for Printing, Publishing and Translation, Basra, 2002.

10-Al-Dulaimi, Khalaf Hussein, Topography, Geomorphology, An Applied Process, Dar Safa for Publishing and Distribution, First Edition, Amman - Jordan, 2011.

11-Dorish, Izz al-Din Jumaa, and Tawfiq Taleb, Jazaat Taleb, The Wind and Rainfall Wind Power Capacity of Khanaqin Region (Study in Geomorphological Processes), Diyala Journal, Issue 49, 2011.

12-Dikran, Duraid Bahjat, translation of Azhar Ali Ghaleb, Report on the Geology of the Monument Painting, NEG 38-10 (A-GM-40) Scale 1/250000, Baghdad, 1995.

13-Decran, Duraid Bahjat, The Arabization of Ali Ghaleb Flowers, Report on the Geology of the Shuyukh Market Painting, NEG / 38-10 GM / 37 Scale 1/250000, 1995.

14-Al-Samarrai, Qusay Abdul Majeed, Abd Makhour Najm al-Rihani, Geography of Dry Lands, University of Baghdad, 1990.

15-Streler, Uther, Arabization of Wafiq Hussain al-Khashab, Abd al-Wahhab alDabbagh, Shapes of the Earth's Surface, a Geomorphological Study, Dar Al-Zaman Press, Baghdad, 1964. 


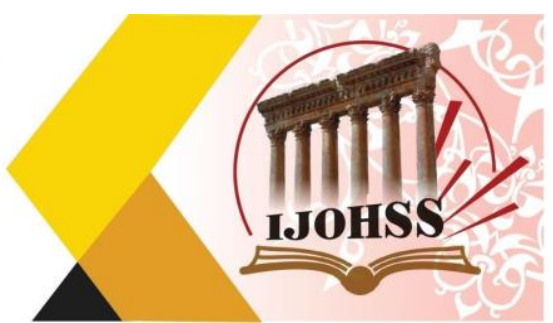

16-Salama, Hassan Ramadan, The Origins of Geomorphology, Dar Al Masarah Publishing and Printing, Amman, Jordan, 2010.

17-Al-Saadi, Abbas Fadel, The Geography of Iraq Its Natural Context - Its Economic Activity - Its Human Side, Baghdad, 2009.

18-Al-Sultani, Ahmed Hashem Abdul-Hussein, Geomorphology and Hydrology of the Shabajah region in southwestern Iraq, $\mathrm{PhD}$ thesis, College of Education, AlMustansiriya University, Baghdad, 2006.

19-Al-Sayegh, Abdul-Hadi, Geology, Baghdad, 1979.

20-Al-Ajili, Abdullah Abboud Sabbar, The Geomorphology and Hydrology of the Desert Depressions (Floods) in the Southern Iraqi Plateau and the Possibility of Their Economic Investments, Al-Ustadh Magazine, No. (210), Volume One, University of Baghdad, 2014.

21-Atallah, Michel Kamel, Basics of Geology, Dar Al Masirah for Publishing, Distribution and Printing, Amman, 1st Edition, 2000.

22-Qasim, a leading staff member, water, land and life between the scientific miracles of the Holy Qur'an and modern geographical knowledge, 1st Edition, The Modern Jamali Office, Alexandria, 2012.

23-Karbal, Abdul-Ilah Razooqi, Geomorphology, Basrah University, Basra University Press, 1986

24-Cleo, Abdul-Hamid Ahmed, Man as a Geomorphological Factor, Its Role in River Geomorphological Processes, Kuwait Geographical Society, College of Arts, Kuwait University, 1985

25-Mahsoub, Mohamed Sabry, Mahmoud Diab Radi, Geomorphological Processes, House of Culture for Publishing and Distribution, Cairo, 1985.

26-Al-Harboud, Hussein Athab Khalif, Study of the Forms of the Earth's Surface in the Salman Region, South-West of Iraq, College of Education, Al-Mustansiriya University, PhD Thesis, 2006

27-General Authority for Geological Survey and Mining, Report on Brite Board, NG 38-1 GM / 31 Scale 1/250000, Baghdad, 1995.

28-Ministry of Planning, Central Bureau of Statistics, Annual Statistical Abstract (unpublished data), 2016.

28- Al-Mubarak, M.A.\& Amin R.M, 1983, Report on the region Geological Mapping of the Eastern Part of the Western Desert and the Western Part of Southern Desert, GEOSURV, Report No. 1380, Baghdad.

29- Chepil , W.S, and sibbway ,F.H,Ambrust ,D.V,chimatic , factor for Estimating Wind Erodibility of form fields , J.soil and water conservation, 1962.

30- Khaldoun Ama'ala . Geomorphology, Iraqi Bull,Goel-min,special lssue, 2003:Geology of Iraqi southern Desert.

31-Khaldoun Ama'ala. Tectonic\&structural Erolution Iraqi Bull.Goel.min.special lssue, 2009:Geology of Iraqi southern Desert . 